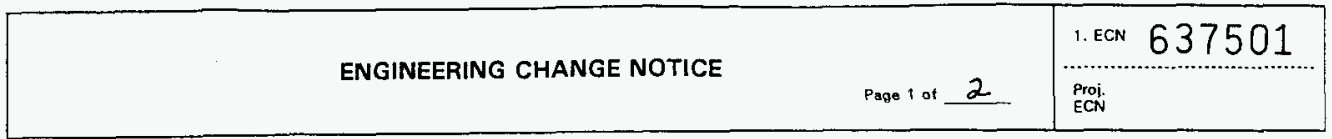

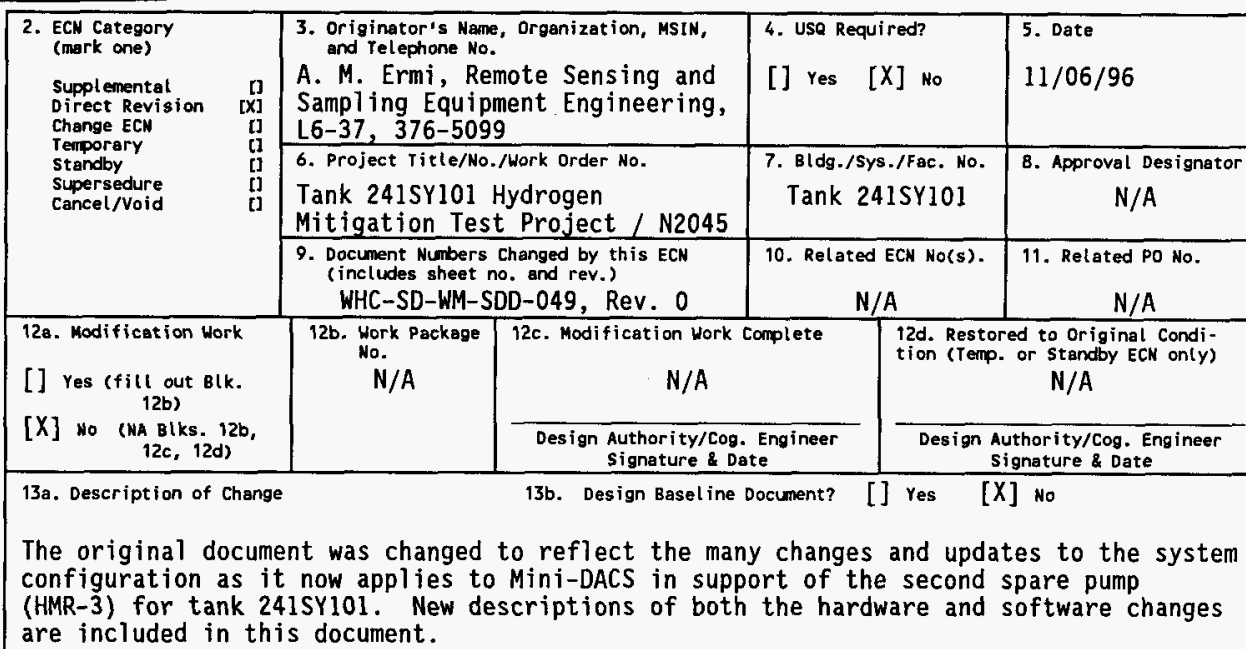

14a. Justification (mark one)

$\begin{array}{llllllll}\text { Criteria Change } & {[X]} & \text { Design Improvement } & {[]} & \text { Environmental } & \text { [] } & \text { Facility Deactivation } \\ \text { As-Found } & \text { [] } & \text { Facilitate Const } & \text { [] } & \text { Const. Error/anission } & \text { [] } & \text { Design Error/Omission } & \text { [] }\end{array}$

14b. Justification Details

This revision documents the current configuration of the Mini-DACS software and hardware in support of the second spare pump (HMR-3) for tank $241 S Y 101$

15. Distribution (include name, MSIN, and no. of copies)

See attached distribution sheet

A-7900-013-2 (05/96) GEF095 


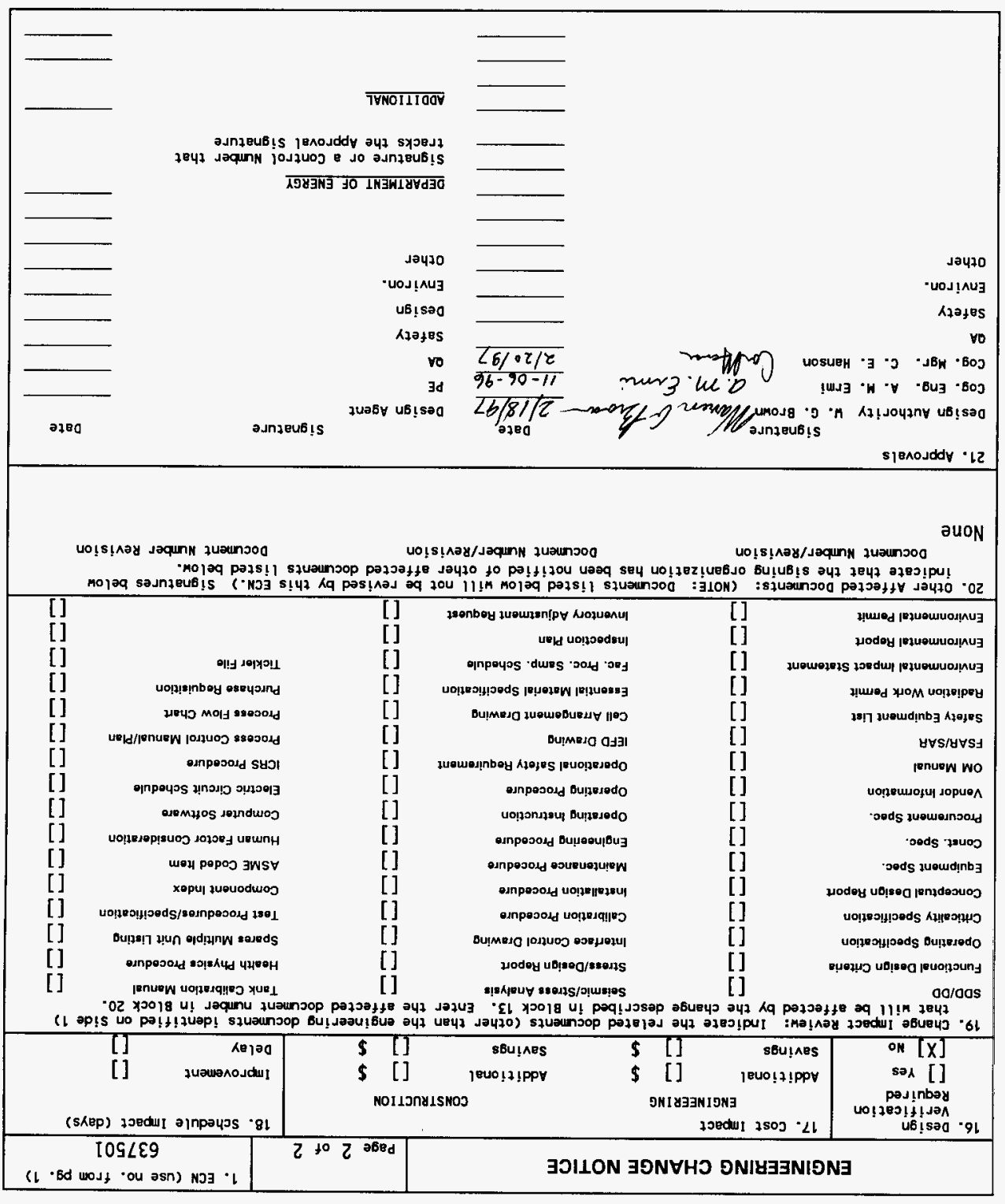




\section{SYSTEM DESIGN DESCRIPTION FOR "MINI-DACS" DATA ACQUISITION AND CONTROL SYSTEM}

A. H. Ermi

SGN Eurisys Services Corporation, Richland, WA 99352

U.S. Department of Energy Contract DE-AC06-96RL13200

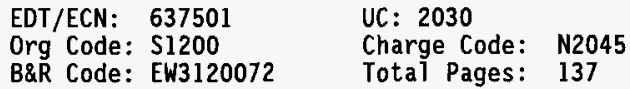

Key Words: MINI-DACS, DACS, DATA ACQUISITION AND CONTROL SYSTEM, 241SY101, SPARE PUMP, HMR-3, SOFTWARE, HARDWARE

Abstract: This document describes the computer software design and associated hardware for the Mini-DACS (Data Acquisition and Control System) in support of testing the second spare pump (HMR-3) for tank 241SY101. The testing of HMR-3 was conducted at the Maintenance and Storage Facility (MASF).

TRADEMARK DISCLAIMER. Reference herein to any specific commercial product, process, or service by trade name, trademark, manufecturer, or otherwise, does not necessarily constitute or imply its endorsement, recomendation, or favoring by the United States Government or any agency thereof or its contractors or subcontractors.

Printed in the United States of America. To obtain copies of this document, contact: Document Control Services, P.0. Box 950, Mailstop H6-08, Richland WA 99352, Phone (509) 372-2420; Fax (509) 376-4989.
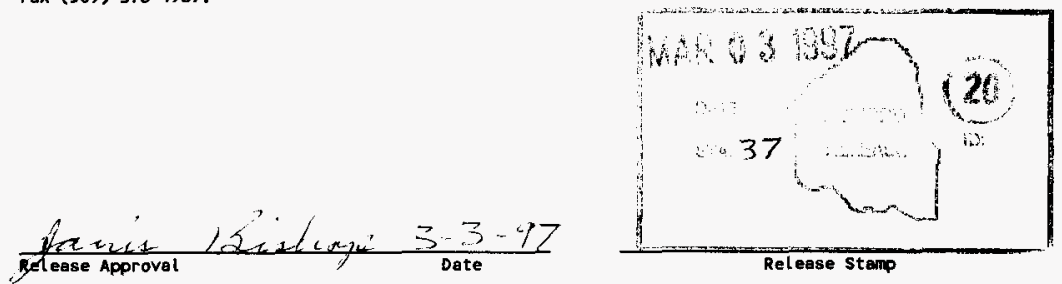

\section{Approved for Public Release}


(2) Title

SYSTEM DESIGN DESCRIPTION FOR "MINI-DACS" DATA ACQUISITION AND CONTROL SYSTEM CHANGE CONTROL RECORD

\begin{tabular}{|c|c|c|c|}
\hline \multirow{2}{*}{ (3) Revision } & \multirow{2}{*}{ (4) Description of Change - Replace, Add, and Delete Pages } & \multicolumn{2}{|c|}{ Authorized for Release } \\
\hline & & (5) Cog. Engr. & (6) Cog. Mgr. \\
\hline Rev. 0 & (7) EDT 602291, Released Sept. 30, 1994 & --- & --- \\
\hline $\begin{array}{ll}\text { Rev. } 1 & \\
& \text { RS }\end{array}$ & $\begin{array}{l}\text { Complete revision per ECN } 637501 \text {, } \\
\text { Nov. 6, 1996; "WHC" document prefix changed } \\
\text { to "HNF" }\end{array}$ & $\begin{array}{l}\text { AM Ermi } \\
\text { AMEmi }\end{array}$ & $\begin{array}{l}\text { CE Hanson } \\
\text { Con }(\text { Aaren } 2 / 20 / 92\end{array}$ \\
\hline & & & \\
\hline & & & \\
\hline & & & \\
\hline & & & \\
\hline & & & \\
\hline & & & \\
\hline & & & \\
\hline & & & \\
\hline & & & \\
\hline & & & \\
\hline & & & \\
\hline & & & \\
\hline & & & \\
\hline & & & \\
\hline & & & \\
\hline & & & \\
\hline & & & \\
\hline & & & \\
\hline & & & \\
\hline & & & \\
\hline & & & \\
\hline & & & \\
\hline & & & \\
\hline & & & \\
\hline & & & \\
\hline & & & \\
\hline & & & \\
\hline & & & \\
\hline & & & \\
\hline
\end{tabular}


HNF-SD-WM-SDD-049

Rev. 1

\title{
SYSTEM DESIGN DESCRIPTION \\ for \\ "Mini-DACS" \\ DATA ACQUISITION AND CONTROL SYSTEM
}

October 1996

Prepared by:

S. O. Smith \& R. W. Truitt, PLCs Plus

\author{
Prepared for: \\ SGN Eurisys Services Corporation, \\ P.O. Box 840 \\ Richland, W.A. 99352
}


1.0 FUNCTION AND DESIGN REQUIREMENTS $\ldots \ldots \ldots \ldots \ldots \ldots \ldots \ldots$

1.1 Introduction ....................... 1

1.2 Basis For Requirements $\ldots \ldots \ldots \ldots \ldots \ldots \ldots \ldots \ldots$

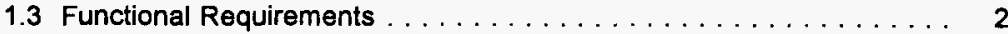

1.4 Hardware Requirements $\ldots \ldots \ldots \ldots \ldots \ldots \ldots \ldots \ldots \ldots \ldots$

1.5 Software Requirements . . . . . . . . . . . . . . . . 3

1.6 Acronyms . . . . . . . . . . . . . . . . . . 3

2.0 DESIGN DESCRIPTION $\ldots \ldots \ldots \ldots \ldots \ldots \ldots \ldots \ldots \ldots \ldots \ldots$

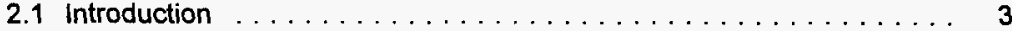

2.2 System Block Diagram $\ldots \ldots \ldots \ldots \ldots \ldots \ldots \ldots \ldots \ldots$

2.3 Site Support $\ldots \ldots \ldots \ldots \ldots \ldots \ldots \ldots \ldots \ldots \ldots \ldots \ldots$

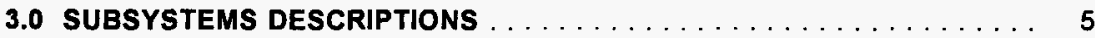

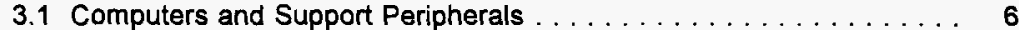

3.2 Programmable Logic Controller and $1 / 0 \ldots \ldots \ldots \ldots \ldots \ldots$

3.3 Genesis (Data Acquisition and Control) $\ldots \ldots \ldots \ldots \ldots \ldots$

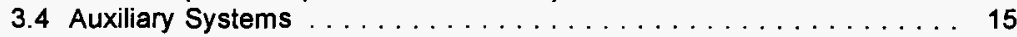

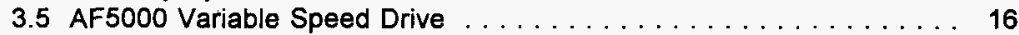

4.0 SYSTEM LIMITATIONS, CASUALTY EVENTS AND RESPONSES $\ldots \ldots \ldots 17$

4.1 System Limitations $\ldots \ldots \ldots \ldots \ldots \ldots \ldots \ldots \ldots \ldots \ldots \ldots$

4.2 Applications Software $\ldots \ldots \ldots \ldots \ldots \ldots \ldots \ldots \ldots \ldots$

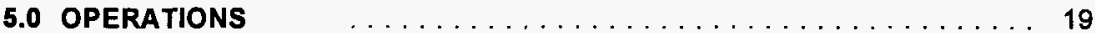

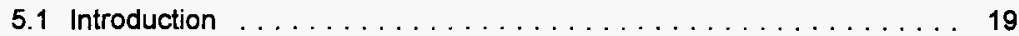

5.2 Pump Operation $\ldots \ldots \ldots \ldots \ldots \ldots \ldots \ldots \ldots \ldots \ldots \ldots \ldots$

5.3 Data Logging . . . . . . . . . . . . . . . . . . . 21

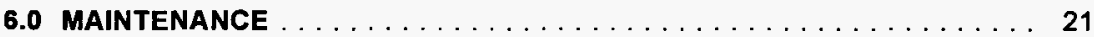

6.1 Computer Maintenance $\ldots \ldots \ldots \ldots \ldots \ldots \ldots \ldots \ldots \ldots \ldots 21$

6.2 Calibration Procedures $\ldots \ldots \ldots \ldots \ldots \ldots \ldots \ldots \ldots \ldots \ldots 22$

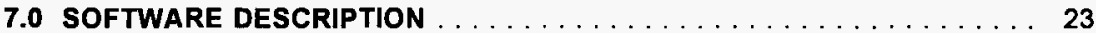

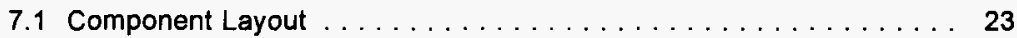

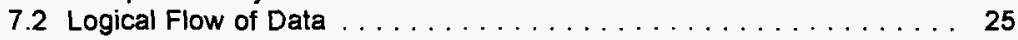

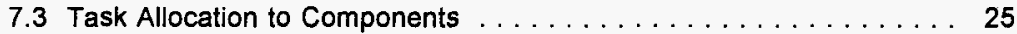


8.0 SYSTEM FUNCTIONS $\ldots \ldots \ldots \ldots \ldots \ldots \ldots \ldots \ldots \ldots \ldots . \ldots \ldots$

8.1 Instrument Monitoring and Data Collection Function (MASFTEST) . . 27

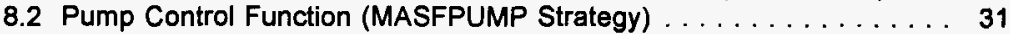

8.3 Modicon PLC Functions $\ldots \ldots \ldots \ldots \ldots \ldots \ldots \ldots \ldots \ldots \ldots$

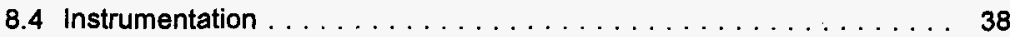

9.0 DESIGN DETAILS . . . . . . . . . . . . . . . . . 39

9.1 Instrument Monitoring and Data Collection Function (MASFTEST) . . 4 40

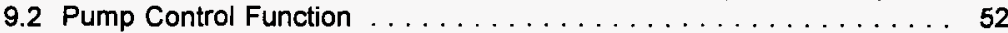

9.3 Modicon PLC Functions $\ldots \ldots \ldots \ldots \ldots \ldots \ldots \ldots \ldots$

9.4 Network Layout $\ldots \ldots \ldots \ldots \ldots \ldots \ldots \ldots \ldots \ldots \ldots$

10.0 REFERENCES $\ldots \ldots \ldots \ldots \ldots \ldots \ldots \ldots \ldots \ldots \ldots \ldots \ldots$

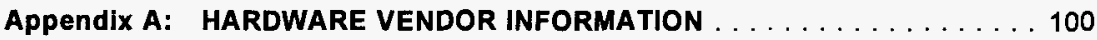

Appendix B: Manufacturer's Manuals and Other Documentation . . . . . 105

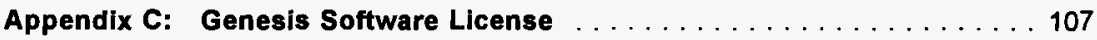

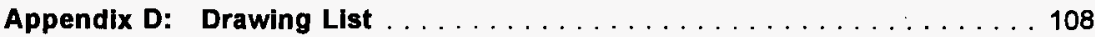

Appendix E: Mini-DACS User Guide $\ldots \ldots \ldots \ldots \ldots \ldots \ldots \ldots \ldots \ldots \ldots$

Appendix F: PLC I/O Status Registers $\ldots \ldots \ldots \ldots \ldots \ldots \ldots \ldots \ldots$

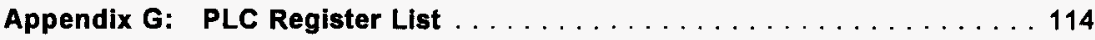

Appendix H: Report and Recipe File Llstings . . . . . . . . . . . . 120

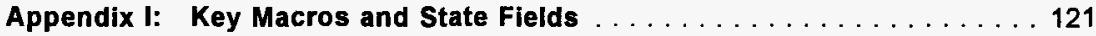

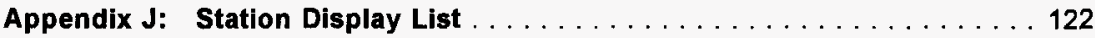

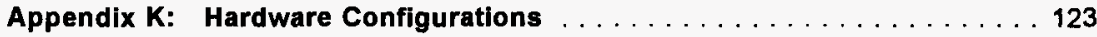

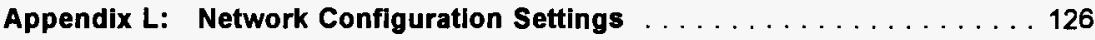

Appendix M: Computer Configurations and Software Versions . . . . 128

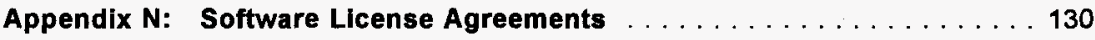

Appendix O: HMR-3 Instrument Ranges, Alarm Limits and Abort Limits . 131 


\subsection{FUNCTION AND DESIGN REQUIREMENTS}

\subsection{Introduction}

The 241-SY-101 high level waste tank, within the Hanford Reservation, has experienced periodic gas releases of hydrogen, nitrous oxide, ammonia, and methane. Because the gas represents a potential danger, as some releases are above the lower flammability limit (LFL), a mixer pump mitigation scheme has been developed to mitigate these gases.

In order to provide a safe reliable method to control the mixer pump, collect and archive data associated with the mitigation process, and ensure operational integrity of the entire process, a Data Acquisition and Control System (DACS) was delivered jointly between Los Alamos National Laboratory, Westinghouse, and EG\&G Energy Measurements. Previous to the installation of the mixer pump into 241-SY-101, several "cold tests" were run on the pump at the Westinghouse Maintenance and Storage Facility (MASF) to determine the pump's overall efficiency, operational readiness, and potential reliability. The pump control and associated instrumentation for these "cold tests" were accomplished by fabricating a scaled-down version of the future Mini-DACS system. The smaller system was intended to be a temporary solution specifically designed to provide operators with data necessary to certify the readiness of the pump through acceptance test procedures (ATP). Now, a more permanent and versatile "Mini-DACS" has been implemented for use at the MASF facility.

The mixer pump was installed into 241-SY-101 in July 1993 and is considered to be successful at the mitigation process. The concept of using this technology to solve gas build-up has been proven and therefore will be used on other tanks with similar characteristics. In addition, a standby replacement pump must be certified to replace the existing pump in 241-SY-101 on the event of it's failure. The original standby pump, HMT-2, was tested by the Mini-DACS in 1994. The latest configuration of the Mini-DACS is in support of the third mixer pump, HMR-3, which is intended to be used in conjunction with the retrieval program.

\subsection{Basis For Requirements}

The requirements for the Mini-DACS as based on the Letter of Instruction (LOI), Westinghouse document $9453516--M i t 94-1889$, requesting fabrication of a Mini-Data Acquisition and Control System to control the operation of the back-up mixer pump as well as providing process control to instrument, monitor and generally support off-line testing and verification of various proposed, and existing, tank mitigation methods. 
Because of open-ended design requirements (proposed and future designs for mitigation), this system will provide the flexibility to be reconfigured to adapt to a changing environment.

\subsection{Functional Requirements}

The Mini-DACS system is required to support the performance testing of mixer pumps and associated hardware at the MASF. Eventually, the pumps, and other mitigation processes, could be inserted at the 241-SY-101 site. In order to provide a smooth, semi-bumpless exchange of the existing pump, the applications software and hardware must mimic the process control functionality of the full DACS-1 system at the SY-101 site.

The Mini-DACS control functions include pump manual control, operation monitoring, test system operating condition indication, and selected displays to advise operating personnel of the current operating status of the systems. For detailed MiniDACS functional requirements, see WHC-SD-WM-CSRS-022.

\subsection{Hardware Requirements}

The Mini-DACS computers and PLC hardware are required to emulate the existing control portion of the 241-SY-101 DACS-1 system as close as reasonably possible.

The computer operator stations will be sturdy, of steel construction, and suitable for the MASF environment. The stations will provide a comfortable environment for the operators (room for two operators) and contain a working surface for miscellaneous paper duties. The operators console will be portable via rolling casters to various locations throughout the MASF. For safety, the console will have the capability to lock against movement.

The Mini-DACS will include a $40^{\prime \prime} \times 60^{\prime \prime}$ Nema type enclosure that is also portable via rolling casters. The enclosure will house a Modicon 984E Programmable Logic Controller (PLC) and I/O modules as described in the bill of material, Appendix A. Again, this portion of the Mini-DACS will emulate that of DACS-1 in functionality.

A data logger, for alarm and event logging, and a screen image copier, for runtime and historical trend analysis, is required. 


\subsection{Software Requirements}

Genesis process control software, from Iconics Inc., is required. Control strategy for two computers and Remote Supervisory Station software for the remaining computer is required. Support software is also required: memory manager, PLC programming software, and DOS 6.0. All software is required to be of the same version as the DACS-1 system.

\subsection{Acronyms}

AFD Adjustable Frequency Drive

AOP Alarm Operational Procedure

ARP Alarm Response Procedure

ASCII American Standard for Computer Information

BASIC Beginner's All-Purpose Symbolic Instruction Code

$B C D \quad$ Binary Coded Decimal

BNC Bayonet connector type $\mathrm{N}$, size $\mathrm{C}$

DACS Data Acquisition and Control System

hp horsepower

LAN Local Area Network

MASF Maintenance and Storage Facility

PC Personal Computer

PLC Programmable Logic Controller

RSS Remote Supervisory Station

RTD Resistance Thermal Device

SA Safety Assessment

VFD Variable Frequency Drive

VSD Variable Speed Drive

Note: VSD and VFD are synonymous (see AFD also).

WAN Wide Area Network

\subsection{DESIGN DESCRIPTION}

\section{1 introduction}

A Mini-DACS to monitor and control cold tests of equipment to be used for mitigation experiments at Hanford was provided by LANL. The Mini-DACS located at the MASF controls both current and future pumps, probes and other conceptual mitigation designs. In addition, Mini-DACS provides process visibility to operators and collects for archive associated test data for dissemination to analysts. 
The majority of the data are recorded at a low frequency of no less that once per second. This system uses commercially available process control software and hardware as the basis for overall operation. However, additional software specifically necessary to operate individual tests will require custom routines within the commercial software.

\subsection{System Block Diagram}

The Mini-DACS system is configured as shown in Figure 2.1.

Mini-DACS is centered on a Personal Computer (PC) platform with computers ( 3 ea.) from Programmable Logic Controller network for communications to the $1 / 0$ field. A dot matrix printer is supplied for alarm and event logging or other uses defined by the test in progress. Each computer has access to the printer via a Black Box printer multiplexer. An Image copier is also multiplexed from each computer to provide a "screen dump" of real-time trending, historical trending, or instant data status as displayed on the computer screens.

A Modicon 984E Programmable controller is supplied with $1 / 0$ hardware as listed in the bill of material, Appendix A.

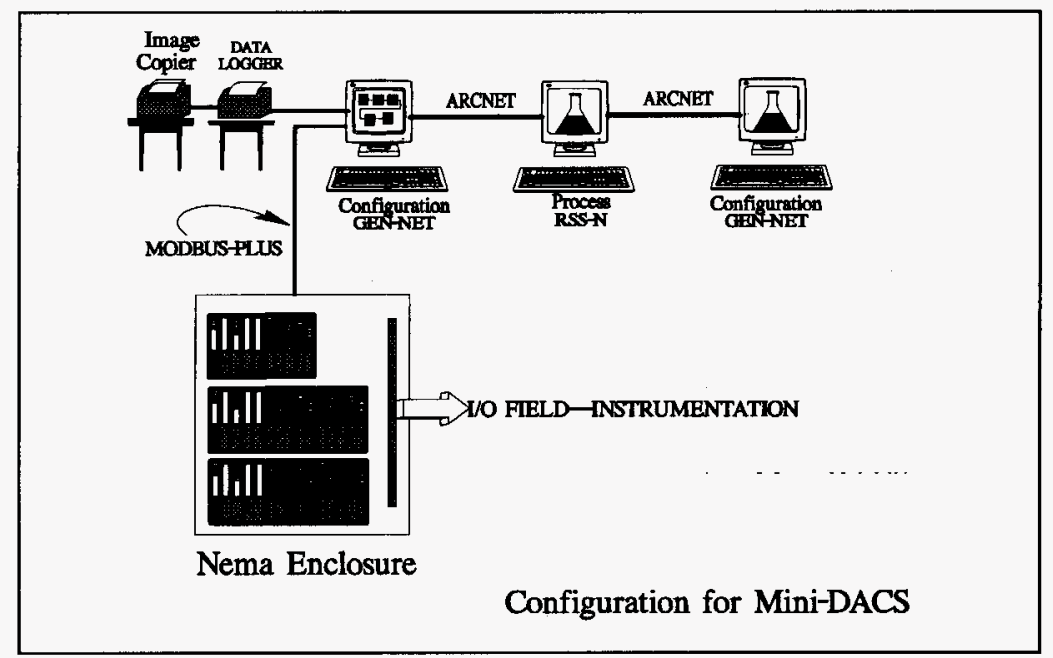

Figure 2.1 MInI-DACS Configuration 


\subsection{Site Support}

The site support required by the MASF is five ea. $20 \mathrm{Amp}$ circuits and four ea. telephone lines. Instrumentation technician support for wiring $1 / O$ and operations personnel for performing pump operations are also necessary.

\subsection{SUBSYSTEMS DESCRIPTIONS}

The Mini-DACS is comprised of three subsystems: computers and support peripherals, PLC and $\mathrm{VO}$, and control system software. The software described in this section is that which is the applications software, not the specific user developed software required to operate the process.

Figure 3.1 shows an overall block diagram of the Mini-DACS. It is divided into three major subsystems:

1. PLC system for instrumentation

2. Genesis control system

3. Auxiliary systems and components

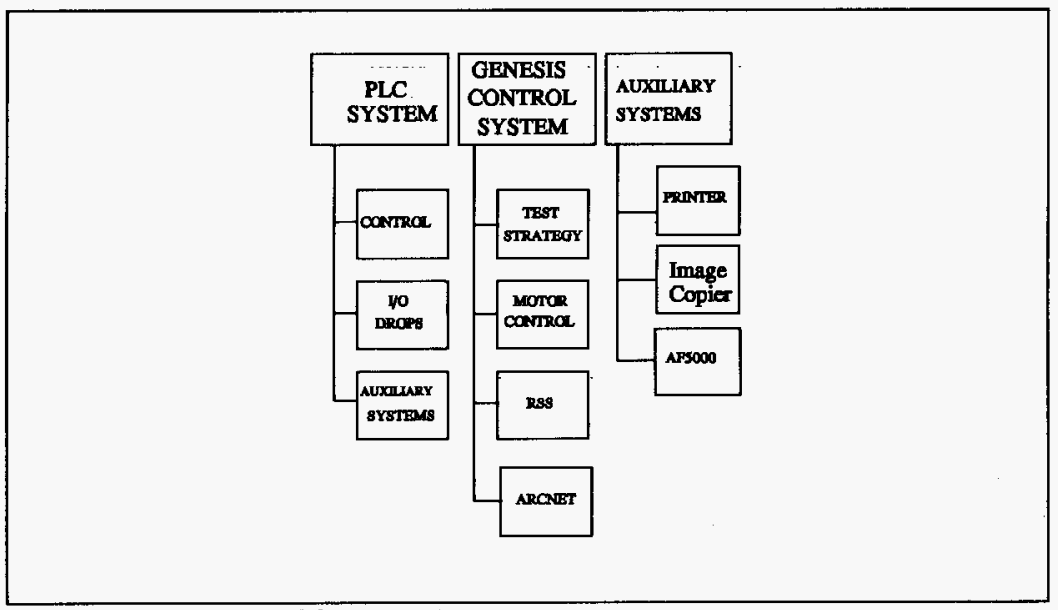

Figure 3.1 Mini-DACS Block Diagram 
Each major subsystem is further divided into its own subsystems and will be described on that basis. The Mini-DACS also provides site support, which is described below.

\subsection{Computers and Support Peripherals}

There are three ea. computers from Texas Micro Systems Inc. delivered with the Mini-DACS. They are model 4210 and contain:

- 2 ea. 3 1/2" Floppy drives

- 1 ea. 245 Meg Hard Drive

- 1 ea. $1 \mathrm{Meg}$ Video Card

- 1 ea. Keyboard

- 1 ea. $19^{\prime \prime}$ Monitor

The Image copier is from Geneval Corp ( Austin, Texas) and is a model CHC443MV, Video Printer. All support equipment, multiplexers, paper, etc. is listed in Appendix A.

The matrix printer is a model IBM 2390 PLUS with the printer multiplexer from Black Box model SW809.

Trackballs are supplied for all three computers by Kensington, model EXPERT MOUSE. Stations 5 and 7 are serial port trackballs, while station 8 is a bus trackball (to accommodate the usage of 2 serial ports for motor control on this station).

\subsubsection{Computer Console Environment}

The computers and peripherals are mounted in a series of standard workstation consoles from Crenlo, Inc. The workstations are designed to provide work space and operations space for two operators. Two workstations are joined by a 30 degree angle and each has provisions for two monitors or other support equipment. The two work stations are then joined by a complimentary set which when combined form a four console environment. The split between workstations was designed to provide for ease of movement around the MASF as well as simplifying shipping.

The Mini-Dacs is designed to provide telephone service within easy reach of operators at either workstation location. Three voice line connections are available. Another line is semi-dedicated for data transmission.

There are three consoles, each with a Texas Microsystems model 4210 industrial-type PC. The consoles are numbered 5,7 , and 8 in a clockwise order. The 
functionality of the Genesis Stations 5, 7, and 8 are described in Section 3.3. In addition to the computer consoles are two printers.

\subsection{Programmable Logic Controller and $1 / O$}

The PLC supplied with Mini-DACS is a Modicon 984E-785 with an S908-110 I/O processor. The major difference between this system and DACS-1 is that the communications cable from the I/O field to the PLC is non-redundant. The $1 / 0$ processor uses an E908-016 Executive Cartridge for up to 1024 In and 1024 out channels for each of 16 drops.

The PLC system consists of the following:

1. Controllers

2. 1/O drops

3. Auxiliary systems

\subsubsection{I/O Housing Hardware}

The 1/O modules are mounted in racks which are attached to a large phenolic slate. The slate is then attached to a Nema enclosure that is portable via large caster wheels. To prevent tipping of the Nema enclosure, out-riggers have been designed to provide a larger apparent footprint than the standard Nema base. Power is received from MASF via a twist-lock connector, and provides 2 ea. 20 Amp circuits.

This document will use the term "I/O drop," or just "drop" to indicate a communication tap, to be consistent with the current documentation $(\mathrm{H}-2$ drawings, the Mini-DACS software, and the $1 / 0$ channel list).

\subsubsection{DROP 1}

The I/O field is made up of Modicon-AEG 800 series $1 / O$. Typical I/O modules being used on the Mini-DACS are: model B875-101 analog input, model B824-16 24Vdc output, and model B883-200 thermocouple. The I/O configuration is flexible. The $1 / O$ is connected to the 984A via coaxial cables to the 984A PLC. To provide for future 1/O configuration capability, 64 analog inputs and 64 discrete are wired for use. Additional reconfiguration is expected and the flexibility is within the design to accomplish those tasks. In addition, several spare and different types of I/O modules have been purchased in anticipation of expected usage and are listed in the bill of material inventory, Appendix A. 


\subsubsection{DROP 2 (Note: For Information only)}

Modicon modules in drop 2 are used for the spare mixer pump instrumentation. It consists of two Modicon racks. In the first rack are 3 model B875-101 modules set for 4-20 mA inputs. In the second rack is a model B827-024 digital input (24-V switch) module and a B865-002 BCD input module. There are no outputs (controls) in this $1 / 0$ drop. The following pump signals are monitored:

1. Intake and discharge pressure

2. Motor stator temperature

3. Pump strain and vibration

4. Motor oil temperature

5. Motor oil moisture limit

6. Rotational motor position

7. Rotational motor limits

\subsubsection{Auxillary Systems for the PLC}

The PLC has a proprietary communications network called ModBus Plus. All the computers contain the Modicon ModBus Plus interface card, SA-85. Each I/O drop has a model P810 rack power supply and a model J890 remote I/O interface module. The J890 is used to control the internal working of the rack(s) in the particular drop, and to communicate with the E984 PLC. Each drop is connected to the E984 controller via coaxial cables. The $\mathrm{J} 890$ modules communicate module status and data to the E984. The J890s also receive setup information from the E984 for the modules in their rack(s).

Where there is more than one Modicon rack in a particular drop, one rack acts as the primary rack while the others are secondary. The primary rack contains the P810 and J890 modules. Communications to the secondary racks are provided via a model W801 multiconductor cable. Power is supplied to the secondary racks via a model W808 cable connecting the two racks.

Where external power is required (i.e., to control relays), power supplies are used. Normally these are 24-V high-current (several Amps) instrument-grade power supplies, physically located beneath the appropriate Modicon model B824-016 module to provide relay power for the "pump in run" signal. 


\subsubsection{Modicon Console (Station 7)}

The EIE-I/O rack houses the Modicon E984 controller. The computer is a Texas Microsystems model 4210. The monitor is a Texas Microsystems model 1006R-G. The connection from the console computer to the Modicon controller is via Modbus Plus. The computer is connected to the system printer through port LPT1. A track ball is used for cursor manipulation and is connected to port COM2.

Installed on Station 7 is Modsoft application software. Modsoft, Modicon's programming and utility software, provides the following functionality: offline program development, online program maintenance, and $1 / O$ module status monitoring. The Modsoft protocol uses these utilities for reading/writing registers or discrete inputs/outputs and for broadcasting data.

Another Modicon software application used in Mini-DACS is Modbus Plus. This software provides a rapid data communication network permitting connectivity between computers, man-machine interfaces, and other Modicon devices. Modbus Plus communications are a reliable method to handle remote data transfers and programming operations.

\subsubsection{Modicon-Genesis Interface}

Interface to the Genesis system is via Modbus-Plus protocol (see Modicon 984 User's manual). Station 5 is used to pass data to and from the Modicon PLC. Information is retrieved and sent to the PLC with Modbus Plus driver that executes in parallel with the other Genesis runtime functions.

\subsection{Genesis (Data Acquisition and Control)}

\subsubsection{General}

Genesis is an industrial process control system produced by Iconics in Foxborough, MA. The software is built on a real-time operating system, AMX, providing a multitasking and preemptive scheduling of events. This networked computer system, using this multi-tasking software shell, is designed to collect data from operator input, the PLC, and the variable frequency drives, display the data in real time to operators, and log the data for archival and future analysis. Functions embedded in the system for controlling and positioning the pump allow the Genesis system to use the data collected from the PLC and variable frequency drives to warn operators of critical conditions. 
The nucleus of the Mini-DACS is the system of three PCs running Genesis. The PCs are called stations and are numbered 5, 7, and 8. Section 3.3 .2 explains the primary function of each PC.

\subsubsection{Genesis Stations}

Station 5 is the Genesis data collection runtime station.

Station 8 is the pump control runtime station.

Station 7 is a local console for the data collection station.

The main functions of the MASFTEST strategy on Station 5 are instrument monitoring, data logging, alarm generation, and PLC control. Essential to these functions are communications with the Modicon PLC, with the Station 8 MASFPUMP strategy and with other stations on the network. In addition to the main functions, the strategy also provides the ability to generate hard-copy reports of the data. Given below is a overview of these MASFTEST strategy functions and the communication paths needed to accomplish them. The Genesis MASFTEST strategy on Station 5 communicates with the Modicon PLC via the Modbus Plus network. It also communicates via the Modbus Plus network with the Station 8 MASFPUMP strategy. Station 5 communicates with Station 7 as an RSS station for operator displays via an ArcNet network.

Data monitoring is one of the primary functions of the MASFTEST strategy. Pump instrumentation data and system status information are presented on a number of operator display screens. The operator displays fall into four basic categories plus a MAINMENU screen. The MAINMENU screen shows the organization of all of the other screens in the system. All four of the screen categories are used for monitoring.

The MASFTEST strategy is responsible for logging data to the Station 5 hard drive. The data are used for monitoring and to evaluate the results of the pump tests.

The runtime MASFPUMP strategy on Station 8 contains logic for controlling and positioning the pump. This logic uses operator input, the current status of the pump and directional motors, and the current feedback signal levels of critical variables to determine what the directional motor should do. This task will command the directional motor's frequency drive to move the pump to the operator's desired position when all conditions are correct.

The mixing pump motor is controlled through its variable frequency drive by the logic associated with pump operation in the MASFPUMP strategy. The logic uses the current values of critical variables to decide if commands from the operators to start or 
stop the pump motors should be honored. If allowable, commands are sent to change the pump's operating status.

There is logic embedded in the MASFPUMP strategy to abort the directional or pump motor operation. This task will immediately shut down operation of either motor if any of the abort criteria becomes active. Station 8 will display alarm conditions in the alarm summary and warn the operator with an audible alarm when a signal goes into alarm state.

\subsubsection{Station 5}

Station 5, the primary data acquisition computer, is connected to the Modicon E984 PLC through Modbus Plus. The strategy functions Station 5 performs are as follows:

1. Send and retrieve field values from the Modicon 800-series VOO drops

2. Write those engineering values to disk as Genesis history files

3. Participate in the watchdog timer with the E984 ladder logic

4. Provide a printed test report as a key macro

5. Look for abort conditions in the strategy

6. Send aborts to the E984 for inclusion in the abort limit ladder logic.

\subsubsection{Station 7}

The primary role for Station 7 is as an RSS. This local RSS station is linked to Station 5 and can receive and send values to the MASFTEST strategy allowing the operator to display and change values in the strategy. This RSS terminal is allowed access to the runtime station strategy through graphic displays developed for the strategy.

The secondary role for Station 7 is to run the Modsoft application, for monitoring and programming the Modicon E984 PLC.

\subsubsection{Station 8}

This personal computer is dedicated to running the Genesis Runtime MASFPUMP strategy. The Gen-Net network node name Station 8 is used to reference this computer. The main task Station 8 performs during communication with the AF5000 + variable frequency drives are monitoring data from the drives and sending commands to them. This is performed with the Eaton AF5000+/Genesis communications driver. 


\subsubsection{Genesis Network (ArcNet)}

\subsubsection{General}

The Genesis system peer-to-peer network communications between control computers is handled via Arcnet protocol and Standard Micro Computer SM-130E network cards. This allows data to be shared between terminals. The Genesis network also supports host communications to multiple supervisory stations, allowing several consoles to access common data. The physical network protocol used by Genesis is ArcNet hardware implemented in a star configuration. The ArcNet and other network connections are coupled to an active hub with coaxial cable.

\subsubsection{Physical Connection}

Each of the Genesis stations is connected via an ArcNet link in a "star" configuration. Each station has an SMC model PC-130 ArcNet card. A BNC connector on the card is attached to a length of RG-62 cable. Each of the cables is connected to a BNC connector on one ArcNet hub module located in trailer equipment rack 8 . The hub module is either a CCSI model MODHUB-16, or SMC model HUB03-120 (both are interchangeable).

\subsubsection{Software Communication}

Information must be exchanged between system components to integrate all of the data and control signals into a workable whole. Communication routines are employed to read signals and data from the PLC and AF5000 devices and to send control commands to the pump equipment. The display terminals share data over ArcNet, a real-time data network. This network permits multiple users to share information and allows strategies to share critical signals and control commands. PLC and strategy-to-strategy communication is accomplished via the Modbus Plus network.

Communication between the MASFTEST and MASFPUMP strategies is accomplished via Modbus Plus using what Genesis refers to as a "node block." The node block allows the MASFPUMP strategy access to the MASFTEST strategy blocks for reading and writing, and vice-versa. Data relating to the variable-speed drives for pump motor control and directional motor control are sent from the MASFPUMP strategy to the MASFTEST strategy. The MASFTEST strategy relays the abort status from the PLC to the MASFPUMP strategy so that it can initiate an independent pump shutdown.

Pump tests are initiated from the MASFPUMP strategy. By using the Modbus Plus network, critical data and other information for the control of the tests are shared 
by the MASFPUMP strategy, the MASFTEST strategy and the PLC. These are such things as test-enable signals and timer durations so the PLC can time the length of a test independently and use abort limit values that vary based upon the pump speed used for a particular test.

Data from the positional encoder are needed in the MASFPUMP strategy. Since these data originate in the PLC, the MASFPUMP strategy acquires this data via Modbus Plus. The MASFTEST strategy also communicates with the Modicon PLC via Modbus Plus.

Data are logged locally on Station 5 by the MASFTEST strategy. It is up to the personnel in charge of each test to manually remove the history files logged on Station 5 for offline analysis.

\subsubsection{Passwords and Security}

There are two types of security implemented on the Mini-DACS: passwords and Genesis security keys. The passwords are kept by the cognizant programmers and the MASF operators.

\subsubsection{Passwords}

Genesis contains three levels of password entry into the Mini-DACS system (and a non-access level). These levels are listed below, along with the privileges afforded by each level. In addition to the operational passwords, is a separate password to protect the configuration. 


\begin{tabular}{||l||l||}
\hline Level & Scope of permitted operation \\
\hline \hline $\begin{array}{l}\text { View only } \\
(0 \text { access })\end{array}$ & $\begin{array}{l}\text { - No changes } \\
\text { - No submenus } \\
\text { - No exit to DOS }\end{array}$ \\
\hline \hline $\begin{array}{l}\text { Operator } \\
1\end{array}$ & $\begin{array}{l}\text { - Data entries in user displays } \\
\text { can be modified } \\
\text { - No submenus displayed } \\
\text { - No exit to DOS }\end{array}$ \\
\hline $\begin{array}{l}\text { Technician } \\
2\end{array}$ & $\begin{array}{l}\text { - Algorithm submenus displayed } \\
\text { and values on first page can be } \\
\text { changed } \\
\text { - Mode of operation can be } \\
\text { switched between auto and } \\
\text { manual }\end{array}$ \\
\hline \hline Engineer & $\begin{array}{l}\text { - All values can be changed } \\
\text { during the runtime session }\end{array}$ \\
\hline 3
\end{tabular}

The four levels listed above apply to operation of the Genesis software. There is another password for the programmer that allows configuration to take place.

Software changes are done offline using special configuration software. No one may change the software without the configuration software, password, and the configuration security key (see below). There may be more than one password for each level, to keep track of who has logged on.

\subsubsection{Security Keys}

The Genesis software is protected from copying and pirating by use of security devices called "keys" or "dongles." In addition to copy protection, is use protection. There are three levels of user protection, all hierarchical. The highest level is called the configuration level, next is the run-time level, and the lowest is the RSS level. Station 5 and Station 8 have configuration keys and Station 7 has an RSS key. All keys are attached to port LPT1 before the printer cable is attached. 


\subsection{Auxiliary Systems}

Auxiliary systems include printers, printer switches, the video copier system, and PC external speakers.

\subsubsection{Printers}

There are two printers in use in the console area.

\subsubsection{Genesis Printer and Security Keys}

Stations 5, 7, and 8 share a single IBM Proprinter. The computers share the printer using a Bufo Enterprises model KC 6012 Auto Data switch. Standard Centronics parallel cables connect from ports LPT1 of each computer to the smart switch. A standard Centronics cable connects the smart switch to the printer. For more information on the hardware security devices see Section 3.3.4.2.

\subsubsection{Video Copier}

The computers share a single Shinko model CHC-443MV2 color video screen copier. The copier has its own multiplexers, model SPA-9-4, tied to the video output of each computer. A push button at each station causes the copier to print the image on the selected screen. Signals for red, green, blue, horizontal and vertical sync, and a signal called $C N I(R, G, B, H, V$, and $C$ ), are all carried on RG-59/U coaxial cables.

Video signals from the backs of the computers are split out from the 15-pin DA connector to separate coaxial lines for each of the signals. Each signal is connected to BNC connectors on the SPA-9-4 units. A separate multiheaded connector attaches from the SPA-9-4 unit to the video monitor, with a 15-pin gender adapter to mate with the monitor connector.

Separate RG-59/U coaxial cables with BNC connectors for each signal (R, G, $B, V, H$, and C) connect the SPA-9-4 units together in a chain, with the Shinko copier at the end of the chain.

\subsubsection{External Speakers}

To increase the volume of the alarms from the Genesis stations, external amplified speakers are connected to the internal PC speakers. For all stations, the connection is made by splicing a 3-mini stereo connector to each PC speaker, then wiring amplified speakers to that connector. The speakers are mounted under the console platforms for the keyboards. 
For Stations 7 and 8 , a Radio Shack 40-1267 amplified stereo speaker is mounted below the respective keyboards. It is powered by a 9-V plug-in power supply (Radio Shack 273-1651B).

Radio Shack 40-167 and 40-1267 amplified speakers are mounted below the respective keyboards. It is powered by a $9-V$ plug-in power supply (Radio Shack 2731651B). Different types of speakers were used to provide different tones for each of Stations 5 and 8.

\subsection{AF5000 Variable Speed Drive (Note: For Information only)}

\subsubsection{General}

The mixer pump and the rotation motor are both controlled by Eaton model AF/IS-5000 + variable (adjustable frequency) speed drives. The mixer pump motor is controlled by a $300 \mathrm{HP}$, unit and the rotational motor is controlled by a $5 \mathrm{hp}$ unit. Both units use a $480 \mathrm{Vac}$ pulse width modulated (PWM) controller. This is a state-of-the-art electronic microprocessor-controlled speed controller manufactured by Eaton, Inc.

The AF- $5000+A F D$ is designed to provide adjustable speed control for three phase motors. These microprocessor-based pulse-width-modulated (PWM) drives have features allowing custom programming of the drive's performance. The mixer pump and rotation motors are both controlled by AF-5000+ AFDs.

\subsubsection{MinI-DACS to AF-5000+ Interface}

The communications link between the AF-5000+ Adjustable Frequency Drive (AFD) units and the Mini-DACS is an RS-232 serial connection between Station 8 and the two motor drives. Because RS-232 is an end-to-end protocol and does not allow "taps" or daisy-chaining, two comm ports are used between Station 8 and the drive units.

In addition to the Station 8 serial link, the AFDs are interfaced with two remote keypads, called Soft Touch Operator Panels (S.T.O.P.). These keypad displays provide drive status and diagnostic information. For more details regarding how these function, consult VI files \# 22570 and 22571 regarding the Eaton AF-5000+. The complete data path for the AF-5000+ AFDs is from the drives to Station 8 using a serial link, then to Station 5 and the PLC utilizing Modbus Plus as described in Section 3.3. 


\subsubsection{Controls}

As mentioned in previous sections, transducers located on the mixer pump that monitor the pump parameters such as flow, pressure, temperature, and strain, interface to the Mini-DACS through the Modicon 1/O. The Mini-DACS monitors, displays, and records the outputs of these transducers to indicate the status of the mixer pump. The Mini-DACS assists the test operator in controlling the mixer pump and the cold test parameters to within predetermined upper and lower safe operating limits. The Mini-DACS compares the incoming data with the stored alarm and abort limits in the software and automatically alerts the operator when limits are exceeded. The Mini-DACS automatically shuts off current to the pump when abort limits are exceeded.

\subsection{SYSTEM LIMITATIONS, CASUALTY EVENTS AND RESPONSES}

\subsection{System Limitations}

The pump rotational motor and the main drive motor are electrically interlocked to prevent both from running at the same time. A so-called "sweep" with the jets rotating at the same time while the pump is running is not currently possible.

\subsubsection{Control Software LImitations}

The control software is designed to shut off an operating pump in a very short time based on any one of dozens of parameters being out of a preset range. Once a parameter is detected out of range, an abort occurs, and the pump is shut off.

\subsubsection{Consequences of Abort Conditions}

Limits for determining an abort are entered on the Genesis hot-test software display called Critical Parameters. The strategy linked to the display stores the limits into registers in the Modicon PLC. Ladder Logic in the PLC continuously looks for conditions calling for an abort by using the limit parameters. If an abort is calculated, a contact is closed in a binary module controlled by the PLC, interrupting power to the pump. In addition, notification of the abort is sent back to Genesis, and the strategy sends stop pulses to the pump and direction AFDs.

\subsubsection{Pump Over-Speed Protection}

Every AF5000+ motor drive has a parameter field MAXSPD, the maximum speed in the recorded speed unit that can be programmed through the SPDSET command. If an operator tries to command the drive to run at a value greater than the 
MAXSPD value, the speed set point becomes the value stored in MAXSPD. The MAXSPD value is stored in nonvolatile RAM so that the last programmed value is present upon power cycling.

Genesis also protects the set-point entry field from being programmed with values out of range. Range extents are entered in AIN blocks in the configurator. These are changed by an operator entering the run-time system at the engineer password level or by a programmer knowing the password for altering the strategy. If an operator tries to over- or under-limit a set point, Genesis restricts the entered value to the appropriate point.

The AF5000+ variable speed motor drives can be controlled by a manual panel or by the Mini-DACS. During pump testing the control will be from the Mini-DACS over an RS-232 communications link. The manual control panels will be disabled to avoid interference with the Mini-DACS. Protection against an inadvertent overspeed command is enabled by setting a MAXSPD in nonvolatile memory in the motor drive. This can be done over the communications link. A command to the speed controller to exceed this speed will be disregarded and the speed set to the value of MAXSPD.

\subsubsection{Genesis vs Modicon Speed}

The PLC is much faster than Genesis running on the PC. For real-time response (under $50 \mathrm{~ms}$ ) ladder logic must be used. Genesis minimum response time is approx. $1 \mathrm{~s}$ or greater. For higher level functions that do not require "instant" response, Genesis may be used.

\subsection{Applications Software}

All of the computers are configured with MS-DOS v6.0 in compliance with Westinghouse site standards and license agreements. In addition each computer has a memory manager from Helix Inc, NetRoom v3.0. NetRoom was purchased with a four "seat" license and is dedicated to Mini-DACS. Expert Mouse driver software is also loaded to support the trackball.

The applications software for process control is by Iconics inc. and called Genesis, v3.72. Stations 5 and 8 contain full Genesis configuration software with GEN-NET-ARC network software, v3.64. Station 7 is configured as a Remote Supervisory Station (RSS) running RSS-Remote-A software, v3.72.

Station 7 is loaded with Modicon Modsoft, v1.2, purchased in a single "seat" license to configure and program the PLC. This software is also dedicated to the Mini-DACS. 


\subsection{OPERATIONS}

\subsection{Introduction}

The three cold test operations are as follow:

1. Pump operation

2. Data logging

3. Configuration changes.

\subsection{Pump Operation}

The operating mode in the MASFPUMP software is completely manual.

\subsubsection{Manual Operation}

On Station 8 , upon pressing the "manual operation" button, the directional drive display is drawn. Operating parameters that can be entered on this display include:

1. Maximum drive speed (rpm)

2. Drive speed set-point (rpm)

3. Acceleration $(\mathrm{rpm} / \mathrm{s})$

4. Deceleration $(\mathrm{rpm} / \mathrm{s})$

5. High-position limit (deg)

6. High-gap limit (deg)

7. Low-gap limit (deg)

Command fields on the directional drive display include a dynamic data entry field for the desired nozzle angle set point and a state field to enable movement of the directional motor. There is also a button to stop the direction drive by sending a stop pulse to the device block. This could be connected in the strategy to the PLC to remove power from the directional motor. Process point fields include:

1. Measured nozzle position

2. Drive ready indicator

3. In-deadband indicator

4. At-speed indicator

5. Low-position

6. Limit-exceeded indicator

7. Drive fault indicator

8. High-position

9. Limit-exceeded indicator 
10. Drive stopped indicator

11. Start inhibit indicator

12. Forward indicator

13. Motor voltage (V)

14. Reverse indicator line voltage $(V)$

15. Reverse enabled indicator

Trying to drive the nozzle position beyond a limit results in a start inhibit until the set point is adjusted to within the position limits.

It is possible to maneuver to the manual pump screen from the direction screen with a press of a button. The pump motor screen has the following operating parameters (some data entry and some process points):

Maximum drive speed (rpm)

Measured acceleration ( $\mathrm{rpm} / \mathrm{min})$

Set point acceleration ( $\mathrm{rpm} / \mathrm{min})$

Measured deceleration(rpm/min)

Set point deceleration $(\mathrm{rpm} / \mathrm{min})$

Command fields on the manual pump screen include a pump speed set point data entry field, start and stop buttons, and a state field to enable starting and stopping. The buttons are only enabled for $6 \mathrm{~s}$. If not pressed within that time, they are again disabled. Once the drive is started, entering a new speed set point causes the pump to ramp to that speed. There is another stop button at the bottom of the screen that issues a stop to the pump drive. However, it could be connected to the PLC to interrupt power to the pump. Process point fields on the manual pump display include:

Measured speed (rpm)

Forward indicator

Drive-ready indicator

Reverse indicator

At-speed indicator

Reverse enabled indicator

Drive fault indicator

Motor current (amp)

Drive stopped indicator

Motor voltage (V)

Forward indicator

Line voltage (V)

Reverse indicator 
Motor oil temperature 1 (deg F)

Reverse enabled indicator

Motor oil temperature 2 (deg F)

\subsubsection{Alarms and Aborts}

Normal pump operation is kept under control of the Modicon Ladder logic and the Genesis strategy software. All parameters are continually monitored by the software. Each parameter is compared against 2 limits; an alarm limit and an abort limit. If any one of the parameters is above the alarm limit, an alarm sounds and the event is logged electronically. If any parameter is above the abort limit, the same type of alarm will sound, the event will be logged, and if the pump was running it will be immediately stopped.

\subsection{Data Logging}

Station 5 is responsible for the data logging operation, also called, "archiving." This function is completely automatic. No operator action is required.

\subsection{MAINTENANCE}

Several procedures have been defined for performing Mini-DACS preventative maintenance. There are two types of maintenance based on who would perform the procedure: computer maintenance and regular system maintenance. In addition are periodic checks to the recording system, and calibrations.

\subsection{Computer Maintenance}

Computer maintenance consists of several procedures to be performed by qualified personnel or under supervision of the cognizant programmer. The list includes:

1. Texas Microsystems PC filter cleaning

2. Texas Microsystems PC floppy disk cleaning

3. Other PC maintenance (virus checks, disk compression)

4. Modicon PLC communication checks

5. Startup and shutdown

\subsubsection{PC Filter Cleaning}

This procedure should be performed monthly. To perform this procedure, the PC chassis must be slid out from the console racks, and they must be powered down. 


\subsubsection{PC Disk Cleaning}

This procedure should be performed monthly or if a particular floppy drive is heavily used. To perform this procedure, the power must be turned on to the PCs. This procedure is given in the technical manual.

\subsubsection{Other PC Maintenance}

Other PC maintenance covers incidental items such as cleaning the video screens, replacing printer ribbons and toner, and replacing paper. These do not require formal procedures, but refer to the manufacturer's directions.

Software maintenance includes: erasing unused temporary files, performing virus checks, and defragmenting the hard disk drives. The cognizant engineer/programmer for the Mini-DACS should have methods to perform these tasks (i.e., Norton Utilities, PC Tools), and following the direction of those methods, perform them on a regular basis.

\subsubsection{Modicon PLC Communication Checks (Note: For information only)}

This procedure should be performed on a regular basis. This procedure is used to check the status of the PLC and can detect problems, early before they are serious. The procedure is given in the Modicon E984 PLC manual.

\subsection{Calibration Procedures}

The following Mini-DACS equipment requires calibration:

1. Modicon $\mathrm{B} 875$

2. Modicon $\mathbf{8 8 8 3}$

\subsubsection{Modicon B875 Calibration}

The Modicon manual for the model B875-101 analog input module provides a procedure for calibration of the internal $10-\mathrm{V}$ reference. Modicon recommends annual recalibration of the reference.

\subsubsection{Modicon B883 Calibration}

Modicon has provided a separate procedure for calibrating the model B883-200 thermocouple modules. Modicon recommends a 3-year cycle for recalibration. This procedure is extensive and should be done by a standards lab. 


\subsection{SOFTWARE DESCRIPTION}

The Mini-DACS contains several components that function in parallel to perform data collection and analysis, data display, alarm indication, monitoring, pump control, and archiving functions. Each component is carefully chosen, based on its capabilities, to perform a specific task. Their close choreography is required to meet the performance requirements of the system.

The system is designed to collect data from the field, display the data to operators, and $\log$ the data for later analysis. The system has the ability to warn the operators of critical conditions. There are control functions embedded in the system to control the position and operation of the pump. During pump control there are several checks on the critical signals to abort operation when a problem is detected. The system is designed to have enhanced effectiveness by being user friendly, and has built-in protection to make the test operation safe.

information must be exchanged between components to integrate all of the data and control signals into a workable whole. Communication routines are implemented to read signals and data from the PLC and AF5000 devices and to send control commands to the pump equipment. The display terminals share data over a real-time data network. This network allows multiple users to share information on critical signals and control commands.

\subsection{Component Layout}

The Mini-DACS is composed of a Modicon PLC, two Eaton AF5000+ frequency drives, a Genesis data collection runtime station, a Genesis pump control runtime station, and a console for sharing data from the data collection runtime station and interfacing with the PLC.

The Eaton AF5000+ frequency drives are used to control electrical motors. The units have microprocessors that have logic functions specifically designed to control the motor and provide for its safe operation. The reading of parameters and sending of control commands for the frequency drives can be done from the front panel of the unit or from serial communication commands. The operating status of the drive can be viewed from the front panel of the unit or it can be requested by serial communication polling.

A communication driver has been written to communicate with the Eaton AF5000+ frequency drives to request data and send control commands. This driver has been specifically designed to function within a personal computer running the Genesis multi-tasking software. 
HNF-SD-WM-SDD-049

Rev. 1

Page 24

The Genesis multi-tasking software is used to display real-time data from the field, perform logic functions, and send commands to the control devices. Each Genesis application is embodied in a database which is referred to as a strategy. This strategy contains algorithms that are executed at specific rates. The algorithms in the strategy are graphically selected by placing blocks in the strategy configuration environment. There are different kinds of algorithm blocks that can be used in the strategy to read data from hardware devices and write data to hardware devices. Genesis provides control-based algorithm blocks to build control logic.

Personal computers that use Genesis to update a strategy from hardware devices are considered runtime stations. Real-time displays are dynamically updated from the current values of the parameters in the algorithm blocks in the Genesis strategy. These displays are interactive and are designed to show current signal readings and allow the operators to change operating parameters. The Genesis software is used to bring data from the field together, perform calculations on that data, and then display the results to the operators.

Each Genesis runtime application can share its data to other Genesis stations over a real-time data network called Gen-Net. The Gen-Net is used to transfer selected real-time data and files between personal computers running the Genesis software. The physical layer of the Gen-Net uses ArcNet hardware in a star configuration. All Gen-Net stations are connected to an active hub with coaxial cable.

One of the Genesis runtime stations is used to pass data to and from the Modicon PLC. Information is retrieved and sent to the PLC with a Modicon ModBus Plus communication driver that executes in parallel with the other Genesis runtime functions. This runtime station is called STATION5 on the Genesis Gen-Net. The Genesis strategy that is executed in this station is called MASFTEST.

Another Genesis runtime station is used for pump control and communicates to the two frequency drives used to position and control the pump. This runtime station is called STATION8 on the Gen-Net. It also passes data to and from the PLC. This is how data is transferred from the frequency drives to the PLC. The Genesis strategy that is executed in this station is called MASFPUMP.

STATION7 can be a second console to the MASFTEST strategy on STATION5 as a Remote Supervisory Station (RSS). The console can bring up dynamic displays that update directly from the MASFTEST strategy. STATION7 can also serve as a direct interface to the PLC using MODSOFT ladder logic configuration software. 
HNF-SD-WM-SDD-049

Rev. 1

Page 25

\subsection{Logical Flow of Data}

Analog and discrete field signals are read from the instruments into the PLC and allocated into registers. This register data is retrieved from the STATION5 running the MASFTEST strategy. This updates the MASFTEST strategy algorithm blocks that are used to read data from the PLC. Data values are sent back to the PLC from algorithm blocks that are used to write data to the PLC. The MASFPUMP strategy is used to communicate bi-directionally with both variable frequency drives. For motor control STATION8 will run the MASFPUMP strategy. PLC communications allows STATION5 and STATION8 to share data between the MASFTEST and MASFPUMP strategies.

The local RSS STATION7 linked to the MASFTEST strategy can receive and send values to the MASFTEST strategy.

\subsection{Task Allocation to Components}

Each component performs at least one main task needed for the system. The following section is a breakdown of the tasks that are performed by each component.

\subsubsection{Modicon PLC.}

The functions of the Modicon PLC are to input data from the field, to abort the pump when critical channels are beyond their abort limits, to provide control and alarm signals and the logic to generate them, to provide timers and enable logic for pump testing, and to provide data and status information to Genesis.

\subsubsection{Eaton AF-5000+ Variable Frequency Drives.}

The variable frequency drives control the motors used to position and operate the pump. Each drive controls its respective motor's critical parameters such as speed, acceleration, deceleration, and maximum speed as well as the starting and stopping of the motor. The drive also monitors current, line voltage, actual speed, and current state of the motor.

The frequency drives communicate with the Genesis MASFPUMP strategy via RS-232 serial communications. Each frequency drive has a unique address for these communications. The drive that controls the pump motor is addressed as 1 , and the drive that controls the directional motor is addressed as 2 . Genesis only acts in a supervisory role in controlling the motors; the drives can run the motors independent of Genesis communication. 
A special signal from the pump motor drive that indicates when the motor is running is wired directly to a discrete input module. This signal is then used by the PLC for accurate timing of the duration of a test run.

\subsubsection{MASFTEST Strategy Terminal, STATION5.}

STATION5 is the primary data acquisition computer and is connected to the Modicon 984 PLC via a ModBus Plus card in STATION5. The strategy functions that STATION5 has to perform are: send and retrieve field values from the Modicon 984 1/O drops, write those engineering values to disk as Genesis history files, participate in the watchdog timer with the $\mathbf{9 8 4}$ ladder logic, provide dynamic display data for operator feedback, download abort limits to the PLC, and generate operator alarms.

\subsubsection{MASFPUMP Strategy Terminal, STATION8.}

This personal computer is dedicated to running the Genesis Runtime MASFPUMP strategy. The Gen-Net node name STATIONB is used to reference this component. This station is also connected to the PLC and the other two stations via the Modbus Plus network.

The main task STATION8 performs is to communicate with the AF5000+ variable frequency drives to monitor data from the drives and send commands to them. This is performed with the Eaton AF5000+ Genesis communications driver.

The MASFPUMP strategy contains logic to control the positioning of the pump. This logic uses operator input, the current status of the pump and directional motors, and the current feedback signal levels of the critical variables in the waste tank to determine what the directional motor should do. This task will command the directional motor's frequency drive to move the pump to the operator's desired position when all conditions are correct.

The mixing pump motor is controlled through its variable frequency drive by the logic associated with the pump operation in the MASFPUMP strategy. The logic uses the current values of the critical variables in the field test to decide if commands from the operators to start the motors should be honored. If allowable, commands are sent to change the pump's operating status.

There is logic embedded in the MASFPUMP strategy to abort the directional or pump motor operation. This task will immediately shut down operation of either motor if any of the abort criteria becomes active. STATION8 will display alarm conditions in the alarm summary and warn the operator with an audible alarm when a signal goes into alarm state. 
The critical control variables for each VFD are set directly by the operator. The desired pump operation time is set by the operator and there is a timing circuit in the MASFPUMP strategy and a timing circuit in the PLC to automatically stop pump operation when the desired time is reached.

\subsubsection{Local RSS Terminal, STATION7.}

The remote supervisory station (RSS) allows access to the runtime station MASFTEST strategy through graphic displays that were developed for the MASFTEST strategy. This network station allows the operator to display and change values in the runtime strategy.

\subsection{SYSTEM FUNCTIONS}

The tasks that are performed by the Mini-DACS are allocated to the PLC, the Eaton AF5000 + variable frequency drives, or the Genesis supervisory control software. The following sections give an overview of those tasks for each of the components.

\subsection{Instrument Monitoring and Data Collection Function (MASFTEST)}

The main functions of the MASFTEST strategy are to monitor the status and values read from the critical signal instruments, log data, generate alarms, and change values in the PLC. Essential to these functions is communication with the Modicon PLC which contains data from the field, status information on abort criteria, and status from the VFD's via the Genesis strategy MASFPUMP run by STATION8. Once the data is brought in from the PLC to the strategy the values can be displayed to the operator. Given below is an overview of these MASFTEST strategy functions and the communication paths needed to accomplish them. The details are reserved for Chapter 9.

\subsubsection{MASFTEST Strategy Communications.}

The MASFTEST strategy communicates with the Modicon PLC via ModBus Plus multiple drop communications. It also shares on-line data with STATION7 via Gen-Net network communications on ArcNet. The RSS station is complete terminal duplication of what data is resident in the MASFTEST strategy running on STATION5. The type of data communicated via each of these pathways is discussed briefly below. 


\subsubsection{Communications with the Modicon PLC.}

All of the pump instrumentation data enter the MASFTEST strategy from the PLC via the ModBus Plus link. This includes data such as mixer nozzle pressure, pump column N2 pressure, volute pressure, mixer pump shroud N2 pressure, mixer pump leg N2 pressure, motor oil temperature, mixer nozzle temperature, instrument cabinet temperature, pump casing vibration, column strain, motor position, and spare signals for backup values. Discrete signals are also retrieved from the PLC which include moisture in motor oil, position limit switches, and pump motor active. There are other signals received from the PLC such as watchoog bits to monitor function of the PLC communications, abort conditions that have occurred, instrument failures, $1 / O$ health status, and critical signals from the VFD's. These signals enter the MASFTEST strategy through one of two device blocks called DEV 1 and DEV 2 . The device blocks accomplish the mapping between the PLC registers and the Genesis TEST strategy 1/O blocks. The device blocks together with the 1/O blocks scale the data to engineering units. The data are then available to be logged to the hard disk, used for alarm indication, or displayed on any of a number of user display screens for the MASFTEST strategy.

The communication with the PLC is a two-way communication, and information is sent from the MASFTEST strategy to the PLC. The MASFTEST strategy sends abort limit values to the PLC for use in the abort comparison logic. It will send an operator-initiated abort reset signal to the PLC, which resets the PLC abort logic.

\subsubsection{Communications from the MASFTEST Strategy to the RSS} Stations.

Communication with the RSS stations is via ArcNet. These stations can display any of the MASFTEST strategy screens for data monitoring. This communications is bi-directional. The operator can change any value from an RSS that can be changed at STATION5.

\subsubsection{Data Monitoring.}

Data monitoring is one of the primary functions of the MASFTEST strategy. Pump instrumentation data and system status information are presented on a number of operator display screens. The operator displays fall into four basic screens plus a MENU screen.

The MENU screen shows the organization of all of the other screens in the system, and is used primarily to navigate to the other screens. 
HNF-SD-WM-SDD-049

Rev. 1

Page 29

\subsubsection{Abort Status Monitoring, PUMPALRM.}

The screen primary used to determine abort conditions is the PUMPALRM display which shows any alarm or abort conditions in the system highlighted red. There is a low alarm, high alarm, and abort level shown for each signal. The condition limit will become red along with the signal name and value to show what status the signal is in. Abort conditions will lock in if the abort coil in the PLC is made active by the condition. To reset the abort coil in the PLC there is a button labeled Reset Abort Coil in the lower right corner.

This screen allows the operator to monitor critical safety-related measurements. These are measurements that need to be within predetermined limits before the pump can be operated safely. These measurements generally have automatic abort functions located in the PLC that automatically shut off the pump motor when the abort limit is exceeded. They generally have alarms associated with them that alert the operator if their value is approaching the abort limit.

\subsubsection{Pump Measurement Monitoring, PUMP.}

This screen allows the operator to view any of the pump instrumentation measurements. The data is presented in a graphic format to show placement of the critical signals for the pump.

\subsubsection{System Status Monitoring, IOSTATUS.}

The IOSTATUS display allows the operator to monitor the status of the Modicon $1 / O$ modules and racks. If a rack or slot is in error the location will be indicated by $B A D$ in red versus $O K$ in green for healthy.

\subsubsection{Trending, PUMPOPS.}

The critical signals are trended over time on this display to show relationships of signals over time. If this display is left and then returned to the trended data is lost and starts the collection of data over time again. The built in system trend does not lose information on the points that are on the trend list. The system trend can be accessed with the $\langle\mathrm{F} 7\rangle$ key.

\subsubsection{PLC Control.}

The MASFTEST strategy provides limited operator control of the PLC. Specifically, from PUMPALRM display (see Section 8.1.2.1) the operator can reset the PLC abort coil. The PLC performs comparisons of certain critical instruments with 
HNF-SD-WM-SDD-049

Rev. 1

Page 30

their abort limits. If one of these measurements exceeds its abort limit then the PLC abort coil is set. The directional motor or pump motor cannot run when this coil is set. This abort coil is latched, which means that if a measurement exceeds its abort limit only momentarily the abort coil will remain set even after the measurement has returned to a normal value. The only way to reset the abort coil is via the button on the abort monitoring screens mentioned above.

The MASFTEST strategy is responsible for downloading some of the abort limits for these measurements to the PLC. This is done once upon startup of the strategy. The only exceptions to these are those limits that change based upon the pump speed. These limits are calculated in the MASFPUMP strategy and relayed to the MASFTEST strategy to be downloaded to the PLC. This occurs when a pump test has been enabled by the operator using the MASFPUMP strategy.

\subsubsection{Data Logging.}

The MASFTEST strategy is responsible for logging data to the hard drive. The stored values are used for long-term pump monitoring and to evaluate the results of the pump tests. Currently 22 data channels are logged. These are stored in 2 history files at intervals ranging from 6 seconds to 5 minutes based on the pump active status.

The MASFTEST strategy creates these history files and assigns file names derived from the time and date the file is created. Data are logged until an evennumbered 2-hour boundary is reached (that is, 2:00, 4:00,6:00, etc.). At this time the current set of history files is closed and a new set is opened. For details of data management refer to section 4.1 .4 of this document.

\subsubsection{Alarming Functions.}

An important function of the MASFTEST strategy is to notify the operator of significant events. This is accomplished by using the alarm features of the Genesis software. The strategy can be set up such that measurements which exceed alarm limits encoded in the strategy blocks cause an audible alarm to sound. Information about the alarm is posted to a special Genesis-provided screen called the Alarm/Event Summary Screen.

The system has been designed to produce alarms when critical pump measurements approach safety limits, when critical instruments fail, when communications have been lost between the MASFTEST strategy and the PLC, and when the PLC has detected an abort condition. 
HNF-SD-WM-SDD-049

Rev. 1

Page 31

\subsection{Pump Control Function (MASFPUMP Strategy)}

The pump is controlled by two variable frequency drives, one for position and one for operation. These variable frequency drives are commanded by the Genesis MASFPUMP strategy using RS-232 asynchronous communications. This strategy has logic functions that control pump position, pump operation, error checking, operation aborting, test selection, network communications, and alarming.

The following section is a description of each task performed by the MASFPUMP strategy. Details on how the task is implemented can be found in Section 9.2 of this document.

\subsubsection{Position Control.}

The position control portion of the Genesis strategy involves several tasks operating in parallel. The desired pump position is selected by the operator or by the current phase of an automated test. The pump position is controlled by an Eaton AF5000+ frequency drive. Parameters are read and set via the Genesis AF5000 driver. The logic portion of the Genesis strategy tells the directional motor to start or stop; the direction of movement is based on the actual position feedback from the PLC.

The starting of the directional motor is controlled by automated logic and enabled by the operator. The automated logic will seek to move the pump within a desired range. When enabled, the logic will set up the direction the pump needs to move and then start the directional motor if the pump is not within the desired range.

The directional motor cannot be started if the pump motor is running. This is a safeguard to ensure equipment is not damaged. At no time are both the directional motor and the pump motor to operate at the same time.

The actual position of the pump must be outside of the desired range for the directional motor to start. If all safeguard conditions are met and the pump is directed to move by the operator, a command is sent to the Eaton AF5000+ frequency drive to start movement of the pump.

The directional motor will stop if the actual position of the pump is within the desired range; it will also stop if the actual position exceeds the limits of movement or overshoots the desired range. An abort condition will also cause the directional motor to stop. The operator can manually stop the directional motor from the console or from the stop button on the VFD control panel. If any logic conditions are met that specify halting of the directional motor, a command is sent to the Eaton AF5000+ 
frequency drive to stop the movement of the pump.

Communications to the Eaton AF5000+ frequency drive are enabled at all times. Parameters can only be read from and sent to the drive when the drive is powered up and receiving asynchronous communication requests. The communication task is responsible for sending control commands and desired operating conditions to the frequency drive. Feedback status from the directional motor is displayed to the operator and is also passed to the PLC abort logic via ModBus Plus communications.

The current position of the pump is requested from the PLC. When the operator requests a position change, the actual position is compared with the desired position to determine if the directional motor should be started. After being started, it is stopped automatically when it is within range or when it overshoots the desired range. "Within range" is defined by a dead-band of 2 degrees above and below the desired position but this range is adjustable by the operator. When the pump is within this range the directional motor is not started. If the pump is out of the desired range and a request to change the position is made, the direction to move is automatically determined by the position control logic. The direction signal is then passed to the frequency drive and the directional motor is started if all critical safety checks are passed.

If for any reason a condition is preventing a successful start of the directional motor an indicator denoted by a question mark will flash on the display. By clicking on the indicator the source of the problem will be displayed to the operator.

When the directional motor is running, limit-checking on the position of the pump assures that the pump will not be moved to a position beyond the maximum bounds set for the pump position. These limits are adjustable by the operator.

The pump can be moved by operator request before or after pump motor operation. There are safeguards in place to disable pump movement during pump operation to protect equipment and test results. There is automated logic that will disable movement after the pump is within the desired range. Any time the directional motor is stopped the movement of the pump is disabled. The logic is set up so the operator must enable position control every time the pump is to be moved.

\subsubsection{Pump Control.}

Several tasks that execute in parallel comprise the pump control. The pump is driven by a motor-controlled Eaton AF5000+ variable frequency drive. Commands to start, stop, and change speeds are processed by a Genesis AF5000 communication 
HNF-SD-WM-SDD-049

Rev. 1

Page 33

driver.

Abort logic is provided to ensure safe operation of the pump. Pump operating status is displayed to the operator and passed on to the PLC for abort logic and for STATION5 to data log critical signals.

An operator request will start the pump provided preventative conditions do not disallow it. An operator can start the pump from the STATION8 console if the directional motor is not operating, all permissives are satisfied, and the enable pump control bit has been set by the operator. If the start logic is satisfied, a command is sent to the Eaton AF5000+ frequency drive that controls the pump motor.

If for any reason a condition is preventing a successful start of the pump motor an indicator denoted by a question mark will flash on the display. By clicking on the indicator the source of the problem will be displayed to the operator.

The pump can be halted automatically from the elapsed test timer, an abort condition, or a manual request by an operator. The operator can halt the operation manually by selecting the stop pump button on the STATION8 console or the stop button on the VFD control panel. If the logical conditions to halt the pump motor are met, a command is sent to the Eaton AF5000+ frequency drive to stop the pump.

Communications from Genesis to the Eaton AF5000+ frequency drive which control the pump motor are enabled at all times, parameters can only be read and sent to the drive when the drive is powered up and receiving asynchronous communication requests. The MASFPUMP strategy is responsible for sending control commands and desired operating conditions to the pump motor and retrieving feedback status from the pump motor.

The current operating values in the frequency drive are compared with the desired operating values set by the operator. If the current operating parameters deviate from the desired operating parameters the operator is warned and the pump is not started. For instance, the desired pump motor speed is compared with the actual pump speed and a warning is displayed to the operator if difference is more than 5 RPM's of the desired speed. The acceleration, deceleration, and maximum speed from the pump VFD are also compared with the desired operating conditions.

The predicted motor current draw is calculated based on the desired speed of the motor and an alarm limit is set on the motor current 10 amps above this limit. The operator will be warned during pump operation if the motor current exceeds this limit. An abort limit is set 20 amps above the predicted current draw. The PLC logic will send an abort command if the motor current exceeds this limit. There is a short delay 
HNF-SD-WM-SDD-049

Rev. 1

Page 34

of 6 seconds after the pump is started or changes speeds before this alarm and abort logic come into effect for the motor amps.

\subsubsection{Abort.}

The directional motor or pump motor will automatically halt operation if an abort condition becomes active from the abort coil in the PLC, a failure in AF5000+ communications, or a failure in PLC communications to STATION8 or STATION5.

There is limit-checking built into the logic used to safeguard the operation of the pump and directional motors. Feedback signals from the PLC are compared with abort limits and desired operating conditions set by the operator (directly or by test selection). Several instrument signals are also monitored by the PLC to ensure safe operating conditions. The PLC can command the mixing pump control and directional control motors to stop if any of these signals exceed their operating range. The following is a list of instrument and motor signals that will cause the abort coil in the PLC to become active.

\begin{tabular}{|l|l|}
\hline VR232050 & Mixer pump speed high. \\
\hline VR232040 & Mixer pump motor amps high. \\
\hline MIP00001 & Moisture in pump motor oil. \\
\hline TIR12A01 & Mixer pump motor oil temperature A high. \\
\hline TIR12A02 & Mixer pump motor oil temperature B high. \\
\hline TIPNO202 & Pump discharge nozzle \#1 temperature high. \\
\hline TIPNO101 & Pump discharge nozzle \#2 temperature high. \\
\hline ZIMPE143 & Position CW limit switch. \\
\hline ZIMPE144 & Position CCW limit switch. \\
\hline WIR12A01 & Pump support column strain \#1 high. \\
\hline WIR12A02 & Pump support column strain \#2 high. \\
\hline WIR12A03 & Pump support column strain \#3 high. \\
\hline WIR12A04 & Pump support column strain \#4 high. \\
\hline
\end{tabular}


HNF-SD-WM-SDD-049

Rev. 1

Page 35

The status of the PLC communications with STATION5 and STATION8 is monitored at all times, and any time if the PLC communications fails both motors will be halted. A failure in communications with either of the AF5000+ frequency drives will also cause an abort condition which will stop both motors. If communications to the VFD's is halted it will probably be unlikely that the stop command will be successfully sent to the VFD's. This condition assumes communications has faulted and revived itself. In any case an alarm warning will be indicated to the operator that an abort condition has occurred and which one of the four sources has caused the motors to stop.

\subsubsection{Test Operation.}

The DACS system at waste tank SY-101 uses predefined tests for pump operation. There is logic in the MASFPUMP strategy to support this feature but there is no display means to access this function. The predefined test operation is not desired for the spare pump testing and it will not be discussed in the details section.

\subsubsection{Pump Bump Operation.}

The pump can be operated for a defined period of time. The operator will determine what the pump acceleration, deceleration, and maximum speed the pump will be constrained to. The desired speed is also set by the operator along with the desired operating time. The acceleration and deceleration rates are limited to 500 RPM's maximum. The desired speed and maximum speed are limited to 1200 RPM's. The maximum pump operation time is limited to 72 hours, 59 minutes, and 59 seconds.

The operators set up the desired bump time and desired pump speed from a specialized display for pump bump operation which is called MASFPUMP. All data entry fields for adjusting desired operating parameters have a blue background field. There are three buttons that are enabled for selection if it is not gray. The operator must first enable a pump bump with the enable button to perform a check on current and desired conditions before pump operation can begin. When pump operation is enabled and passed all enable checks the bump pump button will become green ready for selection. At this time the operator can select to start a pump bump. At any time the operator can select the stop pump button to manually stop pump operation. If a function is disallowed a question mark indication will appear which can be selected to indicate why the function was not allowed. 
When the pump is in operation two elapsed timers are used to keep track of pump operation time, one in the PLC and one in the MASFPUMP Genesis strategy. If either elapsed timer exceeds the desired operation time the pump is automatically stopped.

\subsubsection{PLC Communications.}

PLC communications are enabled in the MASFPUMP strategy for several functions. One is to receive the actual position of the pump to be used in the position pump logic. Also the PLC abort coil status is read into the strategy to stop either motor and disallow the start of a motor if it is active. The desired operating parameters and abort levels that are set in the MASFPUMP strategy are sent to the PLC logic to be used for logic. The current values of the critical variables from the VFD's are also sent to the PLC for abort logic and to be transferred to the MASFTEST strategy for display on STATION5.

\subsubsection{Alarming.}

The operators are warned of signals that exceed limits and the status of events with the alarming function of Genesis. When an alarm condition arises the computer drives an amplified audible alarm and the tag name of the signal that caused it is displayed in the lower right corner of the display. A history of alarm conditions can be viewed from the alarm summary.

The alarms set in the motor strategy pertain mostly to the pump motor and the directional motor. There are some additional signals that are received from the PLC that are also alarmed.

Operator activity is also tracked in the alarm/event summary. If a value is changed by the operator, a record of the change is logged into the alarm/event summary.

\subsubsection{System Parameters.}

There are special algorithm functions in the MASFPUMP strategy that are used to execute Report \& Recipe code, and for version tracking. Please refer to Section 9.2.8 of this document for details on these functions. 


\subsection{Modicon PLC Functions}

The functions of the Modicon PLC are to input data from the field, to abort the pump or position motor when critical channels are beyond their abort limits, to provide control and alarm signals and the logic to generate them, to provide timers and enable logic for pump testing, and to provide data and status information to Genesis. Each of these are discussed functionally in the following sections. The details are in Section 9.3.

\subsubsection{Data Collection from the Field.}

Data enter the PLC via any of a number of Modicon input modules. Different types of modules can accept analog voltage or current inputs, thermocouple inputs, digital inputs of varying levels communications data sharing to the Genesis strategies.

In order to access data from a module, it must be entered into the PLC configuration table known as the Traffic Cop. This involves specifying the module's type, physical location, and the PLC registers which will be used for communication with the module. The physical location is specified in terms of the Modicon I/O drop, the $1 / O$ rack within the drop, and the slot within the rack which contains the module.

For most types of modules, this is all that needs to be done in order to have access to the data. The PLC I/O hardware places the data into the specified registers. From there, the contents of the registers can be sent to Genesis (see Section 8.1.1.1) and can be used within the PLC if further logic operations on the data are required.

\subsubsection{Abort Functions.}

The PLC is responsible for providing an automatic pump shutoff signal (known as the abort signal) whenever certain safety-related or other critical measurements exceed predetermined limits. This function is provided in the PLC rather than in Genesis since the response time of the PLC is much faster (on the order of $50 \mathrm{~ms}$ ).

The abort limits are sent to the PLC from Genesis (see Section 8.1.5). The PLC then continually compares the incoming critical measurements to their abort limits and sends the abort signal to the Genesis strategies if any of the limits are exceeded. The MASFPUMP strategy is responsible for stopping the VFD's through serial communications if the abort coil becomes active. 


\subsubsection{Test Timer and Enable Logic.}

The PLC contains a timer which times the pump operation. The time allowed for the test is sent from Genesis. The PLC timer then runs whenever the pump is running. This provides a backup means for shutting off the pump when the allowed time for the test has elapsed. In most cases, the operator or the MASFPUMP strategy will have already shut off the pump before the allowed time has elapsed in the PLC.

The PLC also contains test enable logic. This is a logic mechanism which ensures that all of the timers are set and abort parameter changes are accomplished before the pump is run.

\subsubsection{Special Data and Status Information.}

In most cases, data can be made available to Genesis without any further PLC logic other than the module configuration setup (see Section 8.3.1). However, some PLC logic is needed to extract data or status information to be sent to Genesis. The status information provides information about the $1 / O$ drop and module status. By extracting only the information needed in the PLC the amount of $1 / O$ between the PLC and Genesis can be reduced.

Also, there is PLC logic which monitors the high-frequency strain alarms for momentary triggers which may otherwise occur too fast to cause an alarm in Genesis.

\subsection{Instrumentation}

Mini-DACS instrumentation provides measurements mainly for mixer pump operation. Data enter the Mini-DACS via one of four general methods. Knowledge of the method used is necessary in order to determine the resolution of the data.

Most of the analog measurements enter the Mini-DACS through Modicon I/O modules which are set up to receive signals ranging from 4-20 mA, 1-5 volts, or 0-5 volts. These modules digitize the signals to a resolution of 12 bits. The range column of the $1 / O$ list gives the corresponding range in engineering units. This represents the full range of the input signal. The engineering unit range is used to scale the digitized input, and this scaled value is recorded to disk, which is performed by Genesis. The useful range does not always correspond to the full range. In some cases, there is an entry in the sub-range column of the channel list which specifies the useful range. If the digitized input signal falls outside of the sub-range, the recorded value of the measurement will be pegged at one or the other boundaries of the subrange. 
Data from the variable speed drives (speed, current, and voltage) enter the Mini-DACS via the AF5000 device driver operating in the MASFPUMP strategy. This is the only category of data which does not enter the PLC via I/O modules.

\subsubsection{Mixer Pump Operation Measurements.}

Mini-DACS provides measurements which monitor the mixer pump operation. There are measurements for the operating characteristics of the pump motors.

\subsubsection{Mixer Pump Motor Operation.}

These measurements provide information about the operating state of the mixer pump motor and the pump directional motor. Most of these measurements originate with the variable speed drive and first enter the MASFPUMP strategy over the RS-232 link. There are 12 measurements giving the motor speed (RPM), the motor voltage, current, percent of load voltage frequency and set-point speed for each motor.

In addition there are measurements for mixer pump motor oil temperature and directional motor position which enter via the Modicon PLC. There are also digital signals which detect moisture in the pump motor oil and when the pump rotational position is at one of its limits. An additional signal measures the pressure of the motor oil in the bottom of the pump stator.

\subsubsection{Discharge Nozzle and Pump Column.}

Mini-DACS provides a set of measurements for detecting the motion and characteristics of the waste (water in MASF) as it moves through the mixer pump. These include measurements for discharge nozzle waste temperature and pressure and pump column pressure.

\subsubsection{Strain Measurements.}

There are measurements which provide strain readings for the pump column. There are a total of 4 low-frequency strain measurements for the pump column. There is also one pump column vibration measurement.

\subsection{DESIGN DETAILS}

This section presents the details of the Mini-DACS design. It includes a discussion of the MASFTEST strategy, the MASFPUMP strategy, and the PLC, focusing upon how each of these accomplishes their various tasks. 
HNF-SD-WM-SDD-049

Rev. 1

Page 40

\subsection{Instrument Monitoring and Data Collection Functlon (MASFTEST)}

In Section 8.1, the functions of the MASFTEST strategy were discussed, including communications with the Modicon PLC, data and status monitoring, alarm generation, data logging, and PLC control. In this section, the details of how these functions are accomplished will be presented.

Some of these functions are accomplished by the MASFTEST strategy blocks, some by the display screens, and some via built-in features of the Genesis system. For those functions that are accomplished via strategy blocks, sample portions of the strategy are shown and explained in the following sections.

\subsubsection{Communications.}

The MASFTEST strategy communicates with the Modicon PLC and with the other stations on the Gen-Net network. The following is a discussion of the details of each of these.

\subsubsection{Communications between MASFTEST Strategy and the Modicon PLC.}

The MASFTEST strategy communicates with the Modicon PLC via specialized multi-drop ModBus Plus communications link. The communication function is performed by a Modicon SA85 card in STATION5.

Communications between Genesis and the PLC is accomplished via two device blocks, called DEV 1 and DEV 2 . DEV 1 is set to scale 12-bit raw data (0-4095) and DEV 2 is set to scale 16-bit raw data (0-65535). The Modicon PLC uses 16-bit registers, but most of the data from the input modules are 12-bit data. In general, DEV 1 is used for most data, and DEV 2 is used when a full 16-bit PLC register is to be transferred.

Each device block has 16 groups that can be set up to accomplish a mapping between PLC registers and Genesis l/O blocks. For each group to be used, one must specify the type of Genesis 1/O block to be connected, the type of PLC register, the starting PLC register address, and the number of connection points within the group. The Genesis I/O block types available are AIN, AOUT, DIN, DOUT, PAIN, PAOT, $P A I O, P D I N, P D O T$, and $P D I O$. In the above terminology "A" stands for analog, "D" for digital, "P" for packed, "IN" for input, "OUT" or "OT" for output, and "IO" for bidirectional input output. The PLC registers available are: CS (Coil/Status bits - Oxxx), IS (Input/Status Bits - 1xxxx), IR (Input Registers - 3xxxx), and HR (Holding Registers - $4 x x x x)$. The starting address specifies the $x x x x$ part of the above registers. 
The Genesis //O block and the PLC register type must be compatible. Coil/Status and input/Status registers must be paired with digital input or output blocks. Input registers must be paired with analog input blocks, and holding registers can be paired with either analog or digital input or output blocks.

The amount of data that can be transferred within one group depends upon the type of I/O block and PLC register that is used. Each group can have up to 16 connections (numbered 0-15). Non-packed blocks transfer one register or one bit per connection depending on whether the block is analog or digital. Packed blocks can transfer $128\left(16^{*} 8\right)$ analog registers or $256\left(16^{*} 16\right)$ digital bits. These bits could be 256 coil/status $(0 x x x x)$ bits or 16 holding registers $(4 x x x x)$ interpreted digitally. Packed communication is much more efficient and should be used whenever possible.

Following is the allocation of communications to registers in the PLC from the MASFTEST strategy.

Table I. PLC register allocation to MASFTEST strategy.

PLC REGISTER

213

241

236-251

243

250

252-267

253

254

255

256

262

263

300-315

300

303

306

307

313

314

315
TAGNAME

WDTRESET

RSTCOIL

G7C1

G7C1.DO8

COMABRT

G7C2

G7C2.DO2

G7C2.DO3

G7C2.DO4

G7C2.DO5

G7C2.D011

G7C2.D012

G5CO

G5C0.DO1

G5C0.DO4

G5C0.DO7

G5C0.DO8

G5C0.D014

G5C0.D015

G5C0.D016
DESCRIPTION

WATCH DOG TIMER FROM GENESIS

RESET ABORT COIL

BUMP TIME REACHED DESIRED TIME

PLC COMMUNICATIONS FAILURE

MIP00001 ABORT

ZIMPE143 ABORT

ZIMPE144 ABORT

WIR12A01 LOW ABORT

WIR12A02 LOW ABORT

WIR12A03 LOW ABORT

DISCHARGE NOZZLE \#2 TEMP ABORT DISCHARGE NOZZLE \#1 TEMP ABORT PUMP MOTOR OIL TEMP A ABORT PUMP MOTOR OIL TEMP B ABORT WIR12A01 HIGH ABORT WIR12A02 HIGH ABORT WIR12A03 HIGH ABORT
BLOCK_TYPE

DIGITAL OUTPUT

DIGITAL OUTPUT

PAK DIGITAL I/O

PAK DIGITAL I/O

DIGITAL OUTPUT

PAK DIGITAL I/O

PAK DIGITAL I/O

PAK DIGITAL I/O

PAK DIGITAL I/O

PAK DIGITAL I/O

PAK DIGITAL I/O

PAK DIGITAL I/O

PAK DIGITAL I/O

PAK DIGITAL I/O

PAK DIGITAL I/O

PAK DIGITAL I/O

PAK DIGITAL $/ O$

PAK DIGITAL I/O

PAK DIGITAL I/O

PAK DIGITAL I/O 


\begin{tabular}{|c|c|c|c|}
\hline $316-331$ & G5C1 & & PAK DIGITAL I/O \\
\hline 316 & G5C1.DO1 & WIR12A04 HIGH ABORT & PAK DIGITAL I/O \\
\hline 325 & G5C1.DO10 & HIGH PUMP MOTOR CURRENT ABORT & PAK DIGITAL I/O \\
\hline 326 & G5C1.D011 & HIGH PUMP MOTOR SPEED ABORT & PAK DIGITAL I/O \\
\hline 331 & G5C1.D016 & WIR12A04 LOW ABORT & PAK DIGITAL I/O \\
\hline $332-347$ & G5C2 & & PAK DIGITAL I/O \\
\hline 341 & G5C2.DO10 & ZIMPE142 LOW GAS PRESS. ABORT & PAK DIGITAL I/O \\
\hline $540-555$ & $\mathrm{G} 8 \mathrm{C} 0$ & & PAK DIGITAL I/O \\
\hline 542 & TZPNO202 & INSTRUMENT PROBLEM - TIPNO202 & OR \\
\hline 543 & TZPNO101 & INSTRUMENT PROBLEM - TIPNO101 & OR \\
\hline 545 & TZR12A01 & INSTRUMENT PROBLEM - TIR12A01 & OR \\
\hline 546 & PYR12A01 & INSTRUMENT PROBLEM - PIR12A01 & OR \\
\hline 547 & TZR12A02 & INSTRUMENT PROBLEM - TIR12A02 & OR \\
\hline 549 & WZR12A02 & INSTRUMENT PROBLEM - WIR12A02 & OR \\
\hline 553 & WZR12A01 & INSTRUMENT PROBLEM - WIR12A01 & OR \\
\hline 554 & WZR12A03 & INSTRUMENT PROBLEM - WIR12A03 & OR \\
\hline $556-571$ & G8C1 & & PAK DIGITAL I/O \\
\hline 556 & WZR12A04 & INSTRUMENT PROBLEM - WIR12A04 & OR \\
\hline 561 & G8C1.DO6 & INSTRUMENT PROBLEM - SPARE2 & OR \\
\hline 562 & G8C1.DO7 & INSTRUMENT PROBLEM - SPARE1 & OR \\
\hline 563 & ZZMPE142 & INSTRUMENT PROBLEM - ZIMPE142 & OR \\
\hline 564 & G8C1.DO9 & INSTRUMENT PROBLEM - PN2PO506 & OR \\
\hline 565 & G8C1.D010 & INSTRUMENT PROBLEM - PN2PO507 & OR \\
\hline 566 & G8C1.D011 & INSTRUMENT PROBLEM - MPICTC01 & OR \\
\hline 567 & G8C1.DO12 & INSTRUMENT PROBLEM - PITNO110 & OR \\
\hline 568 & G8C1.DO13 & INSTRUMENT PROBLEM - PITNO111 & OR \\
\hline 569 & G8C1.DO14 & INSTRUMENT PROBLEM - XIR12AN1 & OR \\
\hline 570 & G8C1.D015 & INSTRUMENT PROBLEM - ZIMPE112 & OR \\
\hline 2001-2016 & G2C0 & & PAK DIGITAL INPUT \\
\hline 2015 & ZIMPE144 & MIX PUMP POS. LIMIT SWITCH CCW & DIGITAL INPUT \\
\hline 2016 & ZIMPE143 & MIX PUMP POS. LIMIT SWITCH CW & DIGITAL INPUT \\
\hline $2017-2032$ & G2C1 & & PAK DIGITAL INPUT \\
\hline 2017 & MIP00001 & MOISTURE IN PUMP MOTOR OIL 1 & DIGITAL INPUT \\
\hline 2033-2048 & $\mathrm{G} 2 \mathrm{C} 2$ & & PAK DIGITAL INPUT \\
\hline 2034 & PMPINRUN & PUMP IN RUN SIGNAL & DIGITAL INPUT \\
\hline 2042 & ABRTCOIL & & DIGITAL INPUT \\
\hline
\end{tabular}




\begin{tabular}{|c|c|c|c|}
\hline 2043 & PLCBEN & LATCHED BUMP ENABLE FROM PLC & DIGITAL INPUT \\
\hline 2044 & PLCWD & WATCH DOG FROM PLC & NOT \\
\hline 2045 & ST8COMFA & STATION8 COMM FAILURE ALARM & DIGITAL INPUT \\
\hline 2046 & PLCOK & 1 - PLC OK; 0 - PLC PROBLEM & DIGITAL INPUT \\
\hline 2047 & A5ABORT & PUMP PROBLEM ALARM & DIGITAL INPUT \\
\hline 2048 & ST5COMFA & & DIGITAL INPUT \\
\hline 2049-2064 & G2C3 & & PAK DIGITAL INPUT \\
\hline 2048 & PMCALARM & PUMP MOTOR CURRENT ALARM & DIGITAL INPUT \\
\hline 2051 & PSPALARM & PUMP SPEED ALARM & DIGITAL INPUT \\
\hline 40108 & $\mathrm{H} 3 \mathrm{CO}$ & DROP 2 RACK $1 \mathrm{l} / O$ HEALTH & PAK DIGITAL INPUT \\
\hline 40108 & H3C0.DO13 & DROP 2 RACK 1 SLOT 4 & PAK DIGITAL INPUT \\
\hline 40108 & H3C0.DO11 & DROP 2 RACK 1 SLOT 6 & PAK DIGITAL INPUT \\
\hline 40109 & H3C1 & DROP 2 RACK 2 I/O HEALTH & PAK DIGITAL INPUT \\
\hline 40109 & H3C1.D016 & DROP 2 RACK 2 SLOT 1 & PAK DIGITAL INPUT \\
\hline 40109 & H3C1.DO15 & DROP 2 RACK 2 SLOT 2 & PAK DIGITAL INPUT \\
\hline 40109 & H3C1.D014 & DROP 2 RACK 2 SLOT 3 & PAK DIGITAL INPUT \\
\hline 40110 & $\mathrm{H} 3 \mathrm{C} 2$ & DROP 1 RACK $1 \mathrm{l} / O$ HEALTH & PAK DIGITAL INPUT \\
\hline 40110 & H3C2.D011 & DROP 1 RACK 1 SLOT 6 & PAK DIGITAL INPUT \\
\hline $40200-40207$ & G4CO & & PAK ANALOG OUTPUT \\
\hline 40205 & HILIM & SET TO 4095 & ANALOG INPUT \\
\hline 40206 & HPMOTLIM & HIGH MOTOR OIL TEMP ABORT LIM & ANALOG INPUT \\
\hline $40224-40231$ & $\mathrm{G} 4 \mathrm{C} 3$ & & PAK ANALOG OUTPUT \\
\hline 40224 & HPCSLIM & PUMP COLUMN STRAIN ABORT LIMIT & ANALOG INPUT \\
\hline 40232-40239 & G4C4 & & PAK ANALOG OUTPUT \\
\hline 40234 & HTEMPLIM & HIGH NOZZLE TEMP ABORT LIMIT & ANALOG INPUT \\
\hline 40238 & LPCSLIM & PUMP COLUMN STRAIN ABORT LIMIT & ANALOG INPUT \\
\hline 42001-42008 & G1Co & & PAK ANALOG INPUT \\
\hline 42001 & TIPNO101 & MIX PUMP DIS. NOZ. 2 TEMP 1 & ANALOG INPUT \\
\hline 42003 & TIR12A02 & PUMP MOTOR OIL TEMPERATURE B & ANALOG INPUT \\
\hline 42004 & TIRT2A01 & PUMP MOTOR OIL TEMPERATURE A & ANALOG INPUT \\
\hline 42006 & ZIMPE142 & PUMP COLUMN N2 PRESSURE & ANALOG INPUT \\
\hline 42007 & PIR12A01 & VOLUTE PRESSURE & ANALOG INPUT \\
\hline 42008 & TIPNO202 & MIX PUMP DIS. NOZ. 1 TEMP 1 & ANALOG INPUT \\
\hline $42017-42024$ & G1C2 & & PAK ANALOG INPUT \\
\hline 42017 & PITNO111 & PUMP DISCHARGE NOZZLE \#1 PRESS & ANALOG INPUT \\
\hline 42018 & PITNO110 & PUMP DISCHARGE NOZZLE \#2 PRESS & ANALOG INPUT \\
\hline
\end{tabular}


HNF-SD-WM-SDD-049

Rev. 1

Page 44

$\begin{array}{llll}42019 & \text { PN2PO506 } & \text { MIXER PUMP SHROUD N2 PRESSURE } & \text { ANALOG INPUT } \\ 42020 & \text { PN2PO507 } & \text { MIXER PUMP LEG N2 PRESSURE } & \text { ANALOG INPUT } \\ 42021 & \text { MPICTC01 } & \text { MIXER PUMP INSTR. CABINET TEMP } & \text { ANALOG INPUT } \\ 42022 & \text { SPARE2 } & \text { SPARE2 } & \text { ANALOG INPUT } \\ 42023 & \text { SPARE1 } & \text { SPARE1 } & \text { ANALOG INPUT } \\ 42065-42072 & \text { G1C8 } & & \text { PAK ANALOG INPUT } \\ 42070 & \text { XIR12AN1 } & \text { PUMP CASING VIBRATION } & \text { ANALOG INPUT } \\ 42071 & \text { WIR12A04 } & \text { PUMP SUPPORT COLUMN STRAIN \#4 } & \text { ANALOG INPUT } \\ 42073-42080 & \text { G1C9 } & & \text { PAK ANALOG INPUT } \\ 42073 & \text { WIR12A01 } & \text { PUMP SUPPORT COLUMN STRAIN \#1 } & \text { ANALOG INPUT } \\ 42074 & \text { WIR12A03 } & \text { PUMP SUPPORT COLUMN STRAIN \#3 } & \text { ANALOG INPUT } \\ 42080 & \text { WIR12A02 } & \text { PUMP SUPPORT COLUMN STRAIN \#2 } & \text { ANALOG INPUT } \\ 42129-42136 & \text { H2C0 } & & \text { PAK ANALOG INPUT } \\ 42131 & \text { ZIMPE112 } & \text { MOTOR POSITION ENCODER BCD } & \text { ANALOG INPUT } \\ 42217-42224 & \text { H2C11 } & & \text { PAK ANALOG INPUT } \\ 42219 & \text { PLCPDPAL } & \text { PUMP DISCHARGE PRESS ALARM LIM } & \text { ANALOG INPUT } \\ 42220 & \text { PLCPDPAB } & \text { HI PUMP DISCHARGE PRESS ABTLIM } & \text { ANALOG INPUT } \\ 42221 & \text { PLCPSLIM } & \text { PUMP SPEED LIMIT FROM PLC } & \text { ANALOG INPUT } \\ 42222 & \text { PLCSPDAL } & \text { PUMP SPEED ALARM LIMIT } & \text { ANALOG INPUT } \\ 42225-42232 & \text { H2C12 } & & \text { PAK ANALOG INPUT } \\ 42225 & \text { VR232050 } & \text { PUMP SPEED } & \text { ANALOG INPUT } \\ 42226 & \text { VR232080 } & \text { ROTATIONAL MOTOR VOLTAGE } & \text { ANALOG INPUT } \\ 42227 & \text { VR232100 } & \text { ROTATIONAL MOTOR CURRENT } & \text { ANALOG INPUT } \\ 42228 & \text { VR232110 } & \text { ROTATIONAL MOTOR SPEED } & \text { ANALOG INPUT } \\ 42229 & \text { VR232040 } & \text { PUMP MOTOR CURRENT } & \text { ANALOG INPUT } \\ 42230 & \text { VR232020 } & \text { MIXER PUMP MOTOR VOLTAGE } & \text { ANALOG INPUT } \\ 42231 & \text { PLCPMCAB } & \text { HIGH PUMP MOTOR CURRENT ABRT L } & \text { ANALOG INPUT } \\ 42232 & \text { PLCPMCAL } & \text { PUMP MOTOR CURRENT ALARM VALUE } & \text { ANALOG INPUT } \\ & & & \end{array}$

For efficient communications, in the PLC I/O section of the STATION5 strategy, most I/O is done via packed blocks. The packed blocks are connected to the device block. To allow each channel to have its own tag name and description, regular AIN blocks are connected to the packed blocks. The I/O blocks are (with few exceptions) organized by device block group such that each horizontal row in the PLC I/O area contains the I/O for one device block group starting with Group 1 at the top.

The packed blocks are named to reflect their device block group and connection number within the group. Thus, the PAIN block G1CO is connected to 
Group 1 , connection 0 of device block 1 . The packed blocks connected to device 1 are named beginning with the letter "G." Those connected to device 2 begin with the letter "H." Thus, a block called "H6C3" would be connected to Group 6, connection 3 of device block 2 .

The regular AIN blocks connected to the packed blocks are arranged by connection number of the packed block starting at the upper left and reading down. Referring to the actual strategy, TIPNO101 is connection 1, TIR12A02 is connection 3 , TIR12A01 is connection 4, ZIMPE142 is connection 6, PIR12A01 is connection 7, TIPNO202 is connection 8 , and connections 2 and 5 are empty. This convention has been followed throughout.

The PAIN blocks include range information for the incoming raw values that allow them to be scaled to engineering units. This scaling information is duplicated in the AIN blocks. In addition, the AIN blocks are configured to include the engineering units, the measurement description, alarm values (if any), and scan period.

The scan period specifies the time between measurement updates. Genesis only allows scan periods of $0.05,0.1,0.25,0.5,1,2,6,12$, and 30 seconds. However, the scan period actually achievable depends upon the number of blocks in the system and the communication rate with the PLC. In addition, the overall communication scan period for each communication link must be specified. The scan rates of individual blocks cannot exceed the overall communication scan rate. The communication link with the PLC is currently set to a 0.5 second scan period. Most of

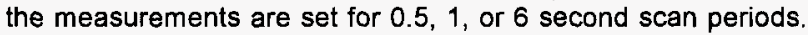

There are two cases where additional manipulation is needed to present the data in engineering format.

\subsubsection{Other Network Communications.}

The MASFTEST strategy communicates over the ArcNet to RSS stations for remote screen display which is the function of STATION7. The details of the ArcNet configuration can be found in Section 9.4 .

\subsubsection{Data Monitoring.}

The data and status monitoring functions of the MASFTEST strategy are accomplished by displaying information to the operators on any of a number of displays including a Genesis-provided system runtime trend and history display. In addition to providing the monitoring function, some displays allow the operator to input control signals that can initiate processes in Genesis or ultimately in the PLC. In 
addition, all displays have a button which, when clicked on with the mouse, allow other displays to be brought up on that particular monitor.

Displays can be brought up independently on the STATION5 or STATION7 computers in the Mini-DACS system. All data that travel to and from the remote displays (in RSS stations) go through the master computer (STATION5) via ArCNet.

There are four main monitoring displays that can be selected from the main menu display. Following is a list of displays with the purpose of each display.

Table II. Displays for MASFTEST strategy.

\begin{tabular}{|c|c|}
\hline NAME & FUNCTION \\
\hline$\overline{\text { IOSTATUS }}$ & Monitor $1 / O$ health status \\
\hline MENU & Legend of all displays for operators to select \\
\hline PUMP & Mixer pump current values \\
\hline PUMPALRM & Critical signals alarm and abort status \\
\hline PUMPOPS & $\begin{array}{l}\text { Pump operations } 2 \text { minute trend of critical } \\
\text { variables }\end{array}$ \\
\hline
\end{tabular}

All of the displays have a similar header bar. The header bar has the title, the current time and date, the application name and version number, and a button to allow the user to bring up the Main Menu. The displays have been designed so that anything in blue can be clicked on with the mouse. These are either buttons that bring up another display or measurement values that bring up a tag details subwindow. The tag details sub-window appears at the bottom of the display and gives further information about the measurement.

Genesis provides two other facilities useful for data monitoring. One is the system runtime trend. This allows the display of runtime graphs for up to 20 predefined measurements. These differ from the runtime trend screens discussed above in that the prior data are not lost when the display is exited momentarily.

Additionally, Genesis provides the ability to examine, graphically or in tabular format any data that are being logged to a history file on the current computer. STATION5 is the only computer that has history files available, so this feature only works on STATION5. Data logging will be discussed further in Section 9.1.4. 


\subsubsection{PLC Control.}

The MASFTEST strategy provides limited control of the PLC. Primarily, it allows the operator to reset the PLC's abort coil. This function was discussed in Section 9.1.2 and the strategy logic to accomplish it will be shown and discussed in Section 9.1.5.

The MASFTEST strategy is also responsible for downloading the abort limits to the PLC. These are the values that the PLC will compare the incoming measurement value with to determine if an abort condition exists. The abort limits are sent via $A / N$ blocks located in the PLC I/O section of the strategy. These AIN blocks get their values from a report SETLIMS.RPS, which contains the actual abort limit values. This report is run at startup to load the AIN blocks with the abort limit values.

The startup logic generates a pulse immediately upon startup as well as a delayed startup pulse. This is implemented by connecting output of the ON DIN block to the PULON pul block and the DELAYON TON block. The ON block is wired to always be 1 . Since at startup, the inputs of all blocks are initialized to 0 , the only time the PULON and DELAYON blocks will see a 0 to 1 transition on their inputs is at startup. This will trigger the pul block PULON and cause the TON block DELAYON to produce its output after the its programmed 45-second delay elapses.

The PULON block initiates the history file naming the phasing process that was discussed in Section 9.1.4. The TON block DELAYON is the block that runs the DOWNLIMS report via the DOWNLIMS REPORT block. The 45-second delay is necessary to allow time for Genesis to PLC communication to be established before the abort limits are downloaded.

\subsubsection{Data Logging.}

The MASFTEST strategy is responsible for logging data to the hard disk and sending the data files over the network to the archiving computer.

The data logging portion is accomplished in Genesis by the use of HIST blocks. The files are known in Genesis terminology as history files.

The top two blocks of the right most column in the MASFTEST strategy are the HIST blocks. The remainder of the blocks are involved with timing the creation of the history files, phasing the creation of the files and logging of the data to avoid system overload and naming the files. 
The functionality of this section of the strategy is by column, and the general flow of the logic is left to right. The left most column consists of TIMER blocks controlling the timing of the opening and closing of the history files. These feed into two OR blocks that feed into a REPORT block. The REPORT block runs a report (HISTFNAM) that creates file names for the about-to-be-opened history files based upon the date and time.

When this process is complete the report sets the pul block, the next block to the right above. This block generates a pulse that causes the SHOT block (the next one over) to generate a one-shot pulse. This pulse starts the TON blocks (the next column of 2 blocks). It is detrimental to start all the history blocks at the same time, so for this reason, the TON (timer-on-delay) blocks lie in-line with every history block. Each TON block has a different delay, spreading the load on the hard disk drive over the total time interval. These delay timer blocks are set to produce their outputs at varying times from the start of the one-shot pulse. They implement the phased stopping and starting of the history files by feeding into the start and stop inputs of the HIST blocks, the right most column of blocks.

A portion of the history strategy section initiates a history file changeover. The system is designed to produce history files that contain 2 hours worth of data each. Every 2 hours throughout the day, the current set of history files is closed a new set is opened. The timer blocks are set to create a pulse at a specific time of day. In this case, the timer blocks are set to create their pulses on the hour spaced 2 hours apart. When one of the timers goes off, the signal feeds through the OR block and causes the report HISTFNAM to be run.

This report implements the history file-naming convention. The files are named "ymdhFFFF.PRN," where

$y$ is the year, with $2=1992,3=1993$, etc.

$m$ is the month, numbered $1-9$ and $A-C$

$d$ is the day, numbered $1-9$ and $A-V$

$h$ is the hour, numbered $0-9$ and $A-N$, and

FFFF is the file code that can be any one to four alphanumeric characters.

HISTFNAM reads the system time/date and creates these file names. It loads the file name field of the HIST blocks with the new file name. It then sets the PUL block GO which in turn initiates the one-shot pulse from the SHOT block XFERPULS. The HISTFNAM report is run at system startup. 
Table III. History file allocation of signals.

$\begin{array}{llll}\text { HIST } & \text { SAMPLE RATE } & \text { FILE NAME TAG } & \text { VAR } \\ \text { BLOCK } & & & \\ \text { PUMP } & 300 / 6 \text { SECONDS ????PUMP MPICTCO1 } & \text { OUT } \\ \text { PUMP } & 300 / 6 \text { SECONDS ????PUMP PIR12A01 } & \text { OUT } \\ \text { PUMP } & 300 / 6 \text { SECONDS ????PUMP PITNO110 } & \text { OUT } \\ \text { PUMP } & 300 / 6 \text { SECONDS ????PUMP PITNO111 } & \text { OUT } \\ \text { PUMP } & 300 / 6 \text { SECONDS ????PUMP PN2PO506 } & \text { OUT } \\ \text { PUMP } & 300 / 6 \text { SECONDS ????PUMP PN2PO507 } & \text { OUT } \\ \text { PUMP } & 300 / 6 \text { SECONDS ????PUMP TIPNO101 } & \text { OUT } \\ \text { PUMP } & 300 / 6 \text { SECONDS ????PUMP TIPNO202 } & \text { OUT } \\ \text { PUMP } & 300 / 6 \text { SECONDS ????PUMP TIR12A01 } & \text { OUT } \\ \text { PUMP } & 300 / 6 \text { SECONDS ????PUMP TIR12A02 } & \text { OUT } \\ \text { PUMP } & 300 / 6 \text { SECONDS ????PUMP XIR12AN1 } & \text { OUT } \\ \text { PUMP } & 300 / 6 \text { SECONDS ????PUMP } & \text { ZIMPE112 } & \text { OUT } \\ \text { PUMP } & 300 / 6 \text { SECONDS ????PUMP } & \text { ZIMPE142 } & \text { OUT } \\ \text { PUMP } & 300 / 6 \text { SECONDS ????PUMP VR232020 } & \text { OUT } \\ \text { PUMP } & 300 / 6 \text { SECONDS ????PUMP VR232040 } & \text { OUT } \\ \text { PUMP } & 300 / 6 \text { SECONDS ????PUMP } & \text { VR232050 } & \text { OUT } \\ \text { PUMP } & 300 / 6 \text { SECONDS ????PUMP SPARE1 } & \text { OUT } \\ \text { PUMP } & 300 / 6 \text { SECONDS ????PUMP SPARE2 } & \text { OUT } \\ \text { PUMP } & 300 / 6 \text { SECONDS ????PUMP MOPSTAB } & \text { OUT } \\ \text { STRAIN } & 300 / 6 \text { SECONDS ????STRN } & \text { WIR12A01 } & \text { OUT } \\ \text { STRAIN } & 300 / 6 \text { SECONDS ????STRN } \text { WIR12A02 } & \text { OUT } \\ \text { STRAIN } & 300 / 6 \text { SECONDS ????STRN WIR12A03 } & \text { OUT } \\ \text { STRAIN } & 300 / 6 \text { SECONDS ????STRN WIR12A04 } & \text { OUT }\end{array}$

\subsubsection{Alarming Functions.}

Operators are notified of significant events by using the alarm capabilities of the Genesis software. Genesis provides a special screen called the alarm/event summary screen. Alarms, operator actions, and other system events are posted to this screen as they occur. In addition, the PC speaker sounds when an alarm arrives. These speakers have been amplified in the trailer producing an effective audible alarm. The operator must hit a keyboard key to silence the alarm. Information about the alarm can be found on the alarm/event summary screen. From there the alarms can be acknowledged by the operator. 

strategy.

Following is a table of tags that are enabled for alarming in the MASFTEST Table IV. Algorithm blocks enabled for alarming.

$\begin{array}{lll}\frac{\text { Tagname }}{\text { A5ABORT }} & \text { Description } & \text { Block Type } \\ \text { ABRTCOIL } & \text { PUMP PROBLEM ALARM } & \text { DIGITAL INPUT } \\ \text { G5C0 } & & \text { DIGITAL INPUT } \\ \text { G5C1 } & & \text { PAK DIGITAL I/O } \\ \text { G7C2 } & & \text { PAK DIGITAL I/O } \\ \text { G8C0 } & & \text { PAK DIGITAL I/O } \\ \text { G8C1 } & \text { PAK DIGITAL I/O } \\ \text { H3C0 } & \text { DROP 2 RACK 1 I/O HEALTH } & \text { PAK DIGITAL I/O } \\ & & \text { PAK DIGITAL } \\ \text { H3C1 } & \text { DROP 2 RACK 2 I/O HEALTH } & \text { INPUT } \\ & & \text { PAK DIGITAL } \\ \text { H3C2 } & \text { DROP 1 RACK 1 I/O HEALTH STATUS } & \text { INPUT } \\ & & \text { PAK DIGITAL } \\ \text { MIP00001 } & \text { MOISTURE IN PUMP MOTOR OIL 1 } & \text { DIGITAL INPUT } \\ \text { MPICTC01 } & \text { MIXER PUMP INSTR. CABINET TEMP } & \text { ANALOG INPUT } \\ \text { PLCFAIL } & \text { FAILURE OF PLC COMMUNICATIONS } & \text { DIGITAL INPUT } \\ \text { PLCOK } & \text { 1 - PLC OK; O - PLC PROBLEM } & \text { DIGITAL INPUT } \\ \text { PMCALARM } & \text { PUMP MOTOR CURRENT ALARM } & \text { DIGITAL INPUT } \\ \text { PN2PO506 } & \text { MIXER PUMP SHROUD N2 PRESSURE } & \text { ANALOG INPUT } \\ \text { PN2PO507 } & \text { MOTOR OIL PRESSURE } & \text { ANALOG INPUT } \\ \text { PSPALARM } & \text { PUMP SPEED ALARM } & \text { DIGITAL INPUT } \\ \text { ST5COMFA } & & \text { DIGITAL INPUT } \\ \text { ST8COMFA } & \text { STATION8 COMM FAILURE ALARM } & \text { DIGITAL INPUT } \\ \text { TIPNO101 } & \text { MOTOR STATOR TEMP 1 } & \text { ANALOG INPUT } \\ \text { TIPNO202 } & \text { MOTOR STATOR TEMP 2 } & \text { ANALOG INPUT } \\ \text { SPARE3 } & \text { MOTOR STATOR TEMP 3 } & \text { ANALOG INPUT } \\ \text { TIR12A01 } & \text { PUMP MOTOR OIL TEMPERATURE A } & \text { ANALOG INPUT } \\ \text { TIR12A02 } & \text { PUMP MOTOR OIL TEMPERATURE B } & \text { ANALOG INPUT } \\ \text { SPARE7 } & \text { PUMP MOTOR OIL TEMPERATURE A } & \text { ANALOG INPUT } \\ \text { SPARE8 } & \text { PUMP MOTOR OIL TEMPERATURE B } & \text { ANALOG INPUT } \\ \text { MOPSTAB } & \text { MOTOR OIL PRESS. STATOR BOTTOM } & \text { ANALOG INPUT } \\ \text { TZPNO101 } & \text { INSTRUMENT PROBLEM - TIPNO101 } & \text { OR } \\ & & \end{array}$




$\begin{array}{lll}\text { TZPNO202 } & \text { INSTRUMENT PROBLEM - TIPNO202 } & \text { OR } \\ \text { TZR12A01 } & \text { INSTRUMENT PROBLEM - TIR12A01 } & \text { OR } \\ \text { TZR12A02 } & \text { INSTRUMENT PROBLEM - TIR12A02 } & \text { OR } \\ \text { WIR12A01 } & \text { PUMP SUPPORT COLUMN STRAIN \#1 } & \text { ANALOG INPUT } \\ \text { WIR12A02 } & \text { PUMP SUPPORT COLUMN STRAIN \#2 } & \text { ANALOG INPUT } \\ \text { WIR12A03 } & \text { PUMP SUPPORT COLUMN STRAIN \#3 } & \text { ANALOG INPUT } \\ \text { WIR12A04 } & \text { PUMP SUPPORT COLUMN STRAIN \#4 } & \text { ANALOG INPUT } \\ \text { WZR12A01 } & \text { INSTRUMENT PROBLEM - WIR12A01 } & \text { OR } \\ \text { WZR12A02 } & \text { INSTRUMENT PROBLEM - WIR12A02 } & \text { OR } \\ \text { WZR12A03 } & \text { INSTRUMENT PROBLEM - WIR12A03 } & \text { OR } \\ \text { WZR12A04 } & \text { INSTRUMENT PROBLEM - WIR12A04 } & \text { OR } \\ \text { ZIMPE142 } & \text { PUMP COLUMN N2 PRESSURE } & \text { ANALOG INPUT } \\ \text { ZIMPE143 } & \text { MIX PUMP POS. LIMIT SWITCH CW } & \text { DIGITAL INPUT } \\ \text { ZIMPE144 } & \text { MIX PUMP POS. LIMIT SWITCH CCW } & \text { DIGITAL INPUT } \\ \text { ZZMPE142 } & \text { INSTRUMENT PROBLEM - ZIMPE142 } & \text { OR }\end{array}$

The ABRTCOIL block comes from the PLC Abort Coil. When set due to an abort detected in the PLC, an alarm is generated in Genesis, which notifies the operator. Alarms are generated in Genesis for each individual abort in the PLC. Since any of a number of signals could have caused the PLC abort, this allows the operator to determine which signal specifically was the cause of the abort.

Since the PLC abort coil remains latched following an abort, the operator needs some means of resetting the coil after the problem has been resolved. This is provided by the PULCOIL and RSTCOIL blocks. When the Reset Abort Coil buttons on the abort coil status screens (see Section 9.1.2) are clicked upon, they cause the PULCOIL to produce a pulse. This is sent via the RSTCOIL digital output block to the PLC where it causes a reset of the PLC abort coil, as well as all of the individual aborts in the PLC.

The PLCCOMFA block is set when Genesis detects a communication failure from the PLC to Genesis. This can be detected by the Modicon driver and accessed by a connection to the FAIL bit of an I/O block. The PLCCOMFA block causes a Genesis alarm whenever this condition occurs. It also attempts to send this information to the PLC so that the abort coil can be set. This is accomplished via the COMABRT block. This is useful in the unlikely event that the communication failure has been only one way and the PLC has not detected a corresponding Genesis to PLC failure. 
The A5ABORT block is set when the MOTOR strategy detects a problem with the AF5000 motor controller. This also causes a Genesis alarm and is sent to the PLC (via the A5ABRT block) so it can set its abort coil.

\subsection{Pump Control Function}

The signals that actually control the pump are assigned by the Eaton AF5000+ variable frequency drives. There is one drive to control the motor that positions the pump and one drive to control the motor that operates the pump. These variable frequency drives receive commands in the form of ASCll strings from a communication driver. This ASCII driver is imbedded in the Genesis MASFPUMP strategy and is represented by two AF5000+ hardware communication device blocks, one for each VFD.

There are several different tasks that are performed in parallel to control the position and operation of the pump. The results of these tasks are sent as commands to the variable frequency drives or as indications to the operators. The following subsections of Section 9.2 supply the details of how the separate tasks of position control, pump control, aborting, test operation, and pump bump operation are implemented in the MOTOR strategy. These will be followed by discussions of PLC communications, alarms, system parameters, and indication of failure of executing tasks.

\subsubsection{Position Control.}

The following are the details related to controlling the position (that is, rotational direction) of the pump.

\subsubsection{Start.}

The directional motor can move the pump only if the actual position is outside the desired range, the actual position is within the safe boundary, the pump is not running, and the operator enables the pump to move. The following tags of the MASFPUMP strategy are used to execute the start of the directional motor.

Table V. Position control start variables.
ABORTOR
BACKWARD
DISMOVE
DMOTOR
FORWARD 


\section{FSTRTDEL GOFORWRD GOREVERS HILIMAND LOLIMAND NOTRUN POSCNTRL POSITION PRUN PSTOP RSTRTDEL START STARTAND STARTSHT STRTAND}

When the output of the one shot block <STARTSHT> goes high, the directional motor will be commanded to start by setting <DMOTOR.start> high. <STARTSHT> is set high when the output of the small logic and block <STARTAND> goes high. <STARTAND> and <STRTAND> are used as the safeguard to disable a start of movement under improper conditions. All of the following conditions must be true before the directional motor can be started.

- $\angle A B O R T O R . Q N O T>$ is high if no abort condition is active.

- $\quad$ START.DOUT> is high indicating a start request is active from the direction control logic.

- <HILIMAND.QNOT> is high indicating the position of the pump is not beyond the maximum boundary.

- <LOLIMAND.QNOT> is high indicating the position of the pump is not beyond the minimum boundary.

- <DISMOVE.QNOT> is high indicating position control is not disabled.

- $<$ PSTOP.DOUT $>$ is high indicating that pump motor is stopped.

- $\quad<P R U N . Q N O T>$ is high indicating the pump motor is not running. 
The small logic or block <START> is the block that will go high when the directional motor is successfully requested to move. <START> has two inputs to move the pump forward or backward.

- $\quad$ FSTRTDEL.DOUT> goes high when the pump is to move in the forward direction. <FSTRTDEL> will go high when both of the following inputs are true.

- <GOFORWARD.DOUT> which goes high when the pump is to go forward.

- <DMOTOR.forward> is high when the position motor is set to move in the forward direction.

- $\quad$ RSTRTDEL.DOUT> goes high when the pump is to move in the reverse direction. <RSTRTDEL> will go high when both of the following inputs are true.

- <GOREVERS.DOUT> which goes high when the pump is to go backward

- <DMOTOR.reverse> is high when the position motor is set to move in the reverse direction.

The actual pump position is monitored from the PLC and is passed to the block called $\angle P O S I T I O N>$ in STATION8. The output of the block $\angle P O S I T I O N\rangle$ is passed to the $D G A P$ control block <POSCNTRL> as the measured process variable.

The DGAP block <POSCNTRL> is used to control forward movement or reverse movement of the directional motor based on the comparison of desired position with actual position. The DGAP block is an on-off control block that sets two digital outputs to various states depending on where the measured position is in relationship to the deadband.

The high gap and low gap of the DGAP block <POSCNTRL > is set to a 2degree dead band around the desired position.

The first output of the DGAP block <POSCNTRL.DOUT> goes high when the measured position is less than the desired position minus the low-gap offset. The output goes on to a one-shot block <GOFORWRD> used to start forward movement of the pump.

The output of <GOFORWRD> will stay high for 15 seconds unless the block is reset. The reset of the block $\angle$ GOFORWRD $>$ is controlled by the inverse of the small logic and block $\angle F O R W A R D\rangle$. When the output of $\angle F O R W A R D\rangle$ is low, the output of $<$ GOFORWRD> will always be low and will not start forward movement. 
The block <FORWARD> has two inputs that must go high for the output to go high to allow the pump to move forward.

- The output of <DISMOVE> must be low. This is the bit used to disable movement mentioned in the disable movement task.

- The output of <NOTRUN> must be high. This is the inverse of the feedback signal from the directional motor frequency drive that goes high when the motor is running.

When the output of $\angle$ GOFORWRD $>$ is allowed to go high it sets $<$ DMOTOR.forwrd> high, which commands the frequency drive to move the motor forward when it is running. The output of $\angle G O F O R W R D>$ also is passed to the block <FSTRTDEL>.

The block <FSTRTDEL> is to ensure that the forward command is sent to the frequency drive before the motor is commanded to start. The output of <FSTRTDEL> sets a small logic or block <START> high, which was mentioned above in the beginning of the start task of position control.

The second output of the DGAP block <POSCNTRL.DO2> goes high when the measured position is greater than the desired position plus the high-gap offset. The output goes on to a one-shot block <GOREVERS> used to start reverse movement of the pump.

The output of <GOREVERS> will stay high for 15 seconds unless the block is reset. The reset of the block <GOREVERS> is controlled by the inverse of the small logic and block $\angle B A C K W A R D>$. When the output of $\angle B A C K W A R D\rangle$ is low the output of $<$ GOREVERS $>$ will always be low and will not start reverse movement.

The block <BACKWARD> has two inputs that must go high for the output to go high and allow the pump to move backward:

- The output of <DISMOVE> must be low. This is the bit used to disable movement mentioned in the disable move task.

- The output of <NOTRUN> must be high. This is the inverse of the feedback signal from the directional motor frequency drive that goes high when the motor is running.

When the output of <GOREVERS> is allowed to go high it sets $<D M O T O R$.revers $>$ high, which tells the frequency drive to move the motor in reverse when it is running. The output of <GOREVERS> also is passed to the block <RSTRTDEL>. 
The block <RSTRTDEL> ensures that the reverse command is sent to the frequency drive before the motor is commanded to start. The output of <RSTRTDEL> sets a small logic or block <START> high, which, as noted above, starts the position motor.

An overshoot condition causes the directional motor to stop operation. This condition is recognized when <POSCNTRL.D02> goes high and the pump is moving forward or <POSCNTRL.DOUT> goes high and the pump is moving in reverse.

The small logic and block <FOROVER> goes high to drive the one-shot block $<$ FOVRSTOP $>$ that stops the directional motor when all three of the following conditions are true:

- <DMOTOR.inforwrd > is high, indicating the motor is moving in the forward direction.

- $\quad$ POSCNTRL.DO2> is high when the actual position is beyond the desired range and the motor should be moved in reverse to achieve the desired position.

- $<D M O T O R$.inrun> is high, indicating the directional motor is running.

The small logic and <REVOVER> goes high to drive the one-shot block $<$ ROVRSTOP $>$ that stops the directional motor when all three of the following conditions are true:

- $<$ DMOTOR.inrevers $>$ is high, indicating the motor is moving in the reverse direction.

- $<$ POSCNTRL.DOUT> is high when the actual position is beyond the desired range and the motor should be moved forward to achieve the desired position.

- $<D M O T O R$.inrun> is high, indicating the directional motor is running.

\subsubsection{Stop.}

The directional motor will be stopped automatically if the position of the pump is within the desired range, the position of the pump exceeds the safe boundary, or an abort condition arises. The directional motor also can be stopped by an operator request from the STATION8 console.

The following signals are involved with the stop task in the MASFPUMP strategy. 
Table VI. Position control stop variables.

\section{BUTPULSE}

DISP1

DMOTOR

FOROVER

FOVRSTOP

GOSTOP

HILIMIT

LOLIMIT

REVOVER

ROVRSTOP

STOP

STOP2

The output of the small logic or block <STOP2> controls <DMOTOR.stop>, which commands the directional motor to halt if the signal transitions from 0 to 1 .

$<$ STOP.DOUT> is also a small logic or block to help compile stop conditions. $<$ STOP2.DOUT> will go high if any one of the following conditions become true.

- <STOPTEST.DOUT> which goes high when the operator requests to stop the pump, an abort condition occurs, or the pump operation time reaches the desired time.

- <GOSTOP.DOUT> goes high, which is automatically set when the pump position comes within the desired range while the directional motor is moving.

- <FOVRSTOP.DOUT> goes high, which indicates an overshoot condition while the pump is moving forward.

- <ROVRSTOP.DOUT> goes high, which indicates an overshoot condition while the pump is moving in reverse.

- <HILIMIT.DOUT> goes high, which indicates the actual pump position has exceeded the maximum boundary. This will be discussed in further detail in the position feedback task in section 9.2.1.4. 
HNF-SD-WM-SDD-049

Rev. 1

Page 58

- <LOLIMIT.DOUT> goes high, which indicates the actual pump position has exceeded the minimum boundary. This will be discussed in further detail in the position feedback task in section 9.2.1.4.

- <BUTPULSE.DOUT> goes high, which indicates the operator requested the motor to stop.

Each time the position motor is stopped the movement is disabled by the output of $<$ STOP2 $>$ setting input 1 of $<$ DISP1 $>$ high to execute the macro DISMOV1. The macro DISMOV1 simply forces <DISMOVE> high. The disable movement task will be discussed in further detail in section 9.2.1.6.

An overshoot condition causes the directional motor to stop operation. This condition is recognized when <POSCNTRL.DO2> goes high and the pump is moving forward or <POSCNTRL.DOUT> goes high and the pump is moving in reverse.

The small logic and block <FOROVER> goes high to drive the one-shot block $\angle F O V R S T O P>$ that stops the directional motor when all three of the following conditions are true.

- <DMOTOR.inforwd> is high, indicating the motor is moving in the forward direction.

- $<$ POSCNTRL.DO2> is high when the actual position is beyond the desired range and the motor should be moved in reverse to achieve the desired position.

- $\angle$ DMOTOR.inrun $>$ is high, indicating the directional motor is running.

The small logic and block <REVOVER> goes high to drive the one-shot block $<$ ROVRSTOP $>$ that stops the directional motor when all three of the following conditions are true.

- <DMOTOR.inrevers> is high, indicating the motor is moving in the reverse direction.

- <POSCNTRL.DOUT> is high when the actual position is beyond the desired range and the motor should be moved in forward to achieve the desired position.

- $<$ DMOTOR.inrun> is high, indicating the directional motor is running. 


\subsubsection{AF5000+ Communications.}

The AF5000 device driver is a communication task that runs in parallel with all other Genesis tasks. The device driver is responsible for sending information to and collecting information from the variable frequency drive. The device block with the tag name <DMOTOR> processes all communications for the frequency drive controlling the directional motor.

The following signals are used to perform the AF5000+ communications to the position motor.

Table VII. Position control AF5000+ communication variables.
AF5COMFA
COMMOR
DACCEL
DATSPEED
DDECEL
DFAULT
DFORWARD
DLINEV
DMAXSPD
DMOTOR
DREADY
DREVENAB
DREVERSE
DRUN
DSTOP
VR232070
VR232080
VR232090
VR232100
VR232110
VR232120
GOFORWRD
GOREVERS
STARTSHT
STOP2 
The following tags are used to issue commands to the frequency drive to change operating value and operating condition.

Table VIII. Position control AF5000+ communication control variables.

\begin{tabular}{|l|l|l|}
\hline \multicolumn{1}{|c|}{ TAG } & \multicolumn{1}{c|}{ VARIABLE } & \multicolumn{1}{c|}{ DESCRIPTION } \\
\hline GOFORWRD & forwrd.do0 & Changes direction of motor to forward \\
\hline GOREVERS & revers.doo & Changes direction of motor to reverse \\
\hline STARTSHT & start.do0 & Causes motor to start \\
\hline STOP2 & stop.do0 & Causes motor to halt \\
\hline
\end{tabular}

The following tags are used as directional motor feedback signals from the AF5000+ device block. Some of these signals are passed to STATION5 with the PLC communication task and some are used for parameter verification.

Table IX. Position control AF5000+ communication read variables.

\begin{tabular}{|l|l|l|}
\hline \multicolumn{1}{|c|}{ TAG } & \multicolumn{1}{|c|}{$\begin{array}{c}\text { AF5000+ } \\
\text { Variable }\end{array}$} & \multicolumn{1}{c|}{ Description } \\
\hline COMMOR.INP1 & ACCEL.fail & Indicates a failure in communications \\
\hline DACCEL & ACCEL.inp & Desired acceleration rate \\
\hline DDECEL & DECEL.inp & Desired deceleration rate \\
\hline VR232090 & FREQ.inp & Stator frequency high range \\
\hline DLINEV & LINEV.hrng & Line voltage \\
\hline VR232070 & LOAD.inp & Motor load \\
\hline DMAXSPD & MAXSPD.inp & Maximum speed \\
\hline VR232100 & MOTORA.inp & Motor current \\
\hline VR232080 & MOTORV.inp & Motor voltage \\
\hline
\end{tabular}




\begin{tabular}{|l|l|l|}
\hline VR232120 & SPDSET.inp & Desired speed of motor \\
\hline VR232110 & SPEED.inp & Actual speed of motor \\
\hline DATSPEED & inatspd.dio & $\begin{array}{l}\text { Actual speed is within } \pm 5 \% \text { of desired } \\
\text { speed }\end{array}$ \\
\hline DFAULT & infault.dio & Frequency drive is faulted \\
\hline DFORWARD & inforward.dio & Direction of motor movement is forward \\
\hline DREADY & inready.dio & Drive is ready to run \\
\hline DREVERSE & inrevers.dio & Direction of motor movement is reverse \\
\hline DRUN & inrun.dio & Drive is running \\
\hline DSTOP & instoppd.di0 & Drive is stopped \\
\hline DREVENAB & reven.dio & Reverse enable \\
\hline \hline
\end{tabular}

The following is a list of variables in the AF5000+ device block <DMOTOR>.

Table X. Position control AF5000+ variables.

\begin{tabular}{|l|l|}
\hline \multicolumn{1}{|c|}{ Variable } & \multicolumn{1}{c|}{ Description } \\
\hline ACCEL & Desired acceleration rate \\
\hline DECEL & Desired deceleration rate \\
\hline FREQ & Stator frequency \\
\hline LINEV & Line voltage \\
\hline LOAD & Motor load \\
\hline MAXSPD & Maximum speed \\
\hline MOTORA & Motor current \\
\hline MOTORV & Motor voltage \\
\hline
\end{tabular}




\begin{tabular}{|l|l|}
\hline SPDSET & Desired speed of motor \\
\hline SPEED & Actual speed of motor \\
\hline forwrd & Changes direction of motor to forward \\
\hline inatspd & $\begin{array}{l}\text { Actual speed is within } \pm 5 \% \text { of desired } \\
\text { speed }\end{array}$ \\
\hline infault & Frequency drive is faulted \\
\hline inforward & Direction of motor movement is forward \\
\hline inready & Drive is ready to run \\
\hline inrevers & Direction of motor movement is reverse \\
\hline inrun & Drive is running \\
\hline instoppd & Drive is stopped \\
\hline reven & Reverse enable \\
\hline revers & Changes direction of motor to reverse \\
\hline start & Causes motor to start \\
\hline stop & Causes motor to halt \\
\hline \hline
\end{tabular}

If a failure of communications arises from the VFD the parameter $\angle D M O T O R . A C C E L$.fail> will go high which is passed on <COMMOR> which alarms $\angle A F 5 C O M F A>$. Communications failure is an abort condition which should cause either motor drive to be automatically stopped as discussed further in the abort task section 9.2.3. 


\subsubsection{Position Feedback.}

There are maximum limits set on the actual position of the pump. The actual position signal comes from the block $\langle P O S I T I O N\rangle$. The high-alarm value of <POSITION> is set to 190 degrees, and the low-alarm value is set to 15 degrees. (These limits can be changed via the manual positioning display, MASFPOSM.)

The following signals are integral to the position feedback task in the MASFPUMP strategy.

Table XI. Position control position feedback variables.
ANTON
HILIMAND
HILIMIT
INBAND
LOLIMAND
LOLIMIT
POSITION

The high-alarm bit from <POSITION> will go high when the actual position exceeds the high alarm value. This high-alarm bit is passed on to a small logic and block <HILIMAND>, which is used to disable the start of the directional motor to start.

The output of $<H I L I M A N D>$ must be low for the directional motor to be enabled to start.

- $\quad$ POSITION.HALM $>$ is high indicating the pump has exceeded the maximum boundary.

- $\quad$ CMOTOR.inforwrd $>$ is high indicating the frequency drive is enabled to move the directional motor forward. 
The high-alarm bit from $\angle P O S I T I O N>$ is currently passed to a small logic and block <HILIMIT>, which is used to stop the directional motor and disable movement of the pump if it is running and the actual position exceeds the high limit. The output of $\langle$ HILIMIT $>$ is passed to the block $\langle S T O P\rangle$, which will cause the directional motor to stop. The output of $\langle$ HILIMIT > will go high when the following three conditions are true.

- $<P O S I T I O N$. HALM $>$ is high, indicating the pump has exceeded the maximum boundary.

- $<D M O T O R$.inrun> is high, indicating the directional motor is running.

- <DMOTOR.inforwrd> is high, indicating the directional motor will move forward when it is started.

The low-alarm bit from <POSITION> will go high when the actual position is less than the low-alarm value. This low-alarm bit is passed on to a small logic and block <LOLIMAND>, the output of which must be low for the directional motor to be enabled to start. The output of $\angle$ LOLIMAND $>$ will go high when both of the following conditions are true.

- $\quad<P O S I T I O N . L A L M>$ is high, indicating the pump has exceeded the minimum boundary.

- $<D M O T O R . i n r e v e r s>$ is high, indicating the frequency drive is enabled to move the directional motor in reverse.

The low-alarm bit from <POSITION> is also passed to a small logic and block $<$ LOLIMIT >, which is used to stop the directional motor and disable movement of the pump, if it is running and the actual position falls below the low limit. The output of $<$ LOLIMIT $>$ is passed to the block $\langle S T O P\rangle$, which will cause the directional motor to stop. The output of $<$ LOLIMIT> will go high when the following three conditions are true.

- $\quad$ POSITION.LALM $>$ is high, indicating the pump has fallen below the minimum boundary.

- $<D M O T O R$.inrun> is high, indicating the directional motor is running.

- <DMOTOR.inrevers> is high, indicating the directional motor will move in reverse when it is started.

The position feedback alarming is disabled on startup of Runtime by controlling the inhibit alarm bit of $<P O S I T I O N>$ by $<A N T O N$. QNOT> which will go low 10 seconds after the strategy is started. When the feedback position is within the deadband of the desired position <INBAND> is set high. 


\subsubsection{Disable Movement.}

The pump is disabled from moving unless the operator enables movement from the console. Each time the pump stops or goes beyond the desired range the pump is disabled from moving automatically.

The following tags in the MASFPUMP strategy are used to execute the disable movement task.

Table XII. Position control disable movement variables.

DISMOV

DISMOV1

DISMOVE

DISP1

INBAND

ON

PBPOSAN2

STOP2

The DIN block <DISMOVE> must have a 0 value in order to start the directional motor; This is the value set when the operator enables pump movement from the STATION8 console. The value of $\angle D I S M O V E>$ is set to 1 any time the directional motor is stopped or when the MOTOR strategy is first started. This is accomplished with two custom macros in EXTRA.KMS. The macro DISMOVO is used to set <DISMOVE.DOUT> low and the macro DISMOV1 is used to set <DISMOVE.DOUT> high which will disable movement of the pump.

The following signal will execute the macro DISMOVo.

- <PBPOSAN2.DOUT> which goes high if the operator selects to position the pump during a full integrated test.

The movement of the pump is also enabled manually by the operator from the MASFPOSM display.

The following signals will execute the macro DISMOV1.

- <STOP2.DOUT> will go high any time the directional motor is stopped.

- <ON.DOUT> when the MASFPUMP strategy is first started. 
- <DISMOV1.DOUT> which goes high any time there is a problem with starting the position motor, the position motor is not running, and the position of the pump is not within the desired deadband.

The function block <DISMOV> is used to stop the directional motor and disable movement when the position of the pump is within the desired range. This block also checks the disable movement bit from <DISMOVE.DOUT>, the forward movement bit from <POSCONTRL.DOUT>, and the reverse movement bit from <POSCNTRL.D02>. When all three conditions are not true an internal control bit $<D R \mid>$ starts an internal counter <AR1>. This counter is used to delay the stop of the pump by 2 seconds after the position is within the dead band. This allows the pump to move closer to the desired position before shutting down movement. When the internal counter reaches 2 seconds the directional motor is commanded to stop and movement is disabled by control bit <DISMOV.DOUT>.

The function block $\angle D I S M O V>$ also has a logic equation to determine if the pump is within the desired range. $<D|S M O V . D 02\rangle$ is passed to $\langle$ INBAND>, which is used to indicate the pump is within the dead band range of 2 degrees.

\subsubsection{Pump Control.}

The following are the details related to controlling the operation of the mixing pump to actually mix the contents of the tank.

\subsubsection{Start.}

The AF5000+ device block variable <PMOTOR.start> requires a transition from 0 to 1 to start operation of the pump motor. The <PMOTOR.start> variable is driven by the output of the block with the tag name <PBSTRTDN>. 〈PBSTRTDN> will go high when the operator successfully starts a fully integrated test for pump operation. Test operation will be explained in detailed sections to follow.

The following blocks are involved with the start pump control start task.

Table XIII. Pump control start variables.

PBSTRTDN

PMOTOR 


\subsubsection{Stop.}

The AF5000+ device block variable <PMOTOR.stop> requires a transition from 0 to 1 to stop operation of the pump motor. The <PMOTOR.stop> variable is driven by the output of a small logic or block with the tag name <STOPTEST>.

The <STOPTEST> block will go high when the pump operation is stopped automatically from an abort condition, from the elapsed time exceeding the desired times, the operator manually stopping pump operation, or failure in communications to either VFD.

The following blocks are involved with the stop pump control task.

Table XIV. Pump control stop variables.

PMOTOR

STOPTEST

\subsubsection{AF5000+ Communications.}

The AF5000+ device driver is a communication task that runs in parallel with all other Genesis tasks. The device driver is responsible for sending information to and collecting information from the variable frequency drive. The device block with the tag name <PMOTOR> processes all communications for the frequency drive controlling the pump motor.

The following signals are used to perform the communications task for the pump control.

Table XV. Pump control AF5000+ communication variables.

AF5COMFA

COMMOR

EQUPSPD

PACCEL

PATSPEED

PDECEL

PFAULT

PFORWARD

PLINEV

PMAXSPD

PMOTOR 


\section{PREADY \\ PREVENAB \\ PREVERSE \\ PRUN \\ PSTOP \\ VR232020 \\ VR232030 \\ VR232040 \\ VR232050 \\ VR232060 \\ VSDRS232}

The following tags are used to issue commands to the frequency drive to change operating values and operating conditions.

Table XVI. Pump control AF5000+ communication control variables.

\begin{tabular}{|l|l|l|}
\hline \multicolumn{1}{|c|}{ TAG } & \multicolumn{1}{|c|}{$\begin{array}{c}\text { AF5000+ } \\
\text { Variable }\end{array}$} & \multicolumn{1}{c|}{ Description } \\
\hline COMMOR.QNOT & forwrd.do0 & Changes direction of motor to forward \\
\hline PBSTRTDN & start.do0 & Causes motor to start \\
\hline STOPTEST & stop.do0 & Causes motor to halt \\
\hline
\end{tabular}

The following tags are used as pump feedback signals from the AF5000+ device block. Some of these signals are passed to STATION5 with the PLC communication task, and some are used for parameter verification. 
Table XVII. Pump control AF5000+ communications read variables.

\begin{tabular}{|l|l|l|}
\hline \multicolumn{1}{|c|}{ TAG } & \multicolumn{1}{|c|}{$\begin{array}{c}\text { AF5000+ } \\
\text { Variable }\end{array}$} & \multicolumn{1}{c|}{ Description } \\
\hline COMMOR.INP2 & ACCEL.fail & Indicates a failure in communications \\
\hline PACCEL & ACCEL.inp & Desired acceleration rate \\
\hline PDECEL & DECEL.inp & Desired deceleration rate \\
\hline VR232030 & FREQ.hrng & Stator frequency high range \\
\hline PLINEV & LINEV.inp & Line voltage \\
\hline VSDRS232 & LOAD.inp & Motor load \\
\hline PMAXSPD & MAXSPD.inp & Maximum speed \\
\hline VR232040 & MOTORA.inp & Motor current \\
\hline VR232020 & MOTORV.inp & Motor voltage \\
\hline VR232060 & SPDSET.inp & Desired speed of motor \\
\hline VR232050 & SPEED.inp & Actual speed of motor \\
\hline VSDRS232 & LOAD.inp & VSD\% load \\
\hline PATSPEED & inatspd.diO & Actual speed is within $\pm 5 \%$ of desired speed \\
\hline PFAULT & infault.diO & Frequency drive is faulted \\
\hline PFORWARD & inforward.diO & Direction of motor movement is forward \\
\hline PREADY & inready.di0 & Drive is ready to run \\
\hline PREVERSE & inrevers.dio & Direction of motor movement is reverse \\
\hline PRUN & inrun.di0 & Drive is running \\
\hline PSTOP & instoppd.di0 & Drive is stopped \\
\hline PREVENAB & reven.di0 & Reverse enable \\
\hline
\end{tabular}


The following is a list of variables in the AF5000+ device block <PMOTOR>.

Table XVIII. Pump control AF5000+ communication variables.

\begin{tabular}{|l|l|}
\hline \multicolumn{1}{|c|}{ Variable } & \multicolumn{1}{c|}{ Description } \\
\hline ACCEL & Desired acceleration rate \\
\hline DECEL & Desired deceleration rate \\
\hline FREQ & Stator frequency \\
\hline LINEV & Line voltage \\
\hline LOAD & Motor load \\
\hline MAXSPD & Maximum speed \\
\hline MOTORA & Motor current \\
\hline MOTORV & Motor voltage \\
\hline SPDSET & Desired speed of motor \\
\hline SPEED & Actual speed of motor \\
\hline forwrd & Changes direction of motor to forward \\
\hline inatspd & $\begin{array}{l}\text { Actual speed is within } \pm 5 \% \text { of desired } \\
\text { speed }\end{array}$ \\
\hline infault & Frequency drive is faulted \\
\hline inforward & Direction of motor movement is forward \\
\hline inready & Drive is ready to run \\
\hline inrevers & Direction of motor movement is reverse \\
\hline inrun & Drive is running \\
\hline instoppd & Drive is stopped \\
\hline reven & Reverse enable \\
\hline revers & Changes direction of motor to reverse \\
\hline start & Causes motor to start \\
\hline stop & Causes motor to halt \\
\hline
\end{tabular}


If a failure of communications arises from the VFD the parameter <PMOTOR.ACCEL.fail> will go high which is passed on <COMMOR> which alarms $\angle A F 5 C O M F A>$. Communications failure is an abort condition which should cause either motor drive to be automatically stopped as discussed further in the abort task section 9.2.3.

\subsubsection{Parameter Verification.}

The following blocks are used for parameter verification in the MASFPUMP strategy.

Table XIX. Pump control parameter verification variables.

CALCURR

CALDISPR

CURABRT

CURALRM

CURPRED

DISPRABT

DISPRALM

DISPRPRE

EQUPSPD

VR232050

VR232060

The function block <EQUPSPD> contains an equation to compare the desired speed set in the frequency drive <VR232060> with the actual speed <VR232050>. The variable <EQUPSPD.DRI> will be high if the actual speed is within $5 \%$ of the desired speed. This will be displayed to the operator as a light green indication on the pump speed bar graphs.

The desired speed value is passed to the function block <CALCURR> uses $<$ CURPRSPD $>$ as the desired speed and automatically calculates the predicted motor current, which is passed to <CURPRED>.

The predicted motor current plus $20 \%$ is passed to $<$ CURALRM $>$ as the alarm limit. The output of <CURALRM > sets the high alarm value of <VR232040> and is passed to the PLC for the high motor alarm. 
The predicted motor current plus $40 \%$ is passed to <CURABRT> as the abort limit. The output of <CURABRT> is passed to the PLC as the abort limit for motor current.

The desired pump speed is also passed to the function block <CALDISPR> which automatically calculates the predicted discharge pressure, which is passed to $<$ DISPRPRE $>$ for operator display.

The predicted discharge pressure plus $20 \%$ is passed to $<$ DISPRALM $>$ as the alarm limit, and the output of $\angle D I S P R A L M>$ is passed to the PLC to set the high alarm value of the discharge pressure signal.

The predicted discharge pressure plus $40 \%$ is passed to $<D I S P R A B T>$ as the abort limit, and the output of $\angle D I S P R A B T>$ is passed to the PLC as the abort limit for the discharge pressure.

\subsubsection{Abort.}

Certain conditions are monitored continuously in the MASFPUMP strategy as abort criteria to stop both motors automatically. Also abort conditions will prevent the start of either motor.

The following blocks are involved with the abort task.

Table XX. Abort variables.

A5ABRT

ABORT

ABORTOR

ABORTPUL

COMMOR

NODEFAIL

PLCFAIL

The current abort status is indicated by the small logic or block <ABORTOR> which has the following input conditions.

- $\angle A B O R T$.DOUT> is high if the abort coil in the PLC is active.

- <COMMOR.DOUT> is high if either VFD has a failure in communications to the MASFPUMP strategy.

- <NODEFAIL.DOUT> is high if a failure in communications from STATION5 to the PLC is recognized. 
- <PLCFAIL.DOUT> is high is a failure of communications to the PLC is recognized from the MASFPUMP strategy.

The output of $\angle A B O R T O R>$ is passed to a small logic pulse block $<A B O R T P U L>$ which is passed on to <STOPTEST> which will stop either VFD with a communication command.

$<C O M M O R>$ is a small logic or block with two inputs from each hardware device block. If communications to either frequency drive goes bad, indicated by a fail bit of the first parameter selected from each hardware device block, $<$ COMMOR.DOUT > will go high. This signal is passed to the PLC with the digital output block <A5ABRT>.

\subsubsection{Test Operation.}

This section provides the details of the actual test operation, including their selection, how the elapsed time is calculated, and the information provided to the operator.

\subsubsection{Test Creation and Selection.}

This section is only intended for Mini-DACS-1 control system to create and select predefined tests. The Mini-DACS system does implement this feature and will not be discussed in detail. The following blocks are related to test creation and selection.

Table XXI. Test creation and selection variables.

ACCELCHG

ANGLECHG

CHANGED

CHGCHK1

CLRMESS

DECELCHG

DELPUL

HRSCHG

INFILE

MANUAL

MAXINDX

MINSCHG

NEXTINDX 
NEXTPUL

OACCEL

OANGLE

ODECEL

OHRS

OLDTEST

OMINS

ORESTIM

OSECS

OSPEED

PBTESTNO

PREVPUL

RESCHG

SAVEPUL

SECSCHG

SPEEDCHG

TESTCHG

TESTSET

TESTSET2

UACCEL

UANGLE

UDECEL

UHRS

UMINS

UMSG1

URESTIM

USECS

USPEED

UTESTNO 


\subsubsection{Elapsed Time Calculation.}

There are two elapsed timers that are used during test operation. The overall timer for test operation keeps track of the total test time. There is a second timer to time pump operation time.

The following blocks are integral is performing the elapsed time calculation task.

Table XXII. Test operation elapsed time calculation variables.

DF65535

DFLTO

DISP4

PB3OSEC

PBCALSEC

PBDNTM

PBHR

PBMIN

PBRAMP

PBRAMPHL

PBSEC

PBSPLIT

RESETPB

RSECPB

SPLITPB

TSTRUNNG

The RAMP block <RSECPB> totals the test time while a test is in operation. When ramp rate 1 becomes active the output of $\angle R S E C P B>$ increments by one every second.

A test is in operation when the rs flip-flop block <TSTRUNNG> is high. This signal controls $\angle R S E C P B . R P I O\rangle$, which activates ramp rate 1 . The elapsed timer $\angle R S E C P B>$ is reset at the beginning of test operation by $<R E S T P B>$ which is set high with the RR code PBSETVAL.RPS when a new test is selected. The elapsed test time is broken down from seconds into hours, minutes, and seconds by the function block <SPLITPB>.

There is a second elapsed timer used to keep track of the pump operation time at each position. The RAMP block <PBRAMP> totals the time the pump is in operation. When ramp rate 1 becomes active, the output of $\langle P B R A M P\rangle$ increments by one every second. 
The pump is in operation when the rs flip-flop block <TSTRUNNG $>$ is high. This signal controls $\langle$ RSECPB.RPIO $>$, which activates ramp rate 1 .

The elapsed timer <PBRAMP> is reset at the beginning of pump operation by <SETVALDN> which goes high when the test values have been successfully set. The high limit of <PBRAMP> is controlled by <PBRAMPHL> which will pass either the value 0 from $<D F L T 0>$ or the maximum pump operation time from $<D F 65535\rangle$. $<$ PBRAMPHL $>$ will pass the value of $<D F 65535>$ when $<$ SETVALDN $>$ is high when the test values are successfully loaded.

The desired pump operation time is set during test selection by setting the test values. The AIN blocks <PBHR>, <PBMIN>, and <PBSEC> contain the desired minutes and seconds for pump operation. The outputs of these blocks are passed to a function block <PBCALSEC>, which merges the values into one desired pump operation time value in seconds. This value is passed to the function block <PBSPLIT>, which is used to stop pump operation when the elapsed time from <PBRAMP> exceeds the desired time from <PBCALSEC>.

The control bit <PBSPLIT.DOUT> will go high when the elapsed time exceeds the desired time and is passed to the DIN <PBDNTM>. The output of this block resets the rs fip-flop block <PBRSFF> mentioned above. The output of $<P B D N T M>$ is passed to logic which stops pump operation by setting <STOPTEST> high. <PBSPLIT> also breaks seconds of pump operation into hours, minutes, and seconds for operator display.

The desired pump operation times are reset by the output of <STOPTEST> executing the macro RESPTIM which is referenced in <DISP4>.

The alarm block <PB30SEC> is used to warn the operator 30 seconds before the end of pump operation. The high alarm value of $\angle P B 30 S E C>$ is set by the second analog output of $\angle P B C A L S E C>$ which is set to 30 less than the desired pump operation time during test operation and to a very large number when a test is not in operation.

\subsubsection{Operator Test Information}

There is logic within the MASFPUMP strategy for indication of test operation status. There is status bits for test values set correctly, pump at desired position, test enabled to start, and test running. If a function is selected by an operator and the task was not successfully executed there is logic to indicate what the problem is. The following sections describe each main task execution and status feedback for indication of success of operation. 


\subsection{Set Test Values.}

The desired test values selected by the operator must be downloaded to the control parameters in the MASFPUMP strategy. This is done by the operator with the set values button. The following blocks are related to the set test values task.

Table XXIII. Set test values variables.

NORUN

PBENABLE

PBREPORT

PBSETAND

SETTEST

SETVALDN

STOPTEST

TSTRUNNG

\section{VALSET}

The small logic pulse block <SETTEST> starts the execution of the set values task. Its output is passed to the small logic and block <PBSETAND> which has the following input conditions to be true before executing the RR code PBSETVAL.RPS by setting input 1 of <PBREPORT> high.

- $\quad$ SETTEST.DOUT> is set high by the operator to set the test values.

- <PBENABLE. QNOT> is high if a test is not already enabled.

- $\quad$ TSTRUNNNG.QNOT> is high if a test is not in progress.

- $<$ NORUN.DOUT > is high if both the pump motor and position motor are stopped.

- <VALSET.QNOT> is high if the test values are not already set.

At the end of the RR code PBSETVAL.RPS <SETVALDN> is set high to indicate the test values are successfully set. $\angle S E T V A L D N>$ has a pulsed output and sets the rs flip-flop block <VALSET> high. <VALSET.DOUT> is the status bit used to indicate that the test values have been successfully set. <VALSET> is reset when $<$ STOPTEST > goes high when a test is stopped.

\subsection{Problem with Setting Test Values.}

If the test values are requested to be set and the task is not successfully completed the following blocks are used to indicate what the problem is. 
Table XXIV. Problem with setting test values variables.
DISP3
NORUN
NOSEPROB
PBBUTSTP
PBPROB
PDISP
RSETPROB
SEDISP
SETPROB
SETPROBA
SETPROBR

The rs flip-flop block $\angle S E T P R O B>$ is used to indicate a problem with setting the test values. $\angle S E T P R O B>$ is set high if the output of $\angle$ SETPROBA $>$ is high and the reset input $\angle$ SETPROBR $>$ is low.

<SETPROBA $>$ is a small logic and block with the following inputs.

- $\quad<$ SETTEST.DOUT > is high if the test values are requested to be set.

- <NORUN.DOUT> is high if both motors are stopped.

- <VALSET.QNOT> is high if the test values are not set.

$<$ SETPROBR $>$ will reset $<$ SETPROB $>$ if any of the following conditions are true.

- $\quad$ RSETPROB.DOUT> which is set high by the operator to reset the problem indication.

- <PBBUTSTP.DOUT> which goes high when the operator manually stops a test.

- <NOSEPROB.DOUT> which is a small logic and block with the following input conditions.

- <PBENABLE.QNOT> is high when a test is not enabled.

- $\quad<T S T R U N N G . Q N O T>$ is high when a test is not running.

- <NORUN.DOUT> is high when both motors are stopped.

When $\angle S E T P R O B>$ goes high $\angle P B P R O B>$ is set high which indicates a test operation problem. The small logic and block $\angle S E D I S P>$ is used to bring up the problem indication display for setting test values. When $\langle S E T P R O B\rangle$ is high and the 
operator sets $\angle P D I S P>$ high to view the problem the display SETPROB is brought up via the display block <DISP3>.

\subsection{Position Pump Selection.}

When the test values are set the desired pump position is compared with the actual position. If the pump is not at the desired position the pump will need to be positioned before a test can be enabled, except for a pump bump which does not need to check pump position. The following blocks are key in the pump position selection.

Table XXV. Pump position selection variables.

ABORTOR

INPOSI

NORUN

PBENABLE

PBPOSAN2

PBPOSAND

PBPOSPMP

POSSET

TSTRUNNG

VALSET

<PBPOSPMP> starts the execution of the pump position selection. Its output is passed to the small logic and block <PBPOSAND> which together with <PBPOSAN2> has the following input conditions before <PBPOSAN2> will start the pump position control by executing the macro DISMOVO as discussed earlier in the disable movement task section.

- $\quad<T S T R U N N G . Q N O T>$ which is high if a test is not running.

- $\angle A B O R T O R . Q N O T>$ which is high if an abort conditions is not active.

- <PBENABLE.QNOT> is high if a test is not enabled.

- <VALSET.DOUT> is high if the test values are set.

- <NORUN.DOUT> is high if both motors are stopped.

- <PBPOSPMP.DOUT> goes high when the operator selects to position the pump.

- $\quad<$ POSSET.QNOT> which is an AND block with the following input conditions.

- $\quad$ VVALSET.DOUT> is high when the test values are set.

- <INPOSI.DOUT> which is high when the pump is at the desired position. 


\subsection{Problem with Position Pump Selection.}

If the pump position selection does not successfully execute the following blocks are used to indicate what the problem is.

Table XXVI. Problem with position pump selection variables.
ABORTOR
DISP3
NOPOPROB
NORUN
PBBUTSTP
PBENABLE
PBPOSPMP
PBPROB
POSDISP
POSPROB
POSPROBA
POSPROBR
POSSET
RPOSPROB
TSTRUNNG

\section{VALSET}

The rs flip-flop block $\angle P O S P R O B>$ is used to indicate a problem with selecting to position the pump. $\angle P O S P R O B>$ is set high if the output of $\angle P O S P R O B A>$ is high and the reset input <POSPROBR> is low. $\angle P O S P R O B A>$ is a small logic and block with the following inputs.

- $\angle P B P O S P M P . D O U T>$ is set high by the operator to position the pump.

- <POSSET.QNOT> which is high when the pump is not in position or the test values are not set.

- <NORUN.DOUT> is high when both motors are stopped.

- <VALSET.DOUT> is high if the test values have been set.

$\angle P O S P R O B R>$ will reset $\angle P O S P R O B>$ if any of the following conditions are true.

- $\quad$ RPOSPROB.DOUT> which is set high by the operator to reset the problem indication. 
- <PBBUTSTP.DOUT> which goes high when the operator manually stops a test.

- <NOPOPROB.DOUT> which is a small logic and block with the following input conditions.

- $\angle A B O R T O R . Q N O T>$ which is high if no abort condition is active.

- <TSTRUNNG.QNOT> is high if a test is not running.

- <PBENABLE.QNOT> is high if a test is not enabled.

- <VALSET.DOUT> is high if the test values are set.

- <NORUN.DOUT> is high if both motors are stopped.

When $\angle P O S P R O B>$ goes high $\angle P B P R O B>$ is set high which indicates a test operation problem. The small logic and block $\angle P O S D I S P\rangle$ is used to bring up the problem indication display for position pump selection. When $\angle P O S P R O B\rangle$ is high and the operator sets $\angle \mathrm{PDISP}>$ high to view the problem the display $\angle \mathrm{POSPROB}\rangle$ is brought up via the display block <DISP3>.

\subsection{Problem with Position Pump Operation.}

When the position motor is to be started to position the pump and a problem prevents the actual movement of the pump the following blocks are used to indicate what the problem is.

Table XXVII. Position pump operation problem variables.
ABORTOR
DDISP
DISMOV1
DISMOVE
DISP1
DISP3
DMDISP
DMPROB
DMPROBDI
DMPROBR
DRUN
DSTOP
ENMOVPUL
ENMOVTON
HILIMAND
HOLDENMO 
INBAND

LOLIMAND

NODMPROB

PBDMPROB

PBPROB

PBPROB2

PDISP

POSDISP

PRUN

PSTOP

RDMPROB

The rs flip-flop block $\angle \mathrm{DMPROB}>$ is used to indicate a problem with positioning the pump. $\angle D M P R O B>$ is set high if the small logic pulse block <ENMOVPUL> is high and the reset input <DMPROBR> is low. <ENMOVPUL> is set high by <ENMOVTON> which delays <HOLDENMO> for 4 seconds. <HOLDENMO> stays high for 5 seconds after the pump is requested to move by <DISMOVE> going low. $\angle D M P R O B R>$ will reset $\angle D M P R O B>$ if any of the following conditions are true.

- $<$ RDMPROB.DOUT $>$ which is set high by the operator to reset the problem indication.

- <NODMPROB.DOUT> which is a small logic and block with the following input conditions.

- $\quad<$ INBAND.QNOT> which indicates the pump is not within the desired position.

- $\angle A B O R T O R . Q N O T>$ which is high if no abort condition is active.

- <HILIMAND.QNOT> is high if the pump position is not beyond the high range.

- <LOLIMAND.QNOT> is high if the pump position is not beyond the low range.

- $\quad$ PSSTOP.DOUT> is high if the pump motor is stopped.

- $\quad$ PPRUN.QNOT $>$ is high pump motor is not running.

If there is a problem indicated by $\angle D M P R O B>$ and the test values are set and the pump is not in position $\angle P B D M P R O B>$ goes high which is then passed to $<P B P R O B>$ through $<P B P R O B 2>$. The small logic and block $\angle D M P R O B D \mid>$ is used to bring up the problem indication display for positioning the pump. When $\angle P B D M P R O B>$ is high and the operator set $\angle$ PDISP $>$ high to view the problem and 
there is no problem with the position selection from <POSDISP.QNOT> the display DMPROB will be brought up via the display block <DISP3>.

The small logic and block <DISMOV1> will execute the macro DISMOV1 to disable movement of the pump. <DISMOV1> has the following input conditions.

- <DISMOVE.QNOT> is high if movement is enabled.

- $\quad \angle D R U N . Q N O T>$ is high if the position motor is not running.

- $\quad$ DSTOP.DOUT $>$ is high if the position motor is stopped.

The small logic and block <DMDISP> is used to bring up the problem indication display for positioning the pump. When $\angle D M P R O B>$ is high and the operator sets $\angle D D I S P>$ high to view the problem from the MASFPUMP display the display DMPROB is brought up via the display block $<$ DISP1>.

\subsection{Test Enable.}

Before test operation can be started a test must be enabled. The enable task is used to check the values set for a test to ensure proper test operation. The following blocks are involved with the test enable function.

Table XXVIII. Test enable variables.

BPOSGATE

CHKCOLOR

D01-6DEV

DO1-7DEV

DO1DEV

DO2DEV

DO3DEV

DO4DEV

DO5DEV

DO6DEV

DO7DEV

ENCHECK

NORUN

PBCHK1

PBCHKCLR

PBENABLE

PBENAND 
PBENOR

PBENREST

PBENRSRS

PBENTIMO

PBENTON

POSORBUM

RSCHECK

RSCHECKR

STOPTEST

TSTRUNNG

The small logic pulse block <CHKCOLOR> starts the execution of the test enable task. Its output is passed to the small logic and block $\angle \mathrm{PBCHKCLR}>$ which works with $\angle P B E N A N D>$ to require the following input conditions before a test can be enabled by setting <PBENABLE> high.

- $<$ CHKCOLOR.DOUT> which is set high by the operator to enable a test.

- <NORUN.DOUT> is high if both motors are stopped.

- <TSTRUNNG.QNOT> is high if a test is not running.

- $<P B E N A B L E . Q N O T>$ is high if a test is not enabled.

- <POSORBUM.DOUT> is high if the pump is in position or a pump bump is to be executed.

- $\angle D O 1-7 D E V . Q N O T>$ is high when all of the following conditions are not active. $\angle D O 1-6 D E V>$ is also used to compile the conditions.

- $\angle$ PBCHK1.DALM> is high when the PLC test time does not match the desired test time.

- <BPOSGATE.DOUT> is high if the pump is not position, $\angle D O 1 D E V . D A L M>$, and the test is not a pump bump.

- $\angle D O 2 D E V . D A L M>$ is high if the desired pump speed does not match the pump speed in the VFD.

- $\angle D O 3 D E V . D A L M>$ is high if the desired pump acceleration does not match the acceleration set in the VFD.

- $<$ DO4DEV.DALM $>$ is high if the desired pump deceleration does not match the deceleration set in the VFD.

- $<$ DO5DEV.DALM $>$ is high if the desired pump maximum speed does not match the VFD feedback.

- $\angle D O 6 D E V . D A L M>$ is high if the set speed alarm does not match the PLC feedback.

- $\angle D O 7 D E V . D A L M>$ is high if the pump speed abort limit does not match the PLC feedback. 
The test enable bit <PBENABLE> is reset when <PBENOR> has one of the following input conditions are true.

- <STOPTEST.DOUT> goes high when a test is stopped.

- $\angle$ PBENREST.DOUT> is a 4 second time delay of the small logic and block <PBENTIMO>. <PBENTIMO> has the following input conditions.

- <PBENTON.DOUT> will go high if a test is enabled and a test is not started within 60 seconds.

- <TSTRUNNG.QNOT> is high if a test is not running.

$<$ ENCHECK $>$ is a status bit used to enable color control on the test operation displays for critical parameters. This bit comes from the rs flip-flop block $<$ RSCHECK > which is set high by $<P B C H K C L R>$ and reset by $<R S C H E C K R>$ which will go high when any of the following conditions go high.

- <SETVALDN.DOUT> goes high when the test values are set.

- <STOPTEST.DOUT> goes high when a test is stopped.

\subsection{Problem with Test Enable.}

If the test enable function was desired but not successfully completed the following blocks are used to indicate what the problem is.

Table XXIX. Problem with test enable variables.

CHKCLRTN

DISP3

D01-7DEV

NOPENAB

NORUN

PBBUTSTP

PBENABLE

PBENADIS

PBENRSRS

PBPROB

PDISP

PENAB

PENABA

PENABR

POSORBUM 


\section{RPENAB}

\section{TSTRUNNG}

The rs flip-flop block $\angle \mathrm{PENAB}>$ is used to indicate a problem with enabling a test. $\angle P E N A B>$ is set high if the output of $\angle P E N A B A>$ is high and the reset input $\angle P E N A B R>$ is low. $\angle P E N A B A>$ is a small logic and block with the following inputs.

- $\quad$ PBENABLE.QNOT> is high if a test is not enabled.

- <NORUN.DOUT> is high if both motors are stopped.

- <CHKCLRTN.DOUT> will go high 1 second after the operator tries to enable a test.

- <POSORBUM.DOUT> is high if the pump is in position or a pump bump is to be executed.

$<P E N A B R>$ will reset $<P E N A B>$ if any of the following conditions are true.

- <RPENAB.DOUT> which is set high by the operator to reset the problem indication.

- <PBBUTSTP.DOUT> which goes high when the operator manually stops a test.

- $<$ NOPENAB.DOUT> which is a small logic and block with the following input conditions.

- $<$ DO1-7DEV.QNOT> is high if no problem exists with the feedback parameters.

- <NORUN.DOUT> is high if both motors are stopped.

- <TSTRUNNG.QNOT> is high if a test is not running.

- $\quad$ POOSORBUM.DOUT > is high if the pump is at the desired position of a pump bump is to be executed.

- <PBENRSRS.DOUT> is high if the test enable has timed out.

When $\angle P E N A B>$ goes high $\angle P B P R O B>$ is set high which indicates a test operation problem. The small logic and block $\angle P B E N A D I S>$ is used to bring up the problem indication display for enabling a test. When $\angle P E N A B\rangle$ is high and the operator sets $\angle P D I S P>$ high to view the problem the display PBENPROB is brought up via the display block <DISP3>. 


\subsection{Test Start.}

After test parameters are downloaded and a test is enabled the operator can start a test which will operate the pump for a desired period of time. The following blocks are related to the test start task.

Table XXX. Test start variables.

ABORTOR

NORUN

PBENABLE

PBENTON

PBSPLIT

PBSTRAN2

PBSTRAND

PBSTRTDN

PBSTTEST

PLCPBENA

STOPTEST

TSTRUNNG

VALSET

The small logic pulse block <PBSTTEST> starts the execution of the test start task. Its output is passed to the small logic and blocks <PBSTRAND> and $<$ PBSTRAN2> which have the following input conditions to be true before starting a test.

- $\angle$ PLCPBENA.DOUT > which is high if the test enable status bit is high in the PLC.

- <PBSTTEST.DOUT> is set high by the operator to start a test.

- <PBENABLE.DOUT> is high if a test is enabled.

- $<T S T R U N N G . Q N O T>$ is high if a test is not running.

- <VALSET.DOUT> is high if the test values are set.

- <NORUN.DOUT> is high if both motors are stopped.

- $\angle A B O R T O R$.QNOT> is high if no abort condition is active.

- $\angle P B E N T O N . D O 2>$ is high when the test enable has not timed out.

- $\quad$ PBSPLIT.DO3> is high if the elapsed test time is not greater than or equal to the desired time.

The output of <PBSTRAN2> is passed onto <PBSTRTDN> which starts the pump motor and sets the rs fip-flop block <TSTRUNNG> high. <TSTRUNNG> is reset from <STOPTEST $>$ when a test is stopped. 


\subsection{Problem with Starting a Test.}

If the start of a test is not permitted the following blocks ware used to indicate what the problem is.

Table XXXI. Problem with start a test variables.

ABORTOR
DISP3
NOPSPRO2
NOPSPROB
NORUN
PBBUTSTP
PBENABLE
PBENTON
PBPROB
PBSPLIT
PBSTTEST
PLCPBENA
PSDISP
PSPROB
PSPROBA
PSPROBR
RPSPROB
TSTRUNNG
VALSET

The rs flip-flop block $\angle P S P R O B>$ is used to indicate a problem with starting a test. $\angle P S P R O B>$ is set high if the output of $\angle P S P R O B A>$ is high and the reset input $\angle P S P R O B R>$ is low. $\angle P S P R O B A>$ is a small logic and block with the following inputs.

- $\quad \angle P B S T T E S T . D O U T>$ is set high by the operator to start a test.

- <TSTRUNNG.QNOT> is high if a test is not running.

- <PBENABLE.DOUT> is high if a test is enabled.

$\angle P S P R O B R>$ will reset $\angle P S P R O B>$ if any of the following conditions are true.

- $<$ RPSPROB.DOUT> which is set high by the operator to reset the problem indication.

- <PBBUTSTP.DOUT> which goes high when the operator manually stops a test. 
- <NOPRPRO2.DOUT> which is a small logic and block that works with $<N O P S P R O B>$ to compile the following input conditions.

- $\angle$ PBENABLE.DOUT> is high if a test is enabled.

- $<$ PLCPBENA.DOUT> is high if the test enable bit in the PLC is high.

- $\quad \angle A B O R T O R . Q N O T>$ is high if no abort condition is active.

- <VALSET.DOUT> is high if the test values are set.

- <NORUN.DOUT> is high if both motors are stopped.

- $\quad<P B E N T O N . D O 2>$ is high if the test enable did not time out.

- $\quad<$ PBSPLIT.DO3> is high if the elapsed test time is less than the desired time.

When $\angle P S P R O B>$ goes high $\angle P B P R O B>$ is set high which indicates a test operation problem. The small logic and block $\langle P S D I S P\rangle$ is used to bring up the problem indication display for starting a test. When $\angle P S P R O B\rangle$ is high and the operator sets $\angle P D I S P>$ high to view the problem the display PSPROB is brought up via the display block $<$ DISP3 $>$.

\subsubsection{Pump Bump Operation.}

The following sections give the details of the "pump bump" operation, which consists of running the pump for short time periods so as not to allow waste to harden inside the pump or to test operation of the pump.

\subsubsection{Pump Bump Enable.}

The pump operation can be started with operator adjustable speed, maximum speed, acceleration, deceleration, and desired runtime. This is done from the MASFPUMP display and this test operation is considered to be a pump bump. Test operation is handled slightly differently for a pump bump. The position of the pump does not have to be at the desired position for a test to be enabled. Also the test values for critical parameters do not come from predefined tests. The following blocks are used to make the existing test operation work for a pump bump. 
Table XXXII. Pump bump enable variables.

BENAB

BPOSGATE

BUMPENAB

CHKANDPO

CHKCLR1

DISP2

ENABBUMP

ENABDLY

NORUN

PBENABLE

POSORBUM

RESETBEN

SETPROB

The small logic pulse block <ENABBUMP> starts the execution of the pump bump task. Its output sets $\angle B E N A B>$ high if the reset input $\angle R E S E T B E N>$ is low. $<$ RESETBEN $>$ is high when one or more of the following are true.

- $<$ CHKANDPO $>$ is set high when the test enable is requested and the pump is in position or a pump bump is requested.

- <SETPROB.DOUT> goes high when a problem occurs with setting the test values.

- $\angle P B E N A B L E . D O U T>$ goes high when a test is enabled.

- $<$ NORUN.QNOT> is high when a motor is running.

The output of $\angle B E N A B>$ is passed to $<$ POSORBUM $>$ so the pump position is ignored for a pump bump. <BENAB.QNOT> is passed to <BPOSGATE> so the pump position is checked for a test enable if a regular test is used. The output of $\angle B E N A B>$ is passed to <BUMPENAB> which executes the macro SETTES1 to set the test values. If the output of $\angle B U M P E N A B>$ is high and the test values are set the small logic and block $<C H K C L R 1>$ goes high. The output of $\langle C H K C L R 1\rangle$ is delayed by 1 second by $<E N A B D L Y>$ before executing the macro in $<D I S P 2>C H K C L R 1$ to enable a test. 


\subsubsection{PLC Communications.}

The MASFPUMP strategy has communications directly to the PLC for update and control of registers and bits in the PLC. The following table is a list of tags that are used for communications to the PLC.

Table XXXIII. PLC communication variables.

\begin{tabular}{|c|c|c|c|}
\hline $\begin{array}{l}\text { PLCC } \\
\text { REGISTER }\end{array}$ & TAGNAME & DESC & BLOCK_TYPE \\
\hline 242 & ST8WDRES & WATCHDOG BIT & DIGITAL OUTPUT \\
\hline 249 & PBENAB & PHASE B TEST ENABLE TO PLC & DIGITAL OUTPUT \\
\hline 251 & A5ABRT & AF5000 COMM ABORT & DIGITAL OUTPUT \\
\hline 2001-2016 & $\mathrm{J} 2 \mathrm{CO}$ & & PAK DIGITAL INPUT \\
\hline 2015 & ZIMPE144 & CCW POSITION LIMIT & DIGITAL INPUT \\
\hline 2016 & ZIMPE143 & CW POSITION LIMIT & DIGITAL INPUT \\
\hline 2017-2032 & $\mathrm{J} 2 \mathrm{C} 1$ & & PAK DIGITAL INPUT \\
\hline 2017 & MIP00001 & MOISTURE IN PUMP MOTOR OIL & DIGITAL INPUT \\
\hline $2033-2048$ & $\mathrm{~J} 2 \mathrm{C} 2$ & & PAK DIGITAL INPUT \\
\hline 2042 & ABORT & PLC ABORT COIL SET & DIGITAL INPUT \\
\hline 2043 & PLCPBENA & TEST ENABLE FROM PLC & DIGITAL INPUT \\
\hline 2044 & PLCWD & WATCH DOG FROM PLC & NOT \\
\hline 2048 & NODEFAIL & STATION5 COMM FAIL & DIGITAL INPUT \\
\hline $40208-40215$ & $12 \mathrm{C} 1$ & & PAK ANALOG OUTPUT \\
\hline 40208 & SWCABRT & PUMP CURRENT ABORT & SWCH \\
\hline 40209 & DISPRABT & DISCH PRESSURE ABORT & ANALOG INPUT \\
\hline 40210 & PBCALSEC & DESIRED HOURS FROM GENESIS & FX \\
\hline 40211 & SWCALRM & PUMP CURRENT ALARM & SWCH \\
\hline 40212 & PBCALSEC & DESIRED SECONDS FROM GENESIS & FX \\
\hline 40213 & SWCSPDAB & PUMP SPEED ABORT SET & SWCH \\
\hline 40214 & SWCSPDAL & PUMP SPEED ALARM SET & SWCH \\
\hline 40215 & VR232020 & PUMP MOTOR VOLTAGE & ANALOG INPUT \\
\hline $40216-40223$ & $12 \mathrm{C} 2$ & & PAK ANALOG OUTPUT \\
\hline 40216 & VR232080 & ROTATION MOTOR VOLTAGE & ANALOG INPUT \\
\hline 40217 & VR232100 & ROTATION MOTOR CURRENT & ANALOG INPUT \\
\hline 40218 & VR232110 & ROTATION MOTOR SPEED & ANALOG INPUT \\
\hline 40219 & VR232040 & PUMP MOTOR CURRENT & ANALOG INPUT \\
\hline
\end{tabular}




\begin{tabular}{|c|c|c|c|}
\hline 40220 & VR232050 & PUMP MOTOR SPEED & ANALOG INPUT \\
\hline 40223 & DISPRALM & DISCH PRESSURE ALARM & ANALOG INPUT \\
\hline $42001-42008$ & $\mathrm{~J} 1 \mathrm{CO}$ & & PAK ANALOG INPUT \\
\hline 42003 & TIR12A02 & MIX PUMP MOTOR OIL TEMP 2 & ANALOG INPUT \\
\hline 42004 & TIR12A01 & MIX PUMP MOTOR OIL TEMP 1 & ANALOG INPUT \\
\hline 42129-42136 & $11 \mathrm{CO}$ & & PAK ANALOG INPUT \\
\hline 42131 & POSITION & POSITION FROM PLC & ANALOG INPUT \\
\hline 42217-422224 & I1C11 & & PAK ANALOG INPUT \\
\hline 42217 & PLCAMPAL & FROM PLC, AMPS ALARM LIMIT & ANALOG INPUT \\
\hline 42218 & PLCAMPAB & FROM PLC, AMPS ABORT LIMIT & ANALOG INPUT \\
\hline 42219 & PLCDPRAL & FROM PLC, DISCH PRESS ALARM & ANALOG INPUT \\
\hline 42220 & PLCDPRAB & FROM PLC, DISCH PRESS ABORT & ANALOG INPUT \\
\hline 42221 & HPSPDLIM & HIGH SPEED ABORT LIMIT & ANALOG INPUT \\
\hline 42222 & VR05OHAV & HIGH SPEED ALARM LIMIT & ANALOG INPUT \\
\hline 42223 & PLCTIADD & PLC DESIRED HOURS & ANALOG INPUT \\
\hline 42224 & PLCTIADD & PLC DESIRED SECONDS & ANALOG INPUT \\
\hline 42225-42232 & $11 C 12$ & & PAK ANALOG INPUT \\
\hline 42231 & PLCCURAB & FROM PLC, PUMP CURRENT ABORT & ANALOG INPUT \\
\hline 42232 & PLCCURAL & FROM PLC, PUMP CURRENT ALARM & ANALOG INPUT \\
\hline
\end{tabular}

To report a failure in PLC the DIN block <PLCFAlL> will alarm in the MASFPUMP strategy. <PLCFAlL> receives the signal from <PLCFAIL2> which is a small logic or block that has three input conditions.

- $\quad$ PLCWDON.DOUT> goes high if the PLC toggle bit <PLCWD stays high for more than 2 seconds.

- <PLCWDOFF.DOUT> goes high if the PLC toggle bit <PLCWD> stays low for more than 2 seconds.

- <I1CO.FAlL> which will go high if there is a failure in communications in the ModPlus Genesis driver.

\subsubsection{Alarming.}

All algorithm blocks with an alarm priority greater than 0 are enabled as alarming signals. If an alarm level is exceeded the tag and description will show up in the alarm summary to tell the operator which signal is in alarm. 


\subsubsection{System Parameters.}

There are several Report blocks used to execute R\&R code. Following is a list of Report blocks in the strategy with the R\&R code that each block serves. Refer to Appendix $\mathrm{H}$ for a description of each R\&R code.

Table XXXIV. Report blocks with Report and Recipe code allocation.

\begin{tabular}{|l|l|l|l|l|}
\hline \multicolumn{1}{|c|}{ TAG } & SOURCE1 & SOURCE2 & SOURCE3 & SOURCE4 \\
\hline TESTSET2 & ULOAD & NEXT & PREV & ILOAD \\
\hline PBREPORT & PBSETVAL & & & \\
\hline TESTSET & SAVE & DELETE & CLRMESS & \\
\hline
\end{tabular}

The $d$ flip-flop block in the center of the database contains the version of the strategy as its tag name. $\langle\mathrm{V} 3.00\rangle$ would be the tag name for version 3.00 of the strategy. The block <VERSION> contains the version number in the descriptive field.

\subsubsection{Stop Test.}

The stop test task will stop operation of either motor and reset operator status feedback. The following blocks are used in the stop task.

Table XXXV. Stop test variables.

ABORTPUL

DISP4

PBBUTSTP

PBDNTM

STOPTEST

The operator can manually stop a test by setting <PBBUTSTP> high. The output of <PBBUTSTP> is passed to <STOPTEST> which stops the motors and resets the desired pump operation time with the macro RESPTIM in the display block <DISP4>. <STOPTEST> also resets the operator feedback status bits for test operation. <STOPTEST> also is controlled by <ABORTPUL.DOUT> which goes high if an abort condition becomes active. <PBDNTM.DOUT> goes high if the elapsed pump operation time exceeds the desired time and sets $<$ STOPTEST $>$ high. 


\subsection{Modicon PLC Functions}

The Modicon PLC is responsible for inputting data from the field instrumentation, providing an abort signal when the values of critical measurements exceed their abort limits, providing control signals to field instruments, providing timers and enable logic for pump operation, and sending data and status information to Genesis. Details of these functions will be presented in the following sections.

Access to and programming of the PLC is provided by the program Modsoft. Modsoft is run on Station 7 in the Mini-DACS console and communicates with the PLC via a ModBus Plus link.

Using Modsoft, the PLC I/O configuration can be defined, the PLC registers can be allocated and named, and the ladder logic can be produced. All of this can be done off-line and later downloaded to the PLC, or can be done online in the PLC as it operates. The latter is not a wise policy for making permanent changes, but can be useful for debugging ladder logic.

Modsoft allows the ladder logic programmer to impose a structure on the ladder logic for ease of understanding. It allows the programmer to break the ladder logic into modules known as objects and to connect the objects using flow control logic. Each object can contain any number of ladder logic networks. This structure is converted by Modsoft to an equivalent flat non-structured form when the logic is downloaded to the PLC.

Modsoft has a documentation feature which allows information about the PLC configuration and ladder logic to be either saved to a file or printed.

\subsubsection{Data Collection From the Field.}

The PLC is responsible for collecting data from the field instruments. These data enter the PLC through any of a number of Modicon I/O modules. There are several different types of modules which accept different types of input. The modules used in the system and their descriptions are listed below. Both input and output modules are listed in this table. The output modules are used for various control functions discussed in Section 9.3.2. 
Table XXXVI. Modicon $1 / O$ modules.

\begin{tabular}{|c|c|c|}
\hline Module & Description & Signals Accepted \\
\hline B875 & $\begin{array}{l}\text { 8-channel analog } \\
\text { input }\end{array}$ & $\begin{array}{l}\text { Configuratable for various voltage or current input } \\
\text { ranges }\end{array}$ \\
\hline B827 & $\begin{array}{l}\text { 32-channel digital } \\
\text { input }\end{array}$ & 24-V digital input \\
\hline B885 & ASCII/BASIC module & RS-232 serial ASCII data \\
\hline B829 & $\begin{array}{l}\text { 16-channel digital } \\
\text { input }\end{array}$ & 5-V TTL digital input \\
\hline B883 & $\begin{array}{l}\text { Thermocouple } \\
\text { module }\end{array}$ & Thermocouple types B, E, J, K, N, R, S, \& T \\
\hline B865 & TTL Register input & $5-V$ digital output \\
\hline B824 & $\begin{array}{l}\text { 16-chan. digital } \\
\text { output }\end{array}$ & 24-V digital output \\
\hline B828 & $\begin{array}{l}\text { 16-chan. digital } \\
\text { output }\end{array}$ & 5-V TTL digital output \\
\hline
\end{tabular}

Each of these modules has a physical location and a set of registers through which it communicates to the PLC. This location and the exact registers used for communication are specified in the configuration module of the Modsoft program. For all but the B885 ASCII/Basic module and the B883 thermocouple module, this is all that needs to be done in order for the PLC to have access to the data from these modules. Both the ASCII/Basic module and the thermocouple require additional ladder logic to set up and operate the module. The operation of these modules will be discussed in the next two sections.

Most of the measurements from the field enter the system through the B875 analog input module. This module can be set to accept inputs with differing characteristics. Commonly used in this system are 1-5 V, 0-5 V and 4-20 mA signals. 
These inputs are digitized with 12 bits of resolution. This 12-bit value is stored in the lower order 12 bits of the Modicon register corresponding to that channel. The most significant bit of the same register is the out-of-range bit. The B875 module will set this bit if it detects an incoming signal which is out of the range specified when the module is set up. For example, if the module has been set to receive 1 to $5-V$ inputs and then receives an input of $0 \mathrm{Vs}$, it will set the out-of-range bit. This out-of-range bit is used for instrument failure detection, a topic which is discussed in Section 9.3.5.

\subsubsection{Abort Functions.}

One of the primary monitoring functions of the Modicon $984 \mathrm{PLC}$ in the MiniDACS system is to check for over- or under-range conditions on various safety parameters. These parameters are sensed by the 984 series $1 / 0$ at drops. Once received by the PLC, these critical values are stored in $30 \times x x$ registers. These are two-byte registers that function as repositories for incoming analog data. Current values of the important parameters are now loaded in the PLC, and are ready for comparison with limit values. This comparison takes place in the ladder logic in the PLC.

Register $A$ is the current value register. Register $B$ is the $40 x \times x$ register containing the limit to be compared with the current value. Register $C$ is the $40 \times x \times$ register containing the difference between the values in $A$ and $B$. The subtract block actually has three outputs available for user logic. The top output is activated if $A$ is greater than $B$. This is the case in which the limit abort logic is mainly interested. With this line high and the reset contact sense in the non-reset condition, the latched abort contact 202 is closed. When it closes, the contact sense in the bottom leg holds or latches the contact closed. Nothing can interrupt power to contact 202 except if the reset contact should close. The reset contact is a "not" of the true reset contact. This means that if the reset contact is open, the ladder element conducts power (is closed).

Values for the abort and alarm limits stored in the $4 x x x x$ registers are written from the MASFTEST and MASFPUMP strategies.

When any of the latched abort contacts closes, a display for the MASFTEST strategy called PUMPALRM shows the class of the abort along with the alarm limit value, the abort limit value, and a button to another screen with more detail on the abort. 


\subsubsection{I/O Health Status.}

The PLC also provides information to Genesis about the health status of I/O modules in the system. The following four conditions must be met for a module to indicate good health:

- The slot has been configured in the Traffic Cop.

- The slot contains a module with the correct personality.

- Valid communications exist between the module and the $\mathrm{J} 890$.

- Valid communications exist between the J890 and the 984 PLC.

Module health is stored in registers in the Modicon PLC. Different PLC's use different registers. To standardize access to this information, a STAT block is added to the ladder logic. During runtime, the status information is moved to registers defined by the STAT block.

None of the drops are full of modules. Thus, not all of the status registers are of use. A STAT block register contains the $1 / O$ health of one crate (alternately referred to as a rack) of modules on a drop.

Display of the $1 / O$ health is available on the graphic IOSTATUS. Each point in the matrix is tied to the PDIN block bit corresponding to the module's health.

Good health is indicated by a green OK; bad health is indicated by a red $B A D$. On startup of Genesis, the graphic will show all the modules in bad health until one scan of transmit registers has been made. The scan rate of the transmit registers is 6 seconds.

A complete table of these PLC $1 / O$ status registers is given in the "I/O Health Status Implementation Table" in Appendix F.

To minimize the communication load, the status registers that correspond to existing racks are copied into a set of transmit registers. It is the transmit registers that Genesis views.

To streamline communication, the Genesis MASFTEST strategy gathers the transmit registers in as packed data. 


\subsection{Network Layout}

The Gen-Net network is composed of three Gen-Net network stations with ArcNet in a star configuration..

The Genesis system allows peer-to-peer communications between Genesis applications. STATION5 serves data to all other stations on the Gen-Net. STATION7 is linked directly to STATION5 and share the database MASFTEST strategy running on STATION5. This station accomplishes this by running Remote Supervisory Software with the MASFTEST strategy on each station.

STATION5 and STATION8 use Gen-Net software to enable networking to a Runtime master station.

Each station is addressed on the Gen-Net by the network card address on the Arc-Net. A station name is linked to a physical address in the Gen-Net software. Refer to Appendix $L$ for details on the network layout. 


\subsection{REFERENCES}

1. Westinghouse Hanford Company, "101-SY Backup Pump Performance Demonstration Test," 4A-93-00063/W.

2. T.R. Benegas, "Tank 241-101-SY Hydrogen Mitigation Test Functional Design Criteria," Westinghouse Hanford Company report WHC-SD-WM-FDC-022, 1992.

3. "Draft Quality Assurance Project Plan for the Data Acquisition and Control (DACS Project)."

4. "Test Plan for Run-ln Acceptance Testing of 241-SY-101 Mitigation Mixer Pump-2," WHC-SD-WM-TP-220.

5. "Los Alamos National Laboratory (LANL) Letter-of-Instruction for the Mini-DATA Acquisition (DACS) at the Maintenance and Storage Facility (MASF), for the Hydrogen Mitigation Program," MIT94-1889, 9453516, G.F. Vargo.

6. "Software Specification for the Mini-DATA Acquisition (DACS) at the Maintenance and Storage Facility (MASF), WHC-SD-WM-CSRS-022, G.F. Vargo.

7. "Mini-DACS Conceptual Design Description," LANL, L.T. Trujillo, March 1994.

8. "Engineering Task Plan for the Mini-DATA Acquisition (DACS) at the Maintenance and Storage Facility (MASF)," WHC-SD-WM-WP-279. 


\section{Appendix A: HARDWARE VENDOR INFORMATION}

\begin{tabular}{|l|c|}
\hline \multicolumn{2}{|c|}{ List of Materials } \\
\hline \multicolumn{2}{|c|}{ TEXAS MICRO SYSTEMS COMPUTERS--REQUIREMENTS ARE 3 EA. } \\
\hline ITEM DESCRIPTION & NUMBER REQUIRED (EA.) \\
\hline \multicolumn{2}{|c|}{} \\
\hline 4210 System Chassis & 3 \\
\hline D486 DXC/33/W 16 Megs Ram & 3 \\
\hline HD 245-IDE 245 Meg Hard Drive & 3 \\
\hline FDE-1.44 3 1/2" Floppy Drive & 6 \\
\hline SVGA 1 Meg Video Card & 3 \\
\hline KB1A-E 101-Keyboard & 3 \\
\hline 1009R 19" Monitor & 3 \\
\hline SR1 20" Rack Slide & 3 \\
\hline SR4 18-20" Rack Slide & 3 \\
\hline
\end{tabular}

ICONICS INC. - GENESIS CONTROL SOFTWARE

\begin{tabular}{|l|c|}
\hline \multicolumn{2}{|c|}{ ICONICS INC. - GENESIS CONTROL SOFTWARE } \\
\hline \multicolumn{2}{|c|}{} \\
\hline ITEM DESCRIPTION & NUMBER REQUIRED (EA.) \\
\hline & 2 \\
\hline GEN-6-C With MOdBus Plus Device Driver & 2 \\
\hline GEN-NET-ARC & 1 \\
\hline RSS-REMOTE-A & \\
\hline
\end{tabular}

\section{STANDARD MICRO COMPUTERS}




\begin{tabular}{|l|l|}
\hline \multicolumn{2}{|c|}{ MODICON INC. } \\
\hline \multicolumn{2}{|c|}{} \\
\hline ITEM DESCRIPTION & NUMBER REQUIRED (EA.) \\
\hline & 1 \\
\hline PC-E984-785 PLC & 1 \\
\hline AS-S908-110 I/O Processor & 1 \\
\hline AS-E908-016 Executive Cartridge & 1 \\
\hline AS-H19-209 Primary Housing & 10 \\
\hline AS-B875-111 Analog Input Module & 2 \\
\hline AS-B824-016 24VDC Output Module & 2 \\
\hline AS-B825-016 24VDC Input module & 3 \\
\hline AS-8883-200 Thermocouple module & 1 \\
\hline AS-B885-002 ASCII Basic Input Module & 3 \\
\hline AS-P810-000 Power Supply & 2 \\
\hline AS-J890-001 Remote I/O Interface & 2 \\
\hline H827-103 Primary Housing & 1 \\
\hline H827-100 Secondary Housing & 1 \\
\hline AS-W801-002 I/O Signal Cable & 1 \\
\hline AS-W808-002 Pwr Cable W/O P.S. & 1 \\
\hline AS-804-002 Pwr Cable W P. S. & 1 \\
\hline MA-0185-100 & 1 \\
\hline MA-0331-000 Splitter & 1 \\
\hline Modsoft -Single User & 3 \\
\hline AM-SA85-000 Modbus Interface & 1 \\
\hline 97-9841-100 Modbus Plus Cable & 1 \\
\hline MBK-T185 Terminating Connector Kit & 1 \\
\hline MBK-T085 "DAISY" Connectors & 1 \\
\hline AS-MBPL-001 Connector Crimp Tool & 1 \\
\hline AS-8534-000 Low Density Connector & 1 \\
\hline AS-8535-000 Analog Connector & 1 \\
\hline & 1 \\
\hline
\end{tabular}




\begin{tabular}{|l|c|}
\hline \multicolumn{2}{|c|}{ ELECTRICON RESOURCES INC. } \\
\hline \multicolumn{2}{|c|}{} \\
\hline ITEM DESCRIPTION & NUMBER REQUIRED (EA.) \\
\hline NEMA Enclosure for I/O & 1 \\
\hline Enclosure Backplate-Phenolic & 1 \\
\hline Cooling Fan Kit & 1 \\
\hline Model A-PA10AXFN-10" Fan & \\
\hline Exaust Kit for 10" Fan & 1 \\
\hline Model A-EXGR4 & \\
\hline
\end{tabular}

\begin{tabular}{|l|c|}
\hline \multicolumn{2}{|c|}{ ARROW ELECTRONICS } \\
\hline \multicolumn{2}{|c|}{} \\
\hline ITEM DESCRIPTION & NUMBER REQUIRED (EA.) \\
\hline & 125 \\
\hline Terminal Block-2 Through Connects & 30 \\
\hline Model 280-524 & 10 \\
\hline End Stops/Seperators 280-343 & 4 \\
\hline End Stops 209-101 & 2 \\
\hline Carrier Rail 210-162 & 1 \\
\hline Operating Tool & 1 \\
\hline Number Labels 1-50, 209-566 & 1 \\
\hline Number Labels 51-100, 209 -507 & \\
\hline Number Labels 100-150, 209-508 & \\
\hline & \\
\hline & \\
\hline & \\
\hline & \\
\hline & \\
\hline
\end{tabular}




\begin{tabular}{|l|c|}
\hline \multicolumn{2}{|c|}{ OPERATOR WORKSTATION - SCRENLO, INC } \\
\hline ITEM DESCRIPTION & NUMBER REQUIRED (EA). \\
\hline Slope Frame W/Writing Top & \\
\hline Model XFRS-312119-WT-EN3BE & 4 \\
\hline 30 Deg Wedge Unit Slope Frame & \\
\hline Model XWFR-312130-A-ENBE & 2 \\
\hline Left Hand Plain Inside Removable Panel & \\
\hline Model XSPI-3121A-LH-EN-3BE & 1 \\
\hline Right Hand Plain Inside Removable Panel & \\
\hline Model XSPI-3121A-RH-EN-3BE & 1 \\
\hline Left Hand Louvered Rear Doors & \\
\hline Model XDS-4919-LV-LH-EN-3BE & \\
\hline CFM Fan Assembly & \\
\hline Model FT-291-3 291 & \\
\hline Casters 3" Above Slope Frames & \\
\hline Model HW-450-LK & \\
\hline Perforated Top Panels & \\
\hline XPN-1919-PA-EN-3BE & \\
\hline Split Writing Top Vintage Oak & \\
\hline XOPT-945219-00-258 & \\
\hline
\end{tabular}

\begin{tabular}{|l|c|}
\hline \multicolumn{2}{|c|}{ IMAGE COPIER - GENEVAL CORP. } \\
\hline \multicolumn{2}{|c|}{} \\
\hline ITEM DESCRIPTION & NUMBER REQUIRED (EA). \\
\hline Shinko CHC-443MV Video Printer & 1 \\
\hline Model 260-443MV & \\
\hline One Channel Multiplexer--Mitsubishi Int'l-SPA-9-4 & 3 \\
\hline
\end{tabular}




\begin{tabular}{|l|c|}
\hline Model 260-650 & 3 \\
\hline Remote Switch-Mitsubishi Int'I-SP1-10-1 & \\
\hline Model 206-655 & 12 \\
\hline 3 Color Ribbon-Mitsubishi Int'I-060-97-0149 & \\
\hline Model 260-400 & 12 \\
\hline 3 Color Paper-Mitsubishi Int'I-060-97-0095-069 & \\
\hline Model 260-410 & \\
\hline
\end{tabular}

\begin{tabular}{|l|c|}
\hline \multicolumn{2}{|c|}{ DOT MATRIX PRINTER - MC BRIDE \& ASSOCIATES } \\
\hline ITEM DESCRIPTION & NUMBER REQUIRED (EA). \\
\hline & 1 \\
\hline IBM Printer Model 2390 Plus & 1 \\
\hline
\end{tabular}

\begin{tabular}{|c|c|}
\hline \multicolumn{2}{|c|}{ PRINTER MULTIPLEXER - BLACK BOX INC. } \\
\hline ITEM DESCRIPTION & NUMBER REQUIRED (EA). \\
\hline Printer Multiplexer--8 Channel SW-809 & 1 \\
\hline
\end{tabular}




\section{Appendix B: Manufacturer's Manuals and Other Documentation}

\begin{tabular}{|c|c|}
\hline MANUAL DESCRIPTION & QUANTITY PROVIDED \\
\hline Advanced Diagnostics Certification-TM Computers & 3 \\
\hline Black Box Multiplexer Print--From Each Station & 1 \\
\hline Texas Micro-User's Manual-CPU Model D486 & 3 \\
\hline Texas Micro-Operator's Manual-4210 Mainframe & 3 \\
\hline Texas Micro-Maintenance Manual-4210 Mainframe & 3 \\
\hline Texas Micro-VGA16 Adapter--User's Manual/Util Software & 3 \\
\hline Intecolor-Operator's Manual--Model 998000-020 & 3 \\
\hline Shinko Electric-User's Guide--Model SPA-9-1, Multiplexer & 3 \\
\hline Shinko Electric-User's Guide-Model SPA-10-1, Copy Switch & 3 \\
\hline Shinko Electric-User's Guide-Model CHC-443MV- Copier & 1 \\
\hline Kensington-User Manual-Expert Mouse & 3 \\
\hline Black Box Corp--User Manual-SW809, Auto Switch & 1 \\
\hline SMC-Configuration Guide-SM-130E, ArcNet Interface & 3 \\
\hline Diagsoft-Diagnostics Software-QA Plus & 3 \\
\hline Modicon-System Planning Guide-PC-E984 & 3 \\
\hline Modicon-Function Control Function Library-Users Guide & 3 \\
\hline
\end{tabular}




\begin{tabular}{|l|c|}
\hline MANUAL DESCRIPTION & QUANTITY PROVIDED \\
\hline Modicon-High/Low Density Installation Instructions & 3 \\
\hline Modicon-Analog Input Installation Instructions-B875-111 & 10 \\
\hline Modicon-User's Guide-IBM Host Based Devices-SA-85 & 3 \\
\hline Modicon-Installation Guide-ModBus Plus Network & 3 \\
\hline Modicon-ASCII BASIC Installation Instructions-B885-002 & 1 \\
\hline Modicon-Thermocouple Module Installation Inst.-B883-200 & 3 \\
\hline Modicon-Remote I/O Interface Installation Inst.-J-890/101 & 2 \\
\hline Modicon-Module Housing Installation Inst.-H819/H827 & 3 \\
\hline Modicon-Remote I/O power Supplies Installation-P810-001 & 3 \\
\hline Modicon-ModSoft Programmable Controller System Manual & 1 \\
\hline Modicon-ModSoft Programmer User Manual & 1 \\
\hline & 2 \\
\hline Iconics-Genesis Users Guide-GEN-NET & 2 \\
\hline Iconics-Genesis Users Guide-ModBus Plus & 1 \\
\hline Iconics-Genesis Users Guide-Remote Supervisory Station & 2 \\
\hline Iconics-Genesis Users Guide-Tutorial & 2 \\
\hline Iconics-Genesis Users Guide Vol. I\&II-Configurator & 3 \\
\hline
\end{tabular}




\section{Appendix C: Genesis Software License}

Genesis software is controlled via a hardware key attached to the parallel port of the Mini-DACS computers. The following list represents the software, as delivered, and control key serial numbers.

- GEN-6-C, full system software. Key serial number-SN1940, Lot 934L52125.

- GEN-6-C, full system software. Key serial number-SN1941, Lot 933152125

- GEN-NET/A, ArcNet software. Serial number-GN-3429.

- GEN-NET/A, ArcNet software. Serial number--GN-3430.

- RSS/A, Remote Supervisory software. Key serial number--RSS-SN877, Lot 9339L52132. Network serial number-GN-3431.

- DD-ModPlus Driver-SN-303.

- Tutorial Software, 2 ea. 
HNF-SD-WM-SDD-049

Rev. 1

Page 108

Appendix D: Drawing List

\begin{tabular}{||l|l|c|c||}
\hline \multicolumn{1}{|c|}{ DRAWING TITLE } & \multicolumn{1}{|c|}{ DESCRIPTION } & $\begin{array}{c}\text { DRAWING } \\
\text { NUMBER }\end{array}$ & $\begin{array}{c}\text { SHEET } \\
\text { No. }\end{array}$ \\
\hline \hline MINI-DACS & SYSTEMS CONFIGURATION & $68 Y-155870$ & 1 \\
\hline $\begin{array}{l}\text { MINI-DACS (CONSOLE } \\
\text { MECHANICAL) }\end{array}$ & ASSEMBLY 100 & $68 Y-155870$ & 2 \\
\hline MINI-DACS & DETAIL 101 & $68 Y-155870$ & 3 \\
\hline $\begin{array}{l}\text { MINI-DACS (NEMA } \\
\text { CABINET) }\end{array}$ & ASSEMBLY 200 & $68 Y-155870$ & 4 \\
\hline MINI-DACS & DETAILS 201 \& 202 & $68 Y-155870$ & 5 \\
\hline MINI-DACS [ConsI_bIKDIA] & $\begin{array}{l}\text { CONSOLE REAR VIEW BLOCK } \\
\text { DIAGRAM }\end{array}$ & $68 Y-155870$ & 201 \\
\hline MINI-DACS [Phen_brdDIA] & $\begin{array}{l}\text { NEMA I/O PANEL BLOCK } \\
\text { DIAGRAM }\end{array}$ & $68 Y-155870$ & 202 \\
\hline MINI-DACS [CPU_C_SLOTS] & $\begin{array}{l}\text { CPU CARD SLOTS BLOCK } \\
\text { DIAGRAM }\end{array}$ & $68 Y-155870$ & 203 \\
\hline MINI-DACS [Wire1_DIA] & $\begin{array}{l}\text { WIRING DIAGRAM FOR DROP 1, } \\
\text { RACKS 182 }\end{array}$ & $68 Y-155870$ & 240 \\
\hline MINI-DACS [Wire2_DIA] & $\begin{array}{l}\text { WIRING DIAGRAM FOR DROP 2 } \\
\text { RACK 1 }\end{array}$ & $68 Y-155870$ & 241 \\
\hline MINI-DACS [Print_DIA] & $\begin{array}{l}\text { PRINTER \& PHONE ONE LINES } \\
\text { WIRING DIAGRAM }\end{array}$ & $68 Y-155870$ & 242 \\
\hline MINI-DACS [ULTIPX_line] & $\begin{array}{l}\text { MULTIPLEXER ONE LINE } \\
\text { WIRING DIAGRAM }\end{array}$ & $68 Y-155870$ & 243 \\
\hline MINI-DACS [driveCBL_DIA] & $\begin{array}{l}\text { DRIVE CABLE ASSEMBLY } \\
\text { WIRING DIAGRAM }\end{array}$ & $68 Y-155870$ & 244 \\
\hline MINI-DACS [Mbus_cbI_ASY] & MODBUS CABLE ASSEMBLY & $68 Y-155870$ & 245 \\
\hline MINI-DACS [PWIF_cbl_dWg] & POWER FEED CABLE DRAWING & $68 Y-155870$ & 246 \\
\hline
\end{tabular}


Appendix-D (cont.) - LANL Drawings Listed With Hanford H-9-XXXXX Numbers.

H-9-5015 SH 1 MINI-DACS ASSEMBLY SYSTEMS CONFIGURATION

H-9-5015 SH 2 MINI-DACS ASSEMBLY ASSEMBLY 100

H-9-5015 SH 3 MINI-DACS ASSEMBLY DETAIL 101

H-9-5015 SH 4 MINI-DACS ASSEMBLY ASSEMBLY 200

H-9-5015 SH 5 MINI-DACS ASSEMBLY DETAILS 201 \& 202

H-9-5016 SH 1 MINI-DACS CONNECTION DIAGRAM FOR DROP 1, RACKS 1 \& 2 H-9-5016 SH 2 MINI-DACS CONNECTION DIAGRAM FOR DROP 2, RACK 1

H-9-5016 SH 3 MINI-DACS CONNECTION DIAGRAM PRINTER \& PHONE 1-LINES

H-9-5016 SH 4 MINI-DACS CONNECTION DIAGRAM MULTIPLEXER ONE LINE

H-9-5017 SH 1 MINI-DACS BLOCK DIAGRAM CONSOLE REAR VIEW

H-9-5017 SH 2 MINI-DACS BLOCK DIAGRAM NEMA I/O PANEL

H-9-5017 SH 3 MINI-DACS BLOCK DIAGRAM CPU CARD SLOTS

H-9-5018 SH 1 MINI-DACS CABLE ASSEMBLY DRIVE CABLE

H-9-5018 SH 2 MINI-DACS CABLE ASSEMBLY MODBUS

H-9-5018 SH 3 MINI-DACS CABLE ASSEMBLY POWER FEED 


\section{Appendix E: Mini-DACS User Guide}

\subsection{LOGON}

A Station 5 (Master Station)

1) Change directory by typing; CD MASFTEST

2) Type; RUNTIME MASFTEST (This will startup station 5 as the Master station.)

3) Pull up the Password - Security menu by entering; ALT-P

4) Type in appropriate password to get to security level 3.

B Station 8 (Pump control Station)

1) Change directory by typing; CD MASFPUMP

2) Type; RUNTIME MASFPUMP (This will startup station 8 as the pump control station.)

3) Pull up the Password - Security Menu by entering; ALT-P

4) Type in appropriate password to get to security level 3.

C Station 7 (RSS Station)

1) Choose option 1> GENESIS (if at C prompt push CTRL-ALT-DEL to reboot the computer and bring up the option of $1>$ GENESIS or 2> MODSOFT)

2) Change directory by typing; CD MASFTEST

3) Type; RSS MASFTEST (This will startup station 7 as the Remote Sensory Station (RSS))

4) Pull up the Password - Security Menu by entering; ALT-P

5) Type in appropriate password to get to security level 3.

\subsection{ALARM RESPONSE}

Respond to every alarm

1) F4 - accesses the Alarm/Event Summary screen

a) alarms received on Master station (5) should be responded to on the Master station.

b) alarms received on Pump Control station (8) should be responded to on the Pump Control station. 
2) with mouse highlight alarm (colored red, green if alarm condition has cleared) then push F4 to acknowledge alarm.

a) Alarm that has not been acknowledged, and has not cleared will be colored red on the Alarm/Event Summary screen.

b) Alarm that has been acknowledged, but has not cleared will be colored yellow.

c) Alarm that has not been acknowledged, but has cleared will be colored green.

d) Alarm that has been acknowledged, and has cleared will clear off the Alarm/Event Summary screen.

e) The most recent alarm will also appear in the bottom right hand corner of the screen.

3) ALT-G - will acknowledge all alarms.

4) can "silence" alarm with any keystroke. (This is not recommended per Conduct Of Operations)

5) remember to log all alarms (don't clear alarms off screen before logging them).

6) Spurious alarms can be silenced by calling up the desired tag name (by entering $\mathbf{F} 2$ and typing the tag name into the tag box on the subscreen, or highlighting the desired tag with the mouse and pressing ENTER) and then highlighting the Priority box in the Tag Details subscreen and entering a 0 and pressing ENTER. (This is not recommended per Conduct of Operations unless proper approval is given)

All alarm priorities are set to default value of 1 which will annunciate alarm and print out alarm on the Alarm/Event Summary screen. When an alarm priority is set to 0 it will no longer annunciate or printout to the Alarm/Event Summary screen.

\subsection{SCREEN MOBILITY}
A Return to previous screen by entering $\mathbf{F} \mathbf{6}$
B Select any screen display by entering F1 and then typing the name of the desired screen.
C Call up Alarm/Event Summary screen by entering F4 


\subsection{HISTORY FILES AND TRENDING}

A History files on the Master station (5) can be called up and graphically displayed and manipulated by;

1) enter ALT-H to pull up History file menu

2) Ensure that the "GRAPHIC" selection has a $Y$ for yes.

3) Pick file to be displayed by highlighting desired file name with mouse and entering $8-F 6$

4) Choose to replay file by entering S-F5

5) Choose to display plot by entering S-F5

6) The tags in the selected file to be displayed can be chosen by using the PAGE DOWN and PAGE UP keys.

7) The blue time line on the plots can be moved through the times on the history file by using the arrow keys.

8) The $y$-axis ranges can be changed for each tag by highlighting the desired range value box (same color as the tag name) with the mouse and typing in the new desired value and pressing ENTER.

B Current values can be plotted on Trend screens, by bringing up the Trend Menu using F7 then choosing the desired tag names to be plotted.

\subsection{LOGOFF}

All Stations

1) Must be logged on at security level 3.

2) enter ALT-E

3) answer $Y$ and press ENTER

\subsection{KEY COMMANDS}

SHIFT-? Heip System

F1 Display Directory (for choosing screens)

F2 Tag Details (for calling up desired tags)

F4 Alarm/Event Summary screen and acknowledge individual alarms

F6 Return to previous screen

F7 Trend Menu

ALT-E Exit Genesis

ALT-G Acknowledge all alarms

ALT-H History Replay

ALT-P Password-Security Menu 


\section{Appendix F: PLC I/O Status Registers}

The Modicon V/O health status alarms Genesis when a module is no longer in good health. The following is a complete list of the PLC registers and their corresponding Genesis strategy variable names.

\begin{tabular}{|c|c|c|c|c|c|c|}
\hline Drop & Rack & Slot & $\begin{array}{l}\text { STAT block } \\
\text { Register }\end{array}$ & $\begin{array}{l}\text { Transmit } \\
\text { Register }\end{array}$ & $\begin{array}{l}\text { DEV 4, GC11 } \\
\text { PDIN }\end{array}$ & Output \\
\hline \multirow[t]{4}{*}{2} & 1 & & 40317 & 40108 & $\mathrm{D} 2 \mathrm{R} 1$ & \\
\hline & & 4 & & & & D013 \\
\hline & & 5 & & & & D012 \\
\hline & & 6 & & & & D011 \\
\hline \multirow[t]{3}{*}{2} & 2 & & 40318 & 40109 & D2R2 & \\
\hline & & 3 & & & & DO14 \\
\hline & & 4 & & & & D013 \\
\hline
\end{tabular}




\section{Appendix G: PLC Register List}

The Modsoft program allows a symbol table to be created. This symbol table allows the programmer to assign symbolic names and comments to the registers used by the PLC. The symbol table is accessed under the Utility Menu of Modsoft. A hard copy print-out can be obtained by using the File $1 / O$ and Export menu choices once the symbol table has been called up.

The symbol table is essential for the ladder logic programmer. It is the definitive record of which PLC registers have been used and which are available for use. Any entry in the symbol table which has a symbolic name has been used by the PLC. If there is no entry in the symbol table for a register, or if there is a register entry without a symbolic name, that register is available for use.

It is essential that the symbol table be kept up to date. Any change which adds or deletes PLC registers (including adding $1 / 0$ modules) must be reflected in the symbol table also.

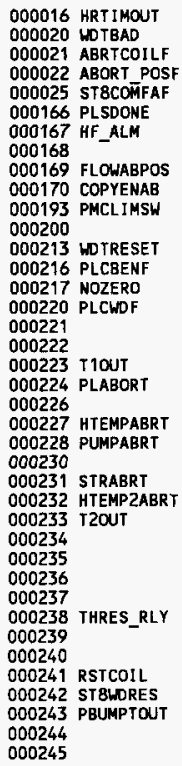

\begin{tabular}{|c|c|c|}
\hline $\begin{array}{l}\text { HOUR TIMEOUT } \\
14.2 .4 .4^{\circ} \text { GENESIS-PLC COMMUNICATI } \\
14.2 .4 .5 \text { COIL FOR ABORT - NEGATI } \\
14.2 .4 .6 \text { ABORT COIL - POSITIVE L } \\
14.2 .4 .9 \text { ST8-PLC COMMUNICATION }\end{array}$ & $\begin{array}{l}\text { ON FAIL } \\
\text { VE LOGIC } \\
\text { OGIC } \\
\text { AIL }\end{array}$ & \\
\hline $\begin{array}{l}\text { HI STRAIN FLOW METER CUT-OFF POS } \\
\text { ENABLE COPY OF CHS TO GENESIS I/ }\end{array}$ & $\begin{array}{l}\text { LOGIC } \\
\text { O REGICN }\end{array}$ & \\
\hline $\begin{array}{l}\text { WATCH DOG TIMER FROM GENESIS } \\
\text { LATCHED BUMP ENABLE } \\
\text { Disal lows test timout when time } \\
\text { PLC } 1 \text { SEC WATCHDOG TIMER RESET }\end{array}$ & cleared & $\begin{array}{l}\text { H1CO } \\
\text { H1C3 } \\
\text { H1C4 } \\
\text { G7C0.1 } \\
\text { G7C0.2 } \\
\text { G7C0.3 }\end{array}$ \\
\hline $\begin{array}{l}\text { PLC WD TIMER } 1 \text { OUTPUT } \\
\text { ABORT POSITIVE LOGIC }\end{array}$ & & $\begin{array}{l}\text { G7C0.4 } \\
\text { G7C0.5 } \\
\text { G7C0.7 }\end{array}$ \\
\hline $\begin{array}{l}\text { HIGH TEMPERATURE ABORT } \\
\text { PUIMP PROBLEM ABORT }\end{array}$ & & $\begin{array}{l}\text { G7C0.8 } \\
\text { G7C0.9 } \\
\text { G7C0.11 }\end{array}$ \\
\hline $\begin{array}{l}\text { SIRAIN ABORT } \\
\text { HIGH TEMP ABORT } 2 \\
\text { PLC WD TIMER } 2 \text { OUTPUT }\end{array}$ & & $\begin{array}{l}\text { G7C0.12 } \\
\text { G7C0.13 } \\
\text { G7C0.14 } \\
\text { G7C0.15 } \\
\text { G7C0.16 } \\
\text { G7C1.1 } \\
\text { G7C1.2 }\end{array}$ \\
\hline COIL FOR THRESHOLO & & $\begin{array}{l}\mathrm{G} 7 \mathrm{C} 1.3 \\
\mathrm{G} 7 \mathrm{C} 1.4 \\
\mathrm{G} 7 \mathrm{C} 1.5\end{array}$ \\
\hline $\begin{array}{l}\text { ST } 8 \text { HATCHDOG TIMER RESET } \\
\text { PUMP BUMP TIMEOUT ABORT }\end{array}$ & $\begin{array}{l}\mathrm{G} 3 \mathrm{CO} \\
\mathrm{G3C1} \\
\mathrm{G} 3 \mathrm{C2} \\
\mathrm{G} 3 \mathrm{C3} \\
\mathrm{G} 3 \mathrm{C} 4\end{array}$ & $\begin{array}{l}\text { G7C1.6 } \\
\text { G7C1.7 } \\
\text { G7C1.8 } \\
\text { GCC1.9 } \\
\text { G7C1.10 }\end{array}$ \\
\hline
\end{tabular}




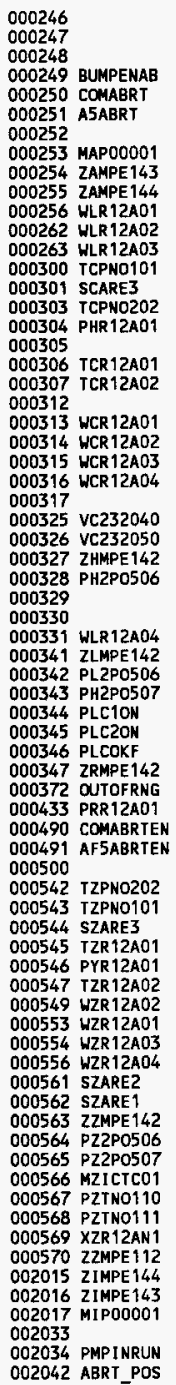

BUMP ENABLE

PLC COMM FAILURE

AF5000 ABORT

MOISTURE IN PUMP ABORT

CW LIMIT SWITCH ABORT

CCW LIMIT SHITCH ABORT

LOW 12A- 1 STRAIN ABORT

LOW 12A-2 STRAIN ABORT

LOW 12A-3 STRAIN ABORT

HIGH TEMP ABORT PUMP 101

HIGH TEMP ABORT PUMP SPARE3

HIGH TEMP ABORT PUMP 202

HIGH PUMP DISCHARGE PRESSURE ABORT

HIGH PUMP MOTOR OIL TEMP ABORT 1

HIGH PUMP MOTOR OIL TEMP ABORT 2

HIGH PUMP COLUMN STRAIN ABORT 1

HIGH PUMP COLUMN STRAIN ABORT 2

HIGH PUMP COLUMN STRAIM ABORT 3

HIGH PUMP COLUMN SIRAIN ABORT 4

HIGH PUMP MOTOR CURRENT ABORT

HIGH PUMP MOTOR SPEED ABORT

HIGH PUMP COLUMH GAS PRESSURE ABORT

HIGH PUMP SHROUD GAS PRESSURE ABORT

LOW 12A-4 STRAIN ABORT

LOW PUMP COLUMN GAS PRESSURE ABORT

LOW PUMP SHROUD GAS PRESSURE ABORT

HIGH PUMP MOTOR OIL PRESSURE ABORT

1-PLC OK; 0-PLC PROBLEM

INSTRUMENT PROBLEM - ZIMPE142

OUT OF RANGE FOR 0-5V CHANNELS

INSTRUMENT PROBLEM PIR12A01

COM ABORT AMDED WITH TEST ENABLES

G3C5 G7C1.11

G3C6 G7C1.12

G3C7 G7C1.13

G3C8 G7C1.14

G3C9 G7C1.15

G3C10 G7C1.16

G3C11 G7C2.1

G3C12 G7C2.2

G3C13 G7C2.3

G3C14 G7C2.4

G3C15 G7C2.5

G7C2.11

G7C2.12

G7C5.1

G7C5.4

G7C5.5

G7C5. 6

G7C5.7

G7C5. 8

G7C5.13

G7C5.14

G7C5.15

G7C5.16

G7C6. 1

G7C6. 2

G7C6. 10

G7C6.11

G7C6. 12

G7C6. 13

G7C6.14

G7C6.15

G7C6.16

G7C7.10

G7C7.11

G7C7.12

G7C7. 13

G7C7.14

G7C7.15

G7C7.16

OUT OF RANGE BIT

G6C0.16

OUT OF RANGE BIT

OUT OF RANGE BIT

OUT OF RANGE BIT

OUT OF RANGE BIT

OUT OF RANGE BIT

OUT OF RANGE BIT

OUI OF RANGE BIT

OUI OF RANGE BIT

OUT OF RANGE BIT

OUT OF RANGE BIT

OUT OF RANGE BIT

OUT OF RANGE BIT

OUT OF RANGE BIT

OUT OF RANGE BIT

OUT OF RANGE BIT

OUT OF RANGE BIT

OUT OF RANGE BIT

OUT OF RANGE BIT

OUT OF RANGE BIT

PUMP OSCIL MOTOR LIMIT SWITCH CCH

PUMP OSCIL MOTOR LIMIT SWITCH CW

MOISTURE IN PUMP MOTOR OIL 1

PUMP MOTOR RUNNING INDICATOR

COIL FOR ABORT - POSITIVE LOGIC
$66 \mathrm{C4} 4.3$

$\mathrm{G6C4} .4$

$\mathrm{G} 6 \mathrm{C} 4.5$

$\mathrm{G} 6 \mathrm{C} 4.6$

G6C4.7

G6C4.8

G6C4. 10

G6C4. 14

G6C4. 15

G6C5.1

G6C5.6

G6C5.7

G6C5.8

G6C5.9

G6C5.10

G6C5.11

G6C5.12

G6C5. 13

G6C5. 14

G2C0.15

G2C0.16

G2C1.1

G2C2. 2

G2C2.10 
LATCHED BUMP ENABLE

PLC 1 sec watchdog reset

STATION 8 COMHUNICATION FAI LURE

1-PLC OK; O-PLC PROBLEM

AF5000 PŔOBLEM

STATION 5 COMMUNICATION FAILURE

PUMP MOTOR CURRENT ALARM

PUMP DISCHARGE PRESSURE ALARM

PUMP SPEED ALARM

G2C2.11

$\mathrm{G} 2 \mathrm{C} 2.12$

G2C2.13

$\mathrm{G} 2 \mathrm{C} 2.14$

G2C2.15

G2C2.16

G2C3.1

G2C3.2

G2C3. 3

$62 \mathrm{C3} .4$

2.2.1.1'MOISTURE IN PUMP MOTOR OIL 1

2.2 .1 .2 PUMP OSCIL MOTOR LIMIT SWITCH CH

2.2.1.3-PUMP OSCIL MOTOR LIMIT SHITCH CCW 2.2.1.4

2.2.3.5

2.2.3.6

2.2.3. $7^{\text {- }}$

2.2.3.8

2.2.3.9

2.2.3.10

2.2.3.11

2.2.3.12

2.2.3.13

2.2.3.14"

2.2.3.15

2.2.3.16

2.2.3.17

2.2.3.18 EMERGENCY STOP MONITOR

2.2.3.19

2.2.3.20

2.2.3.21

2.2.3.22

2.2.3.23-

2.2.3.24

2.2.3.25

2.2.3. $26^{\circ}$

2.2.3.27

2.2.3.28

2.2.3.29

2.2.3.30

2.2.3.31

2.2.3.32

1.2.10.1

1.2.10.2

1.2.10.3

$1.2 .10 .4^{\circ}$

1.2 .10 .5

1.2 .10 .6

1.2.10.7

1.2 .10 .8

1.2.10.9

1.2.10.10

1.2.11.11

1.2.10.12

1.2 .10 .13

1.2.10.14

1.2.10.15

1.2.10.16 PUMP MOTOR RUNNING INDICATOR

2.1.4.1'INSTRUMENT CABINET TEMPERATURE

2.1.4.2'MOTOR STATOR TEMPERATURE

2.1.4.3*MOTOR STATOR TEMPERATURE

2.1.4.4\%OTOR STATOR TEMPERATURE

$2.1 .4 .5^{\circ}$

$2 \cdot 1 \cdot 4.6^{-1}$

2.1 .4 .7

2.1.4.8 PUMP PRESSURE

2.1.6.2 PUMP MOTOR OIL TEMPERATURE B

$2.1 .6 .4^{\circ}$

2.1.6.1 PUMP MOTOR OIL TEMPERATURE A

2.1.6.3. 
300013

300014

300015 PIPNO202F

300016 TIPNO201F

300017

300018

300019

300020 FIPNO202F

300021

300022 PITNO110F

300023 PITNO111F

300024 SPARE1F

300025 SPARE2F

300026 XIR12AN1F

300027 ZIMPE 142F

300028 PN2P0506F

300029 PN2P0507F

300030

300031

300032 HIR12A01F

300033 WIR12A02F

300034 HIR12A03F

300035 HIR12A04F

300040 MOPSTABF

300281 Z1MPE 112F

300295 XIR12AN2F

400001 unused

400075 TIMER5

400076 TIMERG

400077 TIMER7

400078 MULTREG

400079 PMCALMHI

400100 TIMER

400101 TIMER?

400102 IIMER3

400103 TIMER4

400104 HOURCNT

400108 D2R1STAT

400109 D2R2STAT

400110 DIR1STAT

400203 HTEMPL IM

400204 HTDPLIM

400205 HILIM

400206 HPMOTLIM

400207 LVFLLIM

400208 HPMCL IMF

400209 HPDPL IM

400210 BUMPTL IMH

400211 CURALRM

400212 BUMPIL IMF

400213 HPSPDL IM

400214 HPSPDALM

400215 VR232020F

400216 VR232080F

400217 VR232100F

400218 VR232110F

400219 VR232040F

400220 VR232050F

400221

400222

400223 HPDPALM

400224 HPCSLIM

400225 SCRATCH

400232 LPGPL IM

400233 HPMOPL IM

400234 HTMPLIM3

400235 HPGPLIM

400236 HMOTCLIM

400238 LPCSLIM

400253 HVFLLIM1

400254 HVFLLIM2
2.1.5.5

2.1.5.6

2.15.7 PUMP DISCHARGE NOZZLE \#1 PRESSURE-2

2.1.5.8 PUAM DISCHARGE NOZZLE \#1 IEMPERATURE-2

2.1.6.1

2.1.6.2

2.1.6.3

2.1.6.4 PUMP DISCHARGE NOZZLE \#1 FLOW-1

2.2.3.1 PUMP 30 DEG. DISCHARGE NOZZLE PRESSURE

2.2.3.2 PUMP DISCHARGE NOZZLE \#1 PRESSURE

2.2.3.3'SPARE PITNO110F

2.2.3.4. SPARE PITNO111F

2.2.3.5 PLAP CASING VIBRATION

$2.2 .3 .6^{\circ}$ LOW PUMP COLUMN GAS PRESSURE

2.2.3.7 PUAAP SHROUD GAS PRESSURE GAUGE

2.2.3.8 PUMP MOTOR OIL PRESSURE GAUGE

1.1.6.1 PUMP SUPPORT COLUMN STRAIN \#1

1.1.6.2'PUMP SUPPORT COLUMN STRAIN \#2

1.1.6.3 PUMP SUPPORT COLUMN STRAIN \#3

1.1.6.4 PUMP SUPPORT COLUMN STRAIN \#4

1.1.7.1'MOTOR OIL PRESSURE STATOR BOTIOM

MIXER PUMP OSCILLATOR POSITION (B865)

14.2.5.7^PUMP SUPPORT COLUMN VIBRATION

ST8 WATCHDOG TIMER REGISTER 1

ST8 WATCHDOG TIMER REGISTER 2

PUMP MOTOR CURR ALARM LIM $(230 / 238 * 65535)$

TIMER COUNT

IIMER COUNT

TIMER COUNT

TIMER COUNT

HOUR COUNT OF THE TEST

DROP 2 RACK 1 STATUS

DROP 2 RACK 2 STATUS

DROP 1 RACK 1 STATUS

HIGH TEMPERATURE LIMIT

$\mathrm{H} 3 \mathrm{CO}$

H3C

H3C2

SET TO 4095

HIGH PUMP MOTOR OIL TEMP LIMIT

LOW VENTILATION FLOW LIMIT

HIGH PUMP MOTOR CURRENT LIMIT

HIGH PUMP DISCHARGE PRESS LIMIT

PUMP BUMP IIME LIMIT (HOURS)

PUMP MOTOR CURRENT ALARM LIMIT

PUMP BUMP TIME LIMIT (SECS)

HIGH PUMP SPEED LIMIT

HIGH PUMP SPEED ALARM LIMIT

MIXER PUMP MOTOR VOLTAGE

ROTATIONAL MOTOR VOLTAGE

ROIATIONAL MOTOR CURRENT

ROTATIONAL MOTOR SPEED

MIXER PUMP MOTOR CURRENT

MIXER PUMP SPEED (RPM)

G4C0.5

G4C0.7

G4C0.8

G4C1.1

G4C1.2

G4C1.3

G4C1.4

G4C1.5

G4C1.6

G4C1.7

G4C1.8

G4C2.1

G4C2.2

G4C2.3

$\mathrm{G} 4 \mathrm{C2} .4$

G4C2.5

G4C2.6

G4C2.7

PUMP DISCH. PRESS. ALARM LIMIT G4C2.8

HIGH PUMP COLUMN STRAIN LIMIT G4C3.1

SCRATCH

LOW PUMP GAS PRESSURE LIMIT

HIGH TEMP LIMIT FOR PUMP TEMPS G4C4.3

HIGH PUMP GAS PRESSURE LIMIT $\quad$ G4C4.4

HIGH MOTOR CURRENT LIMIT

LOW PUMP COLUMN STRAIN LIMIT $\quad$ G4C4.7

HIGH VENT FLOW LIMIT 1 G4C6.6

HIGH VENTILATION FLOW LIMIT 2 G4C6.7 
400255 MULTREG

400256 PMCHILIM

400257 CURLIMTIM

400301 CONTSTAT

400302 HSTBYSTAT

400303 CNTRLSTAT2

400304 RIOSTAT

400305 CTRLSTOPST

400306 NUMSEGS

400307 EOLPTRADO

400310 RUNDEBUG

400311 NOTUSED

400312 SBO1R1

400313 SBD1R2

400314 SBD 1R3

400315 SBD 1R4

400316 SBD 1R5

400317 SBD2R

400318 SBD2R2

400319 SBD2R3

400320 SBD2R 4

400321 SBD2R5

400322 SBD3R 1

400323 SBD3R

400324 SBD3R3

400325 SBD3R4

400326 SBD3R5

400612 2C_STATF

400615 2C ARF

400654 PCR 12A01F

400682 SCRATCH1

400683 SCRATCH2

400684 SCRATCH3

400691 PDPBASEF

402001 TIPNO101

402002 TIPNO102

402003 SPARE8

402004 IIR 12A02

402005 TIPNO201

402006 ZIMPE 142

402007 PIR 12A01

402008 TIPNO202

402009 PIPNO102

402010 PIPNO202

402011 PIPN0101

402012 PIPNO201

402013 FIPNO201

402014 FIPNO102

402015 FIPNO202

402016 FIPNO101

402017 PITNO111

402018 PITNO110

402019 PN2P0506

402020 PN2P0507

402021 MPICTCO1

402022 SPARE2

402023 SPARE 1

402025 SPARE 3

402026 SPARE 4

402027 SPARES

402028 SPARE 6

402029 TIR12A01

402030 SPARE 7

402070 XIR12AN

402071 WIR12A04

402072 XIR12AN2

402073 WIR12A01

402074 WIR 12A03

402080 WIR $12 A 02$

402129 PCR $12 A 01$

402130 PDPBASE
MOTOR CURR LIMIT $(210 / 225 \star 65535)$

MOTOR CURR LIMIT (238/238*65535)

CURRENT LIMIT DELAY TIMER

Controller status

Hot Standby Status

Controller status?

Remote 1/0 status

Controller stop state

Number of Ladder logic segs

End of logic ptr address

Run load debug status

DROP 1 RACK 1 STATUS

DROP 1 RACK 2 STATUS

DROP 1 RACK 3 STATUS

OROP 1 RACK 4 STATUS

OROP 1 RACK 5 STATUS

DROP 2 RACK 1 STATUS

DROP 2 RACK 2 STATUS

DROP 2 RACK 3 STATUS

DROP 2 RACK 4 STATUS

DROP 2 RACK 5 STATUS

OROP 3 RACK 1 STATUS

DROP 3 RACK 2 STATUS

DROP 3 RACK 3 STATUS

DROP 3 RACK 4 STATUS

DROP 3 RACK 5 STATUS

2ERO CHECK STATUS $1=O K O=E R R O R$

ZERO CHECK AR PARTIAL PRESSURE

PUMP DISCHARGE PRESSURE MINUS BASELINE

SCRATCH REGISTER

TIMER REGISTER

IIMER REGISTER

PUMP DISCHARGE PRESSURE BASEL INE

MOTOR STATOR TEMPERATURE

SPARE8 = TSR12A02 G1C3.6

PUMP MOTOR OIL TEMPERATURE \#2 G1C0.3

PUMP DISCHARGE NOZZLE \#1 TEMPERATURE-2 G1C0.5

LOW PUMP COLUMN GAS PRESSURE $\quad$ G1C0.6

PUMP PRESSURE

MOTOR SIATOR

PLIMP DISCHARGE NOZZLE \#2 PRESSURE-2

PUMP DISCHARGE NOZZLE \#1 PRESSURE-2

PUMP DISCHARGE NOZZLE \#2 PRESSURE-1

PUMP DISCHARGE NOZZLE \#1 PRESSURE-1

PUMP DISCHARGE MOZZLE \#1 FLOW-2

PUMP DISCHARGE NOZZLE \#2 FLOH-2

PUMP DISCHARGE NOZZLE \#1 FLON-1

PUMP DISCHARGE MOZZLE \#2 FLON-1

PUMP DISCHARE NOZZLE H1 PRESSURE

G1C0.7

G1C0.8

G1C1.1

GtC1.2

G1C1.3

G1C1.4

G1C1.5

G1C1.6

G1C1.7

G1C1.8

PUMP 30 DEG. NOZZLE DISCHARGE PRESSURE GIC2.2

PRESSURE GAUGE

PRESSURE GAUGE

INSTRUMENT CABIMET TEMPERATURE

SPARE PITNO111

SPARE PITNO110

MOTOR STATOR TEMPERATURE G1C3.1

G1C3.2

G1C3.3

G1C3.4

PUMP MOTOR OIL TEMPERATURE \#1 G1C0.4

SPARE 7 = TSR 12A01

PUMP CASING VIBRATION

G1C3.5

PUMP SUPPORT COLUMN VIBRATION G1C8.8

PUMP SUPPORT COLUMM STRAIN \#1 45 DEG G1C9.1

PUMP SUPPORT COLUMN STRAIN \#3 225 DEG G1C9.2

PUMP SUPPORT COLUMN STRAIN \$2 135 DEG G1C9.8

PUMP DISCHARGE PRESSURE MINUS BASELINE H2CO.1

PUMP DISCHARGE PRESSURE BASELIME H2CO.2 
402131 2IMPE 112

402134 ZC STAT

402437 2C-AR

402217 HPNTCALM

402218 HPMCLIM

402219 PLCPDPAL

402220 PLCPDPAB

402221 PLCPSLIM

402222 PLCSPDAL

402223 BUMPTLMT

402224 BUMPTLIM

402225 VR232050

402226 VR232080

402227 VR232100

402228 VR232110

402229 VR232040

402230 VR232020

402231 PLCPMCAB

402232 PLCPMCAL

402233 MOPSTAB
MIXER PUMP OSCILLATOR POSITION (B865)

ZERO CHECK STATUS $1=0 K$ O=ERROR

ZERO CHECK ARE PARTIAL PRESSURE

PUMP MOTOR CURRENT ALARM LIMIT

PUMP MOTOR CURRENT ABORT LIMIT

PUMP DISCH. PRESS. ALARM LIMIT

PUMP DISCH. PRESS. ABORT LIMIT

PUMP SPEED ABORT LIMIT

PUMP SPEED ALARM LIMIT

PUMP BUMP TIME LIMIT HOURS

PUMP BUMP TIME LIMIT MINUTES/SECONDS

PUMP SPEED

ROTATIONAL MOTOR VOLTAGE

ROTATIONAL MOTOR CURRENT

ROTATIONAL MOTOR SPEED

PUMP MOTOR CURRENT

MIXER PUMP MOTOR VOLTAGE

PLC PUMP MOTOR CURRENT LIMIT

PLC PUMP MOTOR CURRENT ALARM LIMIT

MOTOR OIL PRESSURE STATOR BOTTOM
H2C 11.1

H2C 11.2

H2C11.3

H2C11.4

H2C 11.5

H2C11.6

H2C11.7

H2C11.8

H2C 12.1

H2C12.2

H2C12.3

H2C12.4

H2C12.5

H2C12.6

H2C12.7

H2C12.8

H2C13.1 


\section{Appendix H: Report and Recipe File Listings}

Report and Recipe (R\&R) code is controlled by the state of bits in the strategy. These bits are connected to REPORT blocks which reference the code as a source file. Please refer to Section 9.2.8 of System Parameters to see which REPORT blocks refer to each piece of R\&R code for the MASFPUMP strategy.

$R \& R$ code is composed of a command and function set provided by the R\&R software option. These commands and functions must follow a syntax format explained in the R\&R Option document provided by Iconics.

Following is a description of each R\&R code's function for the MASFPUMP strategy and when it is executed. Refer to the code itself for details on how the functions are carried out.

R\&R file: PBSETVAL.RPS

REPORT block: PBREPORT

Controlled by: PBSETAND.DOUT Set high when setting the test values is executed.

Purpose: $\quad$ This code will download the desired test values to the critical parameters in the MASFPUMP strategy.

Related task: Set test values

All other Report and Recipe code functions are related to creating and selecting predefined tests and is only applicable for the Mini-DACS-1 system. 


\section{Appendix I: Key Macros and State Fields}

The MASFPUMP strategy utilizes a key macro definition file to redefine the auto/manual function. The text file EXTRA.KMS was created to disable $\langle F 9\rangle$ and add $<$ Alt-F9> as the auto/manual macro. The text file is compiled with KEYMAC EXTRA to create EXTRA.KML. This compiled file must be contained in the MASFPUMP directory where the MASFPUMP strategy is contained. The following is the listing of EXTRA.KMS:

DISMOV1=ON(DISMOVE.OUT).

DISMOVO=OFF(DISMOVE.OUT).

CHKCLR1=ON(CHKCOLOR.OUT).

SETTES $1=$ ON(SETTEST.OUT).

RESPTIM=DOWNLD_PT(O,PBHR.OUT) DOWNLD_PT(0,PBMIN.OUT)

DOWNLD_PT(O,PBSEC.OUT)

DOWNLD_PT(O,PMPSPDAL.OUT) DOWNLD_PT(0,PMPSPDAB.OUT)

DOWNLD_PT(0,DO5DEV.SETP) DOWNLD_PT(0,DO6DEV.SETP).

$[\mathrm{F9}]=\mathrm{DISABLE}$.

$[$ Alt-F9] $=A / M()$.

State fields are useful to tie words to analog or discrete values. The text file STATES.SFS was modified to create three different state fields for the displays linked to the MASFPUMP strategy:

- <Enable-Disable Move> is used to indicate and control the enabling of the position motor.

If a state field is revised (by editing STATES.SFS and compiling it with the command STATECMP STATES), the display connection in the display builder must be redone in order for the changes to come into effect. 


\section{Appendix J: Station Display List}

The following list of displays are currently implemented on STATION8 and are dynamically linked to the MASFPUMP strategy. (See Section 9.1.2 for a list and discussion of the MASFTEST strategy displays).

\begin{tabular}{|l|l|}
\hline \multicolumn{2}{|c|}{ Table J-1. Station Displays } \\
\hline Display & \multicolumn{1}{c|}{ Functions } \\
\hline CURDPRLM & $\begin{array}{l}\text { Pump motor current and discharge pressure alarm and abort } \\
\text { calculation display. }\end{array}$ \\
\hline DMPROB & Position operation problem indication display. \\
\hline MASFMENU & $\begin{array}{l}\text { Main menu for display selection for pump or position motor } \\
\text { control. }\end{array}$ \\
\hline MASFPOSM & Position motor control display. \\
\hline MASFPUMP & Pump motor control display. \\
\hline PBENPROB & Test enable problem indication display. \\
\hline POSPROB & Position selection problem indication display. \\
\hline PSPROB & Test start problem indication display. \\
\hline SETPROB & Test values set problem indication display. \\
\hline
\end{tabular}




\section{Appendix K: Hardware Configurations}

The following is a list of all cards and their settings on all computer stations in the Mini- DACS. The addresses below ("Addr." column) are in hexadecimal. The printer ports are multiplexed; the port on the multiplexer is noted in the "Destination" column; the ARCnet star configuration ports are also noted here. For the Gateway 2000 computers, "(m)" in the Slot column indicates the motherboard.

There are other standard IRQs that are being used by the system in addition to those noted in the tables: IRQ 0 (system timer), IRQ 1 (keyboard), IRQ 2 (cascade from higher IRQs), IRQ 6 (floppy disk), IRQ 8 (clock), IRQ 13 (80486DX), and IRQ 14 (hard disk).

Computer \#5 (Texas Microsystem, in the Mini-DACS)

"Station 5", running the Genesis MASFTEST strategy

\begin{tabular}{|c|c|c|c|c|c|}
\hline Slot & Card & Port(s) & IRQ & Addr. & Destination \\
\hline 1 & (empty) & & & & \\
\hline 2 & (empty) & & & & \\
\hline 3 & SMC ARCnet & $\mathrm{BNC}$ & 5 & $2 \mathrm{E} 0$ & ARCnet hub (port 5) \\
\hline 4 & (empty) & & & & \\
\hline 5 & Texas Micro & $\begin{array}{l}\text { 15-pin } 9 \\
9 \text {-pin } 9\end{array}$ & & & $\begin{array}{l}\text { V2VGA Video; Shinko multiplx. } \\
\text { not used }\end{array}$ \\
\hline 6 & (empty) & & & & \\
\hline 7 & CPU (80486) & $\begin{array}{l}\text { 9-pin } \sigma^{x} \\
25-\text { pin }+\end{array}$ & & & $\begin{array}{l}\text { not used } \\
\text { not used }\end{array}$ \\
\hline 8 & Magic I/O & $\begin{array}{l}\text { 9-pin } 0^{x} \\
25-\text { pin } q\end{array}$ & 7 & 378 & $\begin{array}{l}\text { not used } \\
\text { Genesis C key; Black Box data } \\
\text { switch; Proprinter \#3 (port 1) }\end{array}$ \\
\hline 9 & $\mathrm{I} / \mathrm{O}$ jumper & $\begin{array}{l}\text { 9-pin } 0^{\pi} \\
25-\text { pin } q\end{array}$ & 4 & $\begin{array}{l}3 \mathrm{~F} 8 \\
2 \mathrm{~F} 8\end{array}$ & $\begin{array}{l}\text { Dual ABC box (A) } \\
\text { mouse }\end{array}$ \\
\hline 10 & (empty) & & & & \\
\hline 11 & (empty) & & & & \\
\hline 12 & (empty) & & & & \\
\hline 13 & (empty) & & & & \\
\hline 14 & (empty) & & & & \\
\hline
\end{tabular}


Computer \#7 (Texas Microsystem, in the Mini-DACS)

"Station 7"

\begin{tabular}{|c|c|c|c|c|c|}
\hline Slot & Card & Port(s) & IRQ & Addr. & Destination \\
\hline 1 & (empty) & & & & \\
\hline 2 & (empty) & & & & \\
\hline 3 & (empty) & & & & \\
\hline 4 & (empty) & & & & \\
\hline 5 & Texas Micro & $\begin{array}{l}\text { 15-pin } 9 \\
9 \text {-pin }+9\end{array}$ & & & $\begin{array}{l}\text { V2VGA Video; Shinko multiplx. } \\
\text { not used }\end{array}$ \\
\hline 6 & (empty) & & & & \\
\hline 7 & CPU (80486) & $\begin{array}{l}9-\text { pin } 0^{\pi} \\
25-\text { pin } 9\end{array}$ & & & $\begin{array}{l}\text { not used } \\
\text { not used }\end{array}$ \\
\hline 8 & Magic I/O & $\begin{array}{l}\text { 9-pin on } \\
25 \text {-pin } 9\end{array}$ & 7 & 378 & $\begin{array}{l}\text { not used } \\
\text { Genesis RT key; Black Box data } \\
\text { switch; Proprinter \#3 (port 2) }\end{array}$ \\
\hline 9 & I/O jumper & $\begin{array}{l}\text { 9-pin } \sigma^{7} \\
25-\text { pin } f\end{array}$ & $\begin{array}{l}4 \\
3\end{array}$ & $\begin{array}{l}3 \mathrm{~F} 8 \\
2 \mathrm{~F} 8\end{array}$ & $\begin{array}{l}\text { mouse } \\
\text { Dual ABC box (C) }\end{array}$ \\
\hline 10 & SMC ARCnet & $\mathrm{BNC}$ & 5 & $2 \mathrm{E} 0$ & ARCnet hub (port 7) \\
\hline 11 & (empty) & & & & \\
\hline 12 & (empty) & & & & \\
\hline 13 & (empty) & & & & \\
\hline 14 & (empty) & & & & \\
\hline
\end{tabular}


Computer \#8 (Texas Microsystem, in the Mini-DACS)

"Station 8", running the Genesis MASFPUMP strategy

\begin{tabular}{|c|c|c|c|c|c|}
\hline Slot & Card & Port(s) & IRQ & Addr. & Destination \\
\hline 1 & (empty) & & & & \\
\hline 2 & (empty) & & & & \\
\hline 3 & (empty) & & & & \\
\hline 4 & Everex I/O & $\begin{array}{l}\text { 9-pin o" } \\
25 \text {-pin } 9\end{array}$ & 7 & 278 & $\begin{array}{l}\text { not used } \\
\text { Proprinter \#8 }\end{array}$ \\
\hline 5 & Texas Micro & $\begin{array}{l}\text { 15-pin } 9 \\
\text { 9-pin }+9\end{array}$ & & & $\begin{array}{l}\text { V2VGA Video; Shinko multiplx. } \\
\text { not used }\end{array}$ \\
\hline 6 & (empty) & & & & \\
\hline 7 & CPU (80486) & $\begin{array}{l}\text { 9-pin or } \\
25 \text {-pin } 9\end{array}$ & & & $\begin{array}{l}\text { not used } \\
\text { not used }\end{array}$ \\
\hline 8 & Magic I/O & $\begin{array}{l}\text { 9-pin } \sigma^{7} \\
25-\text { pin } q\end{array}$ & 7 & 378 & $\begin{array}{l}\text { not used } \\
\text { Genesis C key; LaserJet printer } \\
\text { multiplx. (port 8) }\end{array}$ \\
\hline 9 & I/O jumper & $\begin{array}{l}\text { 9-pin or } \\
25-\text { pin } 9\end{array}$ & $\begin{array}{l}4 \\
3\end{array}$ & $\begin{array}{l}3 \mathrm{~F} 8 \\
2 \mathrm{~F} 8\end{array}$ & $\begin{array}{l}\text { Dual } \mathrm{ABC} \text { box }(\mathrm{B}) \\
\text { mouse }\end{array}$ \\
\hline 10 & (empty) & & & & \\
\hline 11 & SMC ARCnet & $\mathrm{BNC}$ & 5 & $2 \mathrm{E} 0$ & ARCnet hub (port 8) \\
\hline 12 & (empty) & & & & \\
\hline 13 & (empty) & & & & \\
\hline 14 & (empty) & & & & \\
\hline
\end{tabular}




\section{Appendix L: Network Configuration Settings}

Station name: STATION5

Function: Runtime Master Station

Network settings

Memory Buffer Address: D980

I/O Port Address: 2e0

IRQ: 5

Data Check Mode: CRC-16

Network address: 5

Node fail time: 10

Watchdog message rate: 2

Performance monitor rate: 1

Network scan time: 1

Message retry count: 1

Transmit Timeout: 2

Primary ACK setting: 20

Net Alarm Squelch After Startup: 0

Net Alarm Squelch During Startup: 10

Net Alarm Buffer size: 4096

Transmit Buffer Full Level: 80

RX Buffers: $32,32,16,16,32$

Rename Duplicates on file transfer: Yes

Alarm broadcasts: ENABLE

Station name: STATION7

Function: Local RSS

Network settings

Memory Buffer Address: D980

1/O Port Address: 2e0

IRQ: 5

Data Check Mode: CRC-16

Network address: 7

Node fail time: 10

Watchdog message rate: 2

Performance monitor rate: 1

Network scan time: 1

Message retry count: 1

Transmit timeout: 2

Primary ACK Setting: 20

Network point database size: 300

RSS master identification: MANUAL

RSS auto reconfiguration: DISABLED

RSS Master Node Name: STATION5 
Station name: STATION8

Function: Runtime Master

Network settings

Memory Buffer Address: D980

1/O Port Address: 2e0

IRQ: 5

Data Check Mode: CRC-16

Network address: 8

Node fail time: 10

Watchdog message rate: 2

Performance monitor rate: 1

Network scan time: 1

Message retry count: 1

Transmit Timeout: 2

Primary ACK setting: 20

Net Alarm Squelch After Startup: 0

Net Alarm Squelch During Startup: 10

Net Alarm Buffer size: $\mathbf{5 1 2}$

Transmit Buffer Full Level: 10

RX Buffers: $8,8,4,4,8$

Rename Duplicates on file transfer: Yes

Alarm broadcasts: DISABLE 


\section{Appendix M: Computer Configurations and Software Versions}

See Appendix $L$ for a general description of the functions and network setup parameters (ArcNet VO Port, Memory Address, and IRQ) of the stations in the network.

All stations are running DOS version 6.0 and Netroom 3 version 3.02 .

The current versions of the Genesis strategies are 1.01 for the MASFTEST strategy (running in Station 5) and 1.01 for the MASFTEST strategy (running in Station 8).

The versions of Iconics software that are in use are:

- Genesis (GEN-6C and GEN-RT)-3.72

- Remote Supervisory System (RSS)-3.72

- Gen-Net-3.64

- Report \& Recipe option (RRCOMBO)-3.62

The directory organization on the computers is the same for the following directories:

- I(Root directory)-AUTOEXEC.BAT and CONFIG.SYS system boot files

- IDOS-MS-DOS system files

- IEXPERT-Mouse driver

- Netroom3- Expanded Memory Manager

Where directories differ between stations, the following table shows what those directories contain.

\begin{tabular}{|lll|}
\hline Station Name & Directory & Contents \\
\hline STATION5 & IGENESIS & $\begin{array}{l}\text { Genesis system, Gen-Net, AF5000+/Genesis } \\
\text { driver, Modicon/Genesis driver, RRCOMBO } \\
\text { option, Help system files }\end{array}$ \\
& MASFTEST strategy files, related displays, \\
& MASTEST & $\begin{array}{l}\text { R\&R code, key macro files, state field files, } \\
\text { startup batch files }\end{array}$ \\
\hline
\end{tabular}




\begin{tabular}{|lll|}
\hline Station Name & Directory & Contents \\
\hline STATION7 & IGENESIS & $\begin{array}{l}\text { RSS software, Gen-Net, AF5000+/Genesis } \\
\text { driver, Modicon/Genesis driver, RRCOMBO } \\
\text { option, Help system files }\end{array}$ \\
& IMASFTEST & $\begin{array}{l}\text { MASFTEST strategy files, related displays, } \\
\text { R\&R code, key macro files, state field files, } \\
\text { startup batch files }\end{array}$ \\
\hline STATION8 & IGENESIS & $\begin{array}{l}\text { Genesis system, Gen-Net, AF5000+/Genesis } \\
\text { driver, Modicon/Genesis driver, RRCOMBO } \\
\text { option, Help system files }\end{array}$ \\
& MOTOR strategy files, related displays, R\&R \\
& MASFPUMP & $\begin{array}{l}\text { code, key macro files, state field files, startup } \\
\text { batch files }\end{array}$ \\
\hline
\end{tabular}




\section{Appendix N: Software License Agreements}

The following is a list of the commercial software that is used in the Mini-DACS system.

$\begin{array}{lll}\text { Company } & \text { Software } & \text { Version(s) } \\ \text { Helix } & \text { Netroom3 } & 3.02 \\ \text { Kensington Microware, Ltd. } & \text { Expert Mouse } & \mathrm{n} / \mathrm{a} \\ \text { Iconics, Inc. } & \text { Genesis Control Series } & 3.72 \\ \text { Iconics, Inc. } & \text { GenNet } & 3.64 \\ \text { Iconics, Inc. } & \text { Remote Supervisory } & 3.72 \\ & \text { Station } & \\ \text { Modicon, Inc } & \text { Modsoft } & 2.1 \\ \text { Microsoft Corp. } & \text { MS-DOS } & 6.0\end{array}$


Appendix 0: HMR-3 Instrument Ranges, Alarm Limits and Abort LImits

\begin{tabular}{|c|c|c|c|c|c|c|c|}
\hline OACS TAC & FE LD TAC & DESCRPFOH & $40 \times 1$ & FULUCALE & Lown & $H O H A M R$ & MOAT \\
\hline \multicolumn{8}{|c|}{ MINI-DACS INSTRUMENTS } \\
\hline PITNO110 & WST-PDT-3106M & $\begin{array}{l}\text { PUMP 30* DISCHARGE NOZZLE } \\
\text { PRESSURE }\end{array}$ & $4-20 \mathrm{~mA}$ & 0 - 70 psig & N/A & N/A & N/A \\
\hline SPARE1 & WST-PDT-3106P & $\begin{array}{l}\text { PUMP } 30^{*} \text { DISCHARGE NOZZLE } \\
\text { PRESSURE }\end{array}$ & 4-20 mA & 0 - 70 psig & N/A & N/A & N/A \\
\hline PITNO111 & WST-PDT-3105M & $\begin{array}{l}\text { PUMP DISCHARGE NOZZLE } \$ 1 \\
\text { PRESSURE }\end{array}$ & 4-20 mA & 0 - 70 psig & N/A & $N / A$ & N/A \\
\hline SPARE2 & WST-PE-3105P & $\begin{array}{l}\text { PUMP DISCHARGE NOZZLE \#1 } \\
\text { PRESSURE }\end{array}$ & 4-20 mA & 0.70 psig & N/A & N/A & N/A \\
\hline TIPNO202 & WST-TE-3127M & MOTOR STATOR TEMPERATURE & Type J & $32-932^{*} \mathrm{~F}$ & N/A & $220^{\circ} \mathrm{F}$ & $250^{\circ} \mathrm{F}$ \\
\hline SPARE3 & WST-TE-3127R & MOTOR STATOR TEMPERATURE & Type J & $32-932^{*} F$ & N/A & $220^{\circ} \mathrm{F}$ & $250^{\circ} \mathrm{F}$ \\
\hline SPARES & TE-101C & & Type K & $32-932^{\circ} F$ & N/A & N/A & N/A \\
\hline TIPNO101 & WST-TE-3127P & MOTOR STATOR TEMPERATURE & Type J & $32-932^{\circ} F$ & N/A & $220^{\circ} \mathrm{F}$ & $250^{\circ} \mathrm{F}$ \\
\hline SPARE4 & $T E-102 B$ & & Type K & $32-932^{\circ} \mathrm{F}$ & N/A & N/A & N/A \\
\hline SPARE 6 & TE-102C & & Type K & $32-932^{\circ} F$ & N/A & N/A & N/A \\
\hline TIR 12A01 & WST-TE-3112M & PUMP MOTOR OIL TEMPERATURE "A" & $100 \Omega$ Platinum & $32-392^{*} F$ & N/A & $2200^{\circ} \mathrm{F}$ & $250^{\circ} \mathrm{F}$ \\
\hline SPARE7 & WST-TE-3113M & PUMP MOTOR OIL TEMPERATURE "A" & $100 \Omega$ Platinum & $32-392^{*} \mathrm{~F}$ & N/A & $220^{\circ} \mathrm{F}$ & $250^{\circ} \mathrm{F}$ \\
\hline TIR12A02 & WST-TE-3112P & PUMP MOTOR OIL TEMPERATURE "B" & $100 \Omega$ Platinum & $32-392^{\circ} \mathrm{F}$ & N/A & $220^{\circ} \mathrm{F}$ & $250^{\circ} \mathrm{F}$ \\
\hline SPARE8 & WST-TE-3113P & PUMP MOTOR OIL TEMPERATURE "B" & 100 o Platinum & $32-392^{*} \mathrm{~F}$ & N/A & $2200^{\circ} \mathrm{F}$ & $250^{\circ} \mathrm{F}$ \\
\hline PIR12A01 & WST-PE-3123M & VOLUTE PRESSURE & 4-21 mV & $0-150$ psia & N/A & N/A & N/A \\
\hline MIP00001 & WSTME-3113M & MOISTURE ELEMENT & Digital & On/Of & N/A & N/A & On \\
\hline XIR 12AN1 & WST-VE-3127P & PUMP CASING VIBRATION & $4-20 \mathrm{~mA}$ & $\pm 0.1 \mathrm{~g}$ to $\pm 80 \mathrm{~g}$ & N/A & N/A & N/A \\
\hline MR12A04 & WST-WE-3115M & PUMP COLUMN STRAIN GAUGE $0^{\circ}$ & \pm 10 VDC & \pm 684 pin/in & N/A & \pm 145.5 pinfin & $\pm 194 \mu$ in/in \\
\hline
\end{tabular}


HNF-SD-WM-SDD-049

Rev. 1

Page 132

\begin{tabular}{|c|c|c|c|c|c|c|c|c|c|c|c|c|c|c|c|c|c|c|c|c|}
\hline g. & $\frac{\frac{g}{2}}{\frac{\underline{z}}{2}}$ & 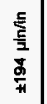 & 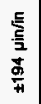 & Б & $\delta$ & 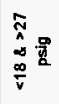 & $\underline{\mathbf{z}}$ & 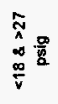 & $\begin{array}{l}\text { 总 } \\
\text { 恶 }\end{array}$ & $\underline{\mathbf{z}}$ & $\mathbb{\mathbf { s }}$ & $\begin{array}{l}a \\
\infty \\
\mathbb{N} \\
\tilde{N}\end{array}$ & $\underline{\mathbf{z}}$ & $\underline{\mathbf{s}}$ & & $\underline{\mathbf{s}}$ & $\begin{array}{l}\stackrel{u}{a} \\
0 \\
0 \\
\underline{p}\end{array}$ & $\mathbf{s}$ & $\frac{\mathbf{s}}{\mathbf{z}}$ & 5 \\
\hline$\frac{3}{3} \frac{3}{9}$ & $\begin{array}{l}\frac{c}{2} \\
\frac{5}{2} \\
\frac{1}{2} \\
\frac{p}{p} \\
\frac{p}{4} \\
1\end{array}$ & 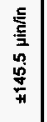 & 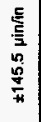 & $\frac{\widehat{s}}{\mathbf{z}}$ & $\underline{\mathbf{x}}$ & $\begin{array}{l}\text { 鄫 } \\
\text { 心 }\end{array}$ & $\$$ & 总 & $\begin{array}{l}\frac{D}{0} \\
\text { 晋 } \\
0\end{array}$ & 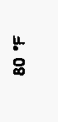 & $\underline{\mathbf{z}}$ & 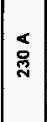 & E్ & $\begin{array}{l}\text { 兽 } \\
\text { 员 }\end{array}$ & & $\underline{\mathbf{z}}$ & $\begin{array}{l}4 \\
: \\
0\end{array}$ & $\underline{\mathbf{z}}$ & $\underline{\mathbf{\Sigma}}$ & $\frac{\mathbf{s}}{\mathbf{z}}$ \\
\hline 85 & $\mathbf{z}$ & $\underline{\mathbf{z}}$ & $\widehat{\mathbf{z}}$ & $\widehat{\mathbf{z}}$ & $\frac{x}{2}$ & $\frac{\mathrm{d}}{\mathrm{d}}$ & $\underline{\mathbf{z}}$ & 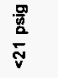 & $\underline{\mathbf{s}}$ & $\stackrel{4}{\circ}$ & $\underline{\mathbf{z}}$ & $\underline{\mathbf{s}}$ & $\underline{\mathbf{z}}$ & $\mathbf{s}$ & & $\underline{\mathbf{s}}$ & $\mathbf{I}$ & $\underline{\mathbf{s}}$ & $\underline{\mathbf{s}}$ & $\begin{array}{l}t \\
g \\
v\end{array}$ \\
\hline$\frac{b_{3}}{8}:{ }_{3}$ & 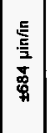 & 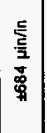 & 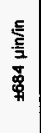 & ఫ్ & $\begin{array}{l}5 \\
\delta\end{array}$ & 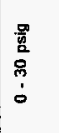 & $\begin{array}{l}\dot{\phi} \\
\dot{d} \\
\vdots \\
0\end{array}$ & $\begin{array}{l}\text { 总 } \\
\text { o. } \\
0 \\
0 \\
0\end{array}$ & $\begin{array}{l}\text { 总 } \\
\dot{0} \\
\dot{0} \\
\vdots \\
0\end{array}$ & 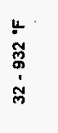 & 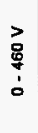 & 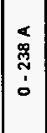 & 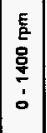 & 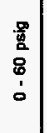 & $\stackrel{\infty}{z}$ & $\begin{array}{c}\text { शి } \\
\text { பे }\end{array}$ & 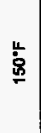 & 능 & $\frac{O}{3}$ & $\begin{array}{l}\frac{1}{2} \\
\vdots \\
0 \\
0\end{array}$ \\
\hline $\begin{array}{l}3 \\
\frac{3}{6}\end{array}$ & $\begin{array}{l}0 \\
\stackrel{0}{0} \\
0 \\
\bar{H}\end{array}$ & $\begin{array}{l}0 \\
\vdots \\
0 \\
\bar{H}\end{array}$ & $\begin{array}{l}0 \\
\stackrel{0}{0} \\
\text { D }\end{array}$ & $\begin{array}{l}\overline{\mathbf{g}} \\
\overline{\mathrm{g}} \\
\overline{\mathbf{g}}\end{array}$ & \begin{tabular}{|l} 
愛 \\
$\overline{\mathbf{b}}$
\end{tabular} & 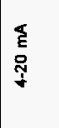 & 吕 & $\begin{array}{l}\overleftarrow{E} \\
\stackrel{\Im}{\xi}\end{array}$ & 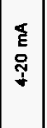 & 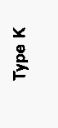 & 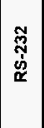 & 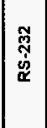 & 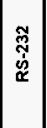 & 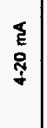 & $\begin{array}{l}\frac{Z}{2} \\
\underset{n}{\alpha} \\
\frac{n}{2}\end{array}$ & $\mathbf{\underline { \mathbf { z } }}$ & $\frac{x}{2}$ & $\mathbf{s}$ & $\underline{\mathbf{z}}$ & $\frac{\pi}{2}$ \\
\hline$\frac{2}{8}$ & 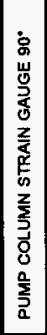 & 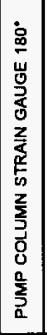 & 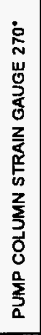 & 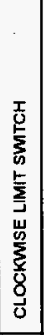 & 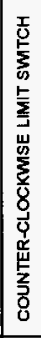 & 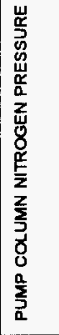 & 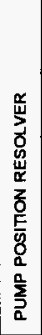 & 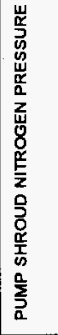 & 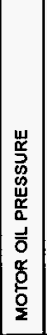 & 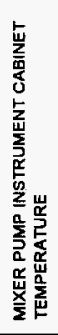 & 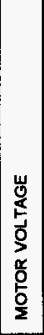 & 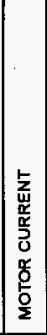 & 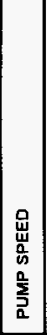 & 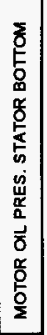 & 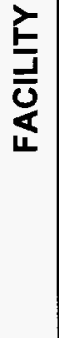 & 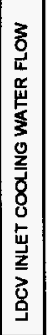 & 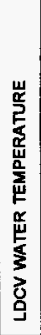 & 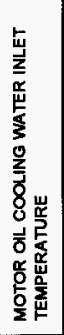 & 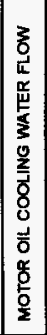 & 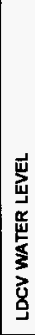 \\
\hline $\begin{array}{l}\frac{9}{g} \\
\frac{g}{4}\end{array}$ & 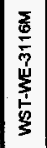 & 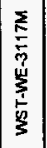 & 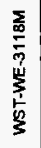 & 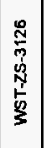 & 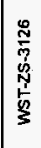 & 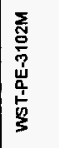 & 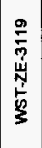 & 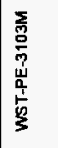 & 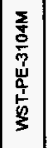 & $\overline{\ddot{\mu}}$ & 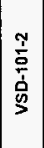 & 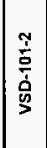 & 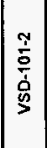 & $\underline{\mathbf{s}}$ & & $\underline{\mathbf{s}}$ & $\underline{\mathbf{s}}$ & $\underline{z}$ & $\mathbf{s}$ & $\underline{\mathbf{z}}$ \\
\hline$\frac{9}{8}$ & 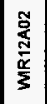 & 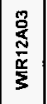 & 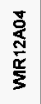 & 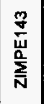 & 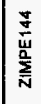 & 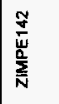 & 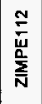 & 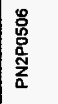 & 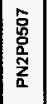 & $\begin{array}{l}\overline{\bar{g}} \\
\frac{\dot{L}}{\frac{0}{2}} \\
\frac{\bar{a}}{\Sigma}\end{array}$ & 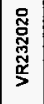 & 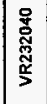 & 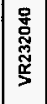 & $\begin{array}{l}\text { 罟 } \\
\text { o. } \\
\frac{0}{2} \\
\end{array}$ & & $\underline{\mathbf{s}}$ & $\frac{\mathbf{s}}{\mathbf{2}}$ & $\frac{\pi}{2}$ & $\frac{\nwarrow}{\mathbf{z}}$ & $\mathbf{s}$ \\
\hline
\end{tabular}




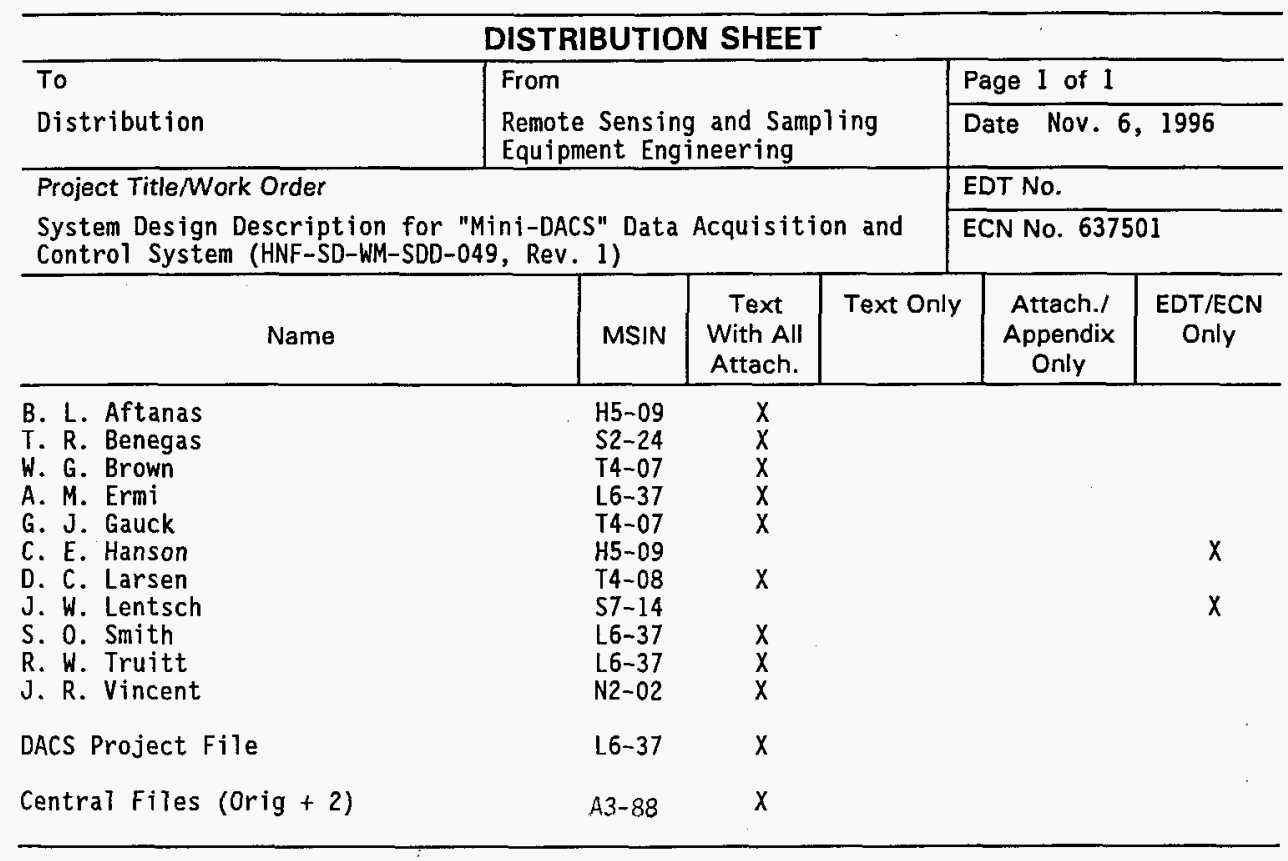

